\title{
5 Die RfA im Krieg. Rechtliche Rahmenbedingungen und die Chimäre des „Altersversorgungswerks“ der DAF im Spiegel der Verwaltungspraxis
}

Der Krieg bedeutete auch in der Entwicklung der RfA und der Angestelltenversicherung einen umfassenden Radikalisierungsprozess, der sich in Behördenorganisation, Gesetzgebung und Verwaltungspraxis, aber auch in der Struktur der Versicherten wie Rentenempfänger sowie einer erheblich gestiegenen Dynamik der Rentenbewegungen bemerkbar machte. Aus Sicht des NS-Regimes galt es, die Sozialversicherungsgesetzgebung wie die dahinterstehende Behördenorganisation den Erfordernissen des Krieges anzupassen, einerseits im Sinne neuer Leistungsversprechen, andererseits aber, weit mehr noch, um die Verwaltungspraxis auf die kriegsbedingten Rückwirkungen auf die Versichertenbiographien abzustellen: durch die kriegsspezifischen Umbrüche in den Beschäftigungsverhältnissen, das massenhafte Ansteigen von Leistungen für Berufsunfähigkeit und Hinterbliebene infolge von Kriegsverletzungen und Tod, die zumindest rudimentäre Ausweitung der Sozialversicherung auf die besetzten west- und osteuropäischen Gebiete, durch die tendenzielle Auseinanderentwicklung der Maßnahmenfokussierung auf Versicherte und Rentner, aber auch von Männern und Frauen - und bei all dem trat anstelle weiterer Inklusionstendenzen eine gegen Juden und Polen gerichtete massive Verschärfung der versicherungsrechtlichen Exklusion ein. Prinzipiell gilt für jeden Krieg, dass die Versicherungsverhältnisse der Rentenversicherung von allen Versicherungen am stärksten betroffen sind. Die erzwungene Beendigung der Beschäftigung infolge der Einberufung zum Militär bringt die Beitragsentrichtung ins Stocken und die daraus entstehenden späteren Nachteile für die Versicherten selbst oder die Hinterbliebenen erfordern staatliche Kompensationen. Gleichzeitig ergeben sich für die Versicherungsträger im Krieg neue und veränderte Leistungserfordernisse und -aufwendungen. Der Krieg ändert nicht nur das materielle Recht, sondern er hat auch Auswirkungen auf die Art und Weise der Verwaltungspraxis, das hatte sich schon im Ersten Weltkrieg gezeigt. Der Blick auf diese Verwaltungspraxis der RfA in dem nun ausgebrochenen Zweiten Weltkrieg und ihre Auseinandersetzung mit der DAF bei der Formulierung und Umsetzung der weiterhin hektischen und vielfach unausgegorenen Rentengesetze wird auch in Bezug auf die Angestellten ein anderes Bild von dem noch immer in der Forschung verbreiteten Schlagort von der nationalsozialistischen Sozialpolitik als angebliche „Bestechungspolitik“ eröffnen. ${ }^{1}$

1 Vgl. Aly, S. 71ff. Besonders vereinfacht und pauschal bei Glootz, S. 100 mit Bezug auf die ältere Forschung von Recker. 


\subsection{Die Leistungsverbesserungsgesetze von 1941 und 1942}

Der Zweite Weltkrieg hatte unmittelbare Folgen für die Sozialversicherung. Am 13. Oktober 1939 erging eine „Verordnung über die Rentenversicherung der Arbeiter und der Angestellten sowie die knappschaftliche Pensionsversicherung während des besonderen Einsatzes zur Wehrmacht“, ergänzt durch einen Anfang November veröffentlichten Erlass über die Versicherungspflicht der Dienstverpflichteten, die zur Sicherstellung des Kräftebedarfs für Aufgaben von besonderer staatspolitischer Bedeutung herangezogen wurden. Darin wurde unter anderem geregelt, dass zum einen sämtliche Bezüge für Wehrmachtsangehörige nicht als Entgelt im Sinne der Reichsversicherungsordnung galten und damit für sie auch keine Sozialversicherungsbeiträge $\mathrm{zu}$ entrichten waren. Zum anderen waren die Wehrmachtsdienstzeiten als Wartezeit und zur Aufrechterhaltung der Anwartschaft anzurechnen. Den Versicherten wurden zudem für die Dauer des Wehrmachteinsatzes aus Mitteln des Reichs Steigerungsbeträge gewährt, deren genaue Höhe jedoch „später festgesetzt“ werden sollte. ${ }^{2}$ Das klang einfach und im Sinne der Verhinderung von Nachteilen für die zur Wehrmacht Eingezogenen logisch, aber wie schon bei den diversen Gesetzen und Verordnungen zuvor ergaben sich in der Verwaltungspraxis schnell offene Fragen, etwa inwieweit diese Bestimmungen auch für freiwillig Versicherte, Selbstversicherte und Handwerker galten. ${ }^{3}$ Was viele Betroffene zudem übersahen, war, dass als Voraussetzung für die Anrechnung bei Beginn des Wehrmachteinsatzes die Anwartschaft bereits bestehen musste. Gleichzeitig aber war die RfA wie alle Rentenversicherungsträger vom RVA aufgefordert worden, in der verwaltungspraktischen Ausübung ihrer Befugnisse und Aufgaben gegenüber Wehrmachtsangehörigen weitgehende Kulanz walten zu lassen. „Bei Nachuntersuchungen der Versicherten und ihrer Hinterbliebenen sowie bei Rentenentziehungen ist Zurückhaltung geboten“, heißt es in einm Rundschreiben vom November 1939. ${ }^{4}$ Auch auf Rückforderung zu Unrecht gewährter Leistungen sollte „tunlichst verzichtet“ werden und vor der Einleitung und Durchführung von Zwangsmaßnahmen zur Beitragseintreibung in Betrieben mussten „zur Vermeidung von Härten“ die Verhältnisse vorher sorgfältig geprüft werden. ${ }^{5}$

Grundlage für die weiteren Maßnahmen war offenbar eine Anfang November 1939 vom Sozialamt der DAF vorgelegte Denkschrift über „Notwendige Kriegsmaßnahmen

2 Vgl. die Verordnung sowie diversen Schriftwechsel dazu, in: RfA-Archiv Nr. 67.

3 Vgl. dazu die Anfrage des Versicherungsamtes der Stadt Köln an die RfA vom 28.5.1940, in: RfAArchiv Fach 19, Nr. 2.

4 Rundschreiben des RVA vom November 1939, in: BArch R 89/3170.

5 Bemerkenswerterweise wollte man sich in der RfA diesen Vorgaben nicht uneingeschränkt und unwidersprochen beugen. In einem Schreiben an das RVA legte Direktor Koch ausführlich seine Auslegung des Rundschreibeninhalts dar und beharrte darauf, dass die Rückforderung nicht schlechthin für jeden Fall ausgeschlossen sein könne. Man halte es für unbillig, von der Rückforderung etwa auch dann abzusehen, wenn die Überzahlung durch ein Verschulden des Empfängers entstanden wäre und sich dann der Betroffene vorsätzlich oder grob fahrlässig einen Vorteil hätte verschaffen können. Vgl. Schreiben Kochs an das RVA vom 4.1.1940, in: BArch R 89/3169. 
in der Sozialversicherung“, die sich jedoch auf 21 Seiten in versicherungsrechtliche Details insbesondere der Krankenversicherung erging und damit die RfA nicht weiter tangierte. ${ }^{6}$ Dabei gab es trotz der kriegsspezifischen und eher symbolpolitischen Maßnahmen zur schonenden Behandlung von Versicherten und Rentnern angesichts der weiterhin wirksamen Kürzungen aus der Notverordnungszeit nach wie vor einen erheblichen grundsätzlichen Reformbedarf in der Angestelltenversicherung. Im RAM hatte man daher im Dezember, ausgelöst durch die Initiative der DAF und bedingt durch die Kriegsverhältnisse, mit der Sammlung von notwendig erscheinenden gesetzlichen Maßnahmen auf dem Gebiet der Rentenversicherung begonnen, und eine entsprechende Umfrage an das RVA und die Versicherungsträger gerichtet. ${ }^{7}$ Das RVA hatte, auch nach Rücksprache bei der RfA, bereits im März 1940 auf 14 Seiten einen umfangreichen Katalog an Vorschlägen an das RAM gesandt. Doch das Sammeln von weiteren Detailmaßnahmen und die daraus resultierenden Vorarbeiten für einen Referentenentwurf zu einem neuen Gesetz gingen das ganze Jahr 1940 über weiter, und an mehreren Stellen mischten sich dabei auch Parteistellen, allen voran der Stellvertreter des Führers mit ein. ${ }^{8}$ Im Dezember 1940 startete seinerseits der Reichsverband Deutscher Rentenversicherungsträger eine ans RAM gerichtete Initiative, um durch diverse Gesetzesänderungen bestehende Härten im Recht der Rentenversicherung zu beseitigen und damit die herrschenden offensichtlichen Unzulänglichkeiten grundsätzlicher Art zu beheben. ${ }^{9}$ Auch die RfA beteiligte sich mit detaillierten Ausarbeitungen von Direktor Koch an den Änderungsvorschlägen, wobei dieser bei der innerbehördlichen Weiterleitung an Direktor Granzow handschriftlich ergänzte:

Ich habe schon oft Vorschläge für Gesetzesänderungen gemacht, ohne dass ich dann irgendeinen Erfolg hatte. Um nicht vergebliche Arbeit leisten zu müssen, scheint es mir erforderlich, dass wir uns zunächst einmal darüber schlüssig werden, welche Grundgedanken aus den Vorschlägen gemacht werden sollen, damit man wenigstens in den Grundzügen weiß, woran gedacht ist und was bezweckt wird. ${ }^{10}$

Ganz oben auf der Liste von Kochs Vorschlägen stand die von der RfA wiederholt vorgebrachte Forderung nach Änderung des Anwartschaftsrechts. Es sei umständlich und für den Versicherten schwer zu verstehen. Mit Recht würde es als unbillig empfunden, dass selbst nach langer Beitragsleistung keine Versicherungsleistung gewährt werde, wenn die Anwartschaft erloschen war und nur einige wenige Beiträge zu ihrer

6 Vgl. die Denkschrift vom 3.11.1939, in: BArch R 89/3170.

7 Vgl. Schreiben des RAM an das RVA vom 21.12.1939, in: BArch R 89/3169.

8 Vgl. Schreiben des RVA an das RAM vom 4.3.1940 sowie Schreiben des RVA an das RAM vom 11.10. 1940, in: ebd.

9 Vgl. das Schreiben von Verbandspräsident Möbius an die Mitglieder vom 25.11.1940, in: RfA-Archiv Fach 109, Nr. 1.

10 Vermerk Kochs vom 2.12.1940, in: ebd. 
Erhaltung fehlten. ${ }^{11}$ Koch schlug eine Reihe von dringend erforderlichen Änderungen im Wanderversicherungsrecht vor ${ }^{12}$ und endete mit einem ebenfalls von der RfA bereits wiederholt vorgetragenen Plädoyer für ein Streichen der Ruhensvorschriften. „Die Kürzung von Renten beim Zusammentreffen mit anderen Renten widerspricht dem Versicherungsgedanken von Leistung und Gegenleistung“, so schrieb er, da für jede Leistung die Beiträge entrichtet worden waren. ${ }^{13}$ Eine gewisse Brisanz hatte diesbezüglich Kochs Vorschlag, auch die Ruhensvorschriften von Rentenberechtigten im Ausland bzw. deutschen Volkszugehörigen fremder Staatsangehörigkeit dahingehend zu ändern, dass die Entscheidungsbefugnis über das Ruhen oder Nichtruhen der Leistung in die Kompetenz der RfA übergehen sollte, die dadurch einen Handlungsspielraum nach Prüfung der jeweiligen Einzelfälle bekäme. Koch hatte dabei offensichtlich vor Zusammenstellung seiner Vorschläge auch von allen Unterabteilungsleitern entsprechende Reform- und Verbesserungsvorschläge erbeten und in einer internen Dienststellenleiterbesprechung der Leistungsabteilung diskutieren lassen. Jeder der Referenten trug dabei vielfältige Vorschläge aus der Fülle jener Fälle der täglichen Verwaltungsarbeit bei, in denen den RfA-Beamten seitens der Versicherten „Härte“, „Kleinlichkeit“ oder „Bürokratie“ vorgeworfen worden war. „Ich habe mich von dem Gedanken leiten lassen“, so heißt es etwa in einer Notiz eines Dienststellenleiters, „das anerkanntermaßen geringe Rentenaufkommen der Versicherten innerhalb des bestehenden Systems durch eine etwas weitherzigere Neufassung oder Ergänzung bestehender Vorschriften nach Möglichkeit zu erhöhen. “14 Bei der Dienststellenleiterbesprechung zeigte sich denn auch einhelliges Einvernehmen über eine rigorose Aufhebung der Ruhens- und Kürzungsbestimmungen, d.h. beispielsweise über der Erhöhung des Grundbetrags auf die vor den Notverordnungskürzungen geltenden 480 RM im Jahr. „Die restlose Beseitigung der Notverordnungsbestimmungen ist und bleibt die Kardinalfrage der bestehenden Sozialversicherung“, heißt es in einem Vermerk, und man müsse alles daransetzen, diese Beschränkungen zu beseitigen. ${ }^{15}$ Geradezu radikal mutete zudem der Vorschlag an, die Beitragsrückerstattung nach § $46 \mathrm{AVG}$ nicht nur für weibliche Versicherte gelten zu lassen, sondern auch auf männliche Versicherte auszudehnen und zudem die vom RfA-Direktorium bereits 1929 vorgeschlagene Einführung einer Elternrente in Angriff zu nehmen. Die sich daraus für die RfA ergebenden finanziellen Belastungen von ca. einer Mio. RM für die Beitragsrückerstattungen und durchaus „mehreren Millionen“ pro Jahr für die Elternrente erschienen als „durchaus tragbar“, denn „wesentliche bereits früher be-

11 Vgl. die Ausarbeitung Kochs vom 12.12.1940, in: ebd.

12 Hier ging es um die von den betroffenen Versicherten vehement bekämpfte Kürzung des Steigerungsbetrags aus der Invalidenversicherung bei denjenigen, die danach langfristig in die AV gewechselt waren. Vgl. dazu das Schreiben der RfA auf die Beschwerde eines Versicherten hin vom 11.1. 1941, in: RfA-Archiv Nr. 25.

13 Ebd., Bl. 7.

14 Notiz vom 9.12.1940, in: RfA-Archiv Nr. 25.

15 Vermerk ohne Datum, in: ebd. 
absichtigte Verbesserungen in den Leistungen der AV wurden mit Rücksicht auf die Invalidenversicherung nicht eingeführt“. ${ }^{16}$ Eine eigens eingerichtete Kommission beim Reichsverband deutscher Versicherungsträger, der seitens der RfA Koch angehörte, fasste schließlich die diversen Änderungsvorschläge zusammen und legte sie Mitte Februar 1941 als Eingabe dem RAM vor. ${ }^{17}$ Doch dort hatte man schon, ohne das Ergebnis der Änderungsvorschläge durch den Reichsverband abzuwarten, am 15. Januar 1941 ein Gesetz über ,weitere Maßnahmen in der Reichsversicherung aus Anlass des Krieges“ erlassen. ${ }^{18}$

Das Gesetz war, wie sich schnell herausstellte, mehr als alle vorgehenden, überhastet entstanden und in Vielem unklar formuliert. Teile der Bestimmungen hatten dabei schon im Voraus in der Verwaltungspraxis der RfA Eingang gefunden. In einer Abteilungsverfügung vom 25. September 1940 war unter anderem festgelegt worden, was in dem bislang nur als Entwurf existierenden Gesetz unter anderem geregelt werden sollte, dass nämlich beim Tod eines Versicherten nach dem 25. August 1939 die Hinterbliebenenrente nach Beantragung bereits mit dem Ablauf des Sterbemonats begann. Der Beginn der Rentenzahlung war damit nicht mehr wie bisher vom Tag der Antragstellung abhängig, sondern richtete sich nach dem Tod des Versicherten. Danach sollte nun bei neu festzusetzenden Hinterbliebenenrenten verfahren werden. Bei den bereits festgesetzten Hinterbliebenenrenten eines nach jenem 25. August gestorbenen Versicherten sollte jedoch eine Änderung des Rentenbeginns nur dann vorgenommen werden, wenn die Rente von einem Berechtigten noch einmal gesondert beantragt wurde. ${ }^{19}$ Wie schon oft zuvor war auch hier vor einem Gesetzeserlass eine für alle Beteiligten verwirrende Rechts- und Verwaltungspraxis ausgeübt worden, die Ungleichheiten geschaffen hatte. Entscheidend waren jedoch zwei andere Bestimmungen des Gesetzes. Zum einen wurden die bestehenden Anwartschaftsfristen aufgehoben, d.h. auf die Erfüllung der Wartezeit bei Soldaten, die während des Krieges starben oder berufsunfähig bzw. invalide wurden, wurde verzichtet. Zum anderen wurde nun die den Erfordernissen der Kriegswirtschaft zuwiderlaufende Bestimmung beseitigt, nach der eine wegen Berufsunfähigkeit gewährte Rente bei Wiederaufnahme einer Tätigkeit entzogen bzw. zum Ruhen gebracht werden konnte. Rentenempfänger konnten nun wieder invaliden- oder angestelltenversicherungspflichtige Beschäftigungen aufnehmen und erhielten ihre jeweiligen Ruhegelder weiter, da diese Beschäftigungen nun in der Verwaltungspraxis unabhängig von ihrer Dauer als vorübergehend bzw. als gelegentliche Aushilfe betrachtet wurden. Die RfAÜberwachungsbeamten wurden gleichzeitig aufgefordert, in den Kreisen der Invali-

16 Vermerk über die Dienststellenleiterbesprechung vom 11.12.1940, in: RfA-Archiv Nr. 25.

17 Vgl. die Eingabe vom 15.2.1941, in: ebd.

18 Vgl. das Gesetz in: Mitteilungen der RfA Nr. 4, 1941, S. 13-16.

19 Vgl. Abteilungsverfügung vom 25.9.1940, in: RfA-Archiv Fach 3, Nr. 4. 
den- und Angestelltenrentner für „weiteste Bekanntmachung“ dieser zur Mobilisierung zusätzlicher Arbeitskräfte wichtigen Bestimmung zu sorgen. ${ }^{20}$

Doch was auf den ersten Blick als erfolgreiche Instrumentalisierung des Rentenversicherungsrechts zugunsten der Kriegswirtschaft aussah, entfaltete schnell nicht beabsichtigte, gleichwohl aus Sicht des Regimes höchst unangenehme Folgewirkungen. Das Gesetz unterschied nicht mehr zwischen Renten wegen dauernder und vorübergehender Invalidität bzw. Berufsunfähigkeit, so dass es immer häufiger dazu kam, dass vorübergehend invalide Rentner nach Wiedereintritt in eine Beschäftigung neben dem vollen Lohn auch die Renten weiterbezahlt bekamen und auch noch die Beitragsanteile für die Rentenversicherung sparten. Ein älterer, in seiner Leistungsfähigkeit beeinträchtigter Akkordarbeiter oder auch Angestellter, der die Invaliditäts- bzw. Berufsunfähigkeitsgrenze noch nicht erreicht hatte, verdiente dann erheblich weniger als ein gesunder junger Beschäftigter, der wegen einer früheren vorübergehenden Berufsunfähigkeit die Rente bekam. Nicht zu Unrecht befürchtete daher der Reichsverband der Rentenversicherungsträger, „dass dadurch das Gegenteil dessen eintritt, was der Gesetzgeber zunächst beabsichtigte“. ${ }^{21}$ Bereits im Oktober 1941 diskutierten daher Vertreter der verschiedenen Versicherungsträger, des RAM und der DAF im Reichsversicherungsamt Möglichkeiten und Wege, die damaligen Bestimmungen wieder einzuschränken. Man habe, so gestanden die RAM-Vertreter zu, bei Erlass der Verordnung mit einer kürzeren Dauer des Krieges gerechnet. Nun zwinge „bei aller Anerkennung der notwendigen Förderung des Arbeitseinsatzes vor allem die ungünstige psychologische Wirkung wieder voll berufsfähiger und berufstätiger Rentenempfänger auf die keine Rente beziehenden Arbeitskameraden und deren Willen zum Arbeitseinsatz“ zum Handeln. ${ }^{22}$ Doch die RfA und auch die DAF befanden sich in einer Zwickmühle. Eine Auszählung von 1000 Ruhegeldbescheiden hatte ergeben, dass der Anteil der Bescheide wegen vorübergehender Berufsunfähigkeit von einst ca. 32 Prozent inzwischen auf 68 Prozent hochgeschnellt war. Somit wären von der Rückkehr zur früheren, viel kritisierten Verwaltungspraxis der Nachprüfung und Entziehung innerhalb eines Jahres, wie es Koch für die RfA auf der Besprechung im RVA vorgeschlagen hatte, eine erhebliche Zahl von Versicherten und Rentnern betroffen, mit entsprechenden stimmungsmäßigen und negativen loyalitätspolitischen Folgen. ${ }^{23}$ Mitte Februar 1943 erst sollte sich das RVA zu einer Regelung des Problems dahingehend durchringen, dass, „um bei der langen Dauer des Krieges einem unberechtigt langen Rentenbezug“ in den Fällen vorübergehender Invalidität bzw. Be-

20 Vgl. Rundschreiben Nr. 63 an die Überwachungsbeamten vom 24.5.1941, in: RfA-Archiv, Ordner Rundschreiben, ohne Sign.

21 Schreiben vom 11.11.1942, in: RfA-Archiv Nr. 27.

22 Vgl. Vermerk Kochs vom 12.10.1941 über eine Besprechung im RVA, in: RfA-Archiv Nr. 27.

23 Vgl. Schreiben der RfA an den Reichsverband der Deutschen Rentenversicherungsträger vom 27.11. 1942, in: ebd. 
rufsunfähigkeit vorzubeugen, auf der Basis eines ärztlichen Gutachtens ein von vornherein zeitlich begrenzter Rentenbezug festgelegt wurde. ${ }^{24}$

Das Gesetz vom 15. Januar 1941 verlängerte auch die Verjährungsfristen, was konkret erheblich erweiterte Nachzahlungsmöglichkeiten von Pflichtbeiträgen zuließ. Gerade die Fristenregelungen sorgten allerdings für reichlich Verwirrung. Rechtsberatungsstellen der DAF überhäuften ebenso wie Versicherungsämter die RfA mit Anfragen zur Klärung der in der Praxis widersprüchlichen Bestimmungen. Einerseits galten die Nachentrichtungsmöglichkeiten aufgrund der Bestimmungen des Ausbaugesetzes nur noch bis zum 31. Dezember 1941, andererseits aber nun offenbar bis zum Ablauf des auf das Kriegsende folgenden Kalenderjahres. ${ }^{25}$ Vor allem die Auslegung des zentralen $\S 17$ des Gesetzes über die Erfüllung der Wartezeit für verwundete oder gestorbene Soldaten bereitete den RfA-Beamten erhebliches Kopfzerbrechen. Fand der Paragraph auch dann Anwendung, wenn der Soldat von dem ihm zustehenden Selbstversicherungsrecht Gebrauch machte und erst, nachdem er schon Soldat geworden war, begonnen hatte, Beiträge zur Angestelltenversicherung zu entrichten? Wenn ja, dann hätte das dazu geführt, dass der Soldat durch die Leistung eines einzigen Beitrags den Versicherungsschutz im Invaliden- oder Todesfall in Form einer monatlichen Grundrente von 30 RM erwerben konnte, was für die RfA eine erhebliche finanzielle Belastung bedeutet hätte. ${ }^{26}$ Über die Auslegung dieser strittigen Frage entspannte sich ein umfangreicher Schriftwechsel zwischen DAF, RVA, RfA, der LVA Westfalen und der Reichsknappschaft. ${ }^{27}$ In einem eigens erstellten Gutachten für die Gaurechtsberatungsstelle der DAF Kurhessen in Kassel kam man seitens des RVA zu dem Schluss, dass es sich bei der Bestimmung um eine kriegsbedingte Sondervorschrift handelte, die aber nur denjenigen die Vergünstigung der Erfüllung der Wartezeit zukommen lasse, die bereits Versicherte gewesen waren.

Es ist wohl nicht die Absicht des Gesetzgebers gewesen, auch solche Personen zu begünstigen, die, ohne jemals in der Rentenversicherung Versicherte gewesen zu sein, durch die an sich mögliche Entrichtung freiwilliger Beiträge auf ein Jahr zurück nach der Einberufung zum Wehrdienst sich die Eigenschaft eines Versicherten und dies unter Umständen mit einem sehr hohen Beitrag für die Zeit vor der Einberufung zu verschaffen. ${ }^{28}$

Unklar war auch die Wehrmachtzugehörigkeit als Voraussetzung. Für erhebliche Aufregung sorgte etwa im Oktober 1941 der Tod eines Angehörigen der Transport-

24 Vgl. Rundschreiben des RVA vom 23.2.1943 sowie die daraufhin erfolgte Abteilungsverfügung vom 29.3.1943, in: ebd.

25 Vgl. dazu die diversen Anfragen vom Juni 1941, in: RfA-Archiv Nr. 27.

26 Vgl. die umfangreiche Ausarbeitung zur Auslegung von $\S 17$ vom 24.1.1941, in: RfA-Archiv Nr. 27. 27 Vgl. dazu die Schriftwechsel und internen Vermerke vom Februar 1941, in: ebd. Hier auch ein Entwurf zu einem als streng vertraulich gekennzeichneten Manuskript des Direktors des Versicherungsamtes in München über „Zweifelsfragen der Rentenversicherung im Gesetz vom 15.1.1941“.

28 Das Gutachten vom 30.4.1942 sowie auch die entsprechende Grundsatzentscheidung des Beschlusssenats der RVA vom 8.5.1942, in: BArch R 89/22706. 
standarte Speer beim Einsatz in Frankreich durch feindlichen Fliegerangriff. Da der Betroffene formal kein Angehöriger des Wehrmacht gewesen war, konnten auch die Bestimmungen des Gesetzes vom 15. Januar 1941 nicht angewendet werden und die RfA hatte daher den entsprechenden Antrag der Witwe auf Hinterbliebenenrente abgelehnt. ${ }^{29}$ Trotz Intervention des Generalbauinspektors und obwohl auch seitens der RfA zugestanden wurde, dass die Ablehnung „eine unbillige Härte“ darstelle und „mit dem gesunden Volksempfinden nicht im Einklang“ stehe, blieb der Fall auch im November 1942 weiter in der Schwebe. ${ }^{30}$

Auch die am 13. September 1941 zu dem Gesetz erlassene erste Durchführungsverordnung - auf deren Erlass mit einer Reihe von konkreten Bestimmungen die RfA bereits im März erfolglos gedrungen hatte - schuf keine Klärung, sondern im Gegenteil auf anderen Gebieten neue massive Unklarheiten und strittige Rechtsauslegungen sowie offene Fragen. ${ }^{31}$ Im Mittelpunkt stand dabei die Anrechnung der bei einem anderen Versicherungszweig zurückgelegten Kriegsdienstzeiten auf die Wartezeit auch in der Angestelltenversicherung. Die Verordnung ließ völlig offen, wie diese Zeiten angerechnet werden sollten. Im Herbst war es darüber nicht nur mit den Landesversicherungsanstalten $\mathrm{zu}$ einem offenen Dissens gekommen, sondern auch RfA-intern war eine höchst kontroverse Diskussion entbrannt. „Die durch $\S 1544 \mathrm{a}$ Abs. 2 RVO geschaffene Rechtslage ist wahrlich kompliziert und zwar nicht nur dem Versicherten als Laien, sondern auch dem Sozialversicherungsbeamten als Praktiker höchst unverständlich“, hieß es dazu Ende Dezember 1941 resigniert in einem internen Vermerk eines Dienststellenleiters der Leistungsabteilung. Dadurch habe man

nichts halbes aber auch nichts ganzes geschaffen. Man hat diese neue Vorschrift ins Gesetz hineingestellt, ohne sich auch nur um ihre Auswirkungen auf die anderen Wanderversicherungsparagraphen zu kümmern. Man hätte schon klar sagen sollen, die InvalidenversicherungsKriegsdienstzeit steht den Invalidenversicherungs- oder aber den Angestelltenversicherungsbeiträgen gleich. Ich glaube, wir werden mit jedem neuen Paragraphen noch manchen unerfreulichen Streit haben, der nur unfruchtbare Verwaltungsarbeit macht - und leider verbittert. Vielleicht könnte man erreichen, dass die Weltkriegs- und jetzigen Kriegszeiten nach den gleichen Grundsätzen behandelt werden. Die Anrechnung der Kriegsdienstzeit wird auch in Zukunft noch auf lange Zeit eine große Rolle spielen, bei den älteren Versicherten der Weltkrieg und bei den

29 Vgl. dazu das Schreiben der RfA an das RVA vom 11.10.1941, in: RfA-Archiv Nr. 27.

30 Vgl. Schreiben der NSKK-Transportstandarte Speer an die RfA vom 25.9.1941, in: BArch R 89/3170 sowie das dazugehörige Schreiben der RfA an das RVA vom 13.11.1942, in: ebd.

31 Vgl. dazu das Schreiben der RfA an den Reichsverband Deutscher Rentenversicherungsträger betr. Anregungen zur Durchführungsverordnung vom 15.3.1941, in: RfA-Archiv Nr. 69. Vgl. zur damaligen regen Debatte in den diversen Fachzeitschriften etwa den Kommentar vom H. Künstler, „Die Durchführung des Gesetzes über weitere Maßnahmen der Reichsregierung aus Anlass des Krieges“, in: Deutsche Rentenversicherung Nr. 1 (1942), S. 5-9, der ebenfalls beklagt, dass die Durchführungsverordnung vom 13.9. auf die meisten der in den verschiedenen Aufsätzen diskutierten Fragen und Wünsche „leider nicht eingeht“. 
jüngeren Versicherten der jetzige Krieg. Das Kriegsdienstzeitproblem wird erst aufhören, wenn der jüngste Teilnehmer des jetzigen Krieges seine Rente aus der Sozialversicherung erhalten hat. ${ }^{32}$

Das strittige Thema war kein verwaltungsrechtliches Detailproblem, sondern berührte eine zentrale Frage der Rentenversicherung im Krieg und weit darüber hinaus.

Letztendlich generierten die Bestimmungen bloße Rentenleistungsansprüche zu einem späteren Zeitpunkt und stellten damit Zukunftsversprechungen für die Zeit nach dem Krieg dar, jedoch kaum faktische Rentenerhöhungen. Sie begünstigte mehr die Versicherten, weniger die Rentner. Allerdings stellten die RfA-Beamten in den folgenden Monaten fest, dass immer häufiger Rentenfälle zur Erledigung kamen, in denen alte Teilrentenbescheide infolge der Anwendung der neuen Bestimmungen aufgehoben wurden und aus den bisher gezahlten Teilrenten nun Vollrenten wurden. ${ }^{33}$ Da dafür keine Ausgleichs- oder Zuschusszahlungen durch das Reich vorgesehen waren, gingen die neuen Ausgaben ausschließlich auf Kosten der RfA. Und dabei war eine weitere potentielle finanzielle Belastung, die angekündigte Entscheidung über die Steigerungsbeträge für die jetzigen Kriegsteilnehmer, weiterhin ausgesetzt, „weil sich die finanziellen Auswirkungen in keiner Weise übersehen lassen“, wie es in einem Schreiben des RAM an die Versicherungsträger heißt. ${ }^{34}$ Wie auch immer: Die großen Hoffnungen und Erwartungen auf eine Änderung der Gesetze, die es nicht nur in weiten Teilen der Bevölkerung, sondern wie gesehen auch innerhalb der RfA gab, erfüllten sich mit dem Gesetz vom 15. Januar 1941 nicht; Kochs resignierte Feststellung vom Dezember 1940 über seine vergeblichen Änderungsvorschläge schien sich mithin erneut zu bestätigen. Auch RVA-Vizepräsident Schmitt, ein strammer NS-Parteigänger, gestand nach dem Erlass des Gesetzes vom Januar 1941 ein, dass man „gerade in der Sozialversicherung ohne Übertreibung von einem wahren Dschungel der Gesetze und Verordnungen sprechen [kann], in dem eigentlich keiner mehr sich zurecht findet““.35

Anders als es sich das NS-Regime und das RAM von dem Gesetz erhofft hatten, war die Stimmung unter weiten Teilen der Versicherten wie Rentner Mitte 1941 nach wie vor schlecht und von Unmut geprägt. Ein Überwachungsbeamter schrieb in seinem direkt an Präsident Grießmeyer gerichteten Bericht Mitte Februar 1941:

Wie sich im Schriftwechsel die Stimmung der Arbeitgeber und Versicherten wiederspiegelt, so haben die Überwachungsbeamten täglich Gelegenheit, Wünsche und Beschwerden oft mit unbeschwerter Hemmungslosigkeit kennenzulernen. Letzthin musste ich bei der Prüfung des Berliner Büros einer Dortmunder Firma Unter den Linden hier auch wieder mal den explodierenden

32 Vermerk vom 24.12.1941, in: ebd. sowie dort auch der weitere Schriftwechsel und die Vermerke, auch von Direktor Koch, vom Dezember 1941 und Januar 1942.

33 Vgl. u.a. die Vermerke vom 27. und 28.2.1942, in: ebd.

34 Vgl. die Abschrift der Verfügung vom 5.6.1940 in einer Abteilungsverfügung vom 15.7.1940, in: ebd. 35 Brief Schmitts an den Präsidenten des Reichsverwaltungsgerichts Sommer vom 28.7.1941, in: BArch R 89/2639. 
Ausbruch eines hier vorübergehend tätigen Ingenieurs über die Unzulänglichkeiten der Leistungen der Angestelltenversicherung über mich ergehen lassen. ${ }^{36}$

Diese und ähnliche Kritik sei typisch und man höre sie mehr oder minder scharf täglich, so fuhr der Beamte fort und appellierte daher an die RfA-Leitung dringend, alles zu tun, um die Leistungen wieder zu steigern. Dazu gehöre allem voran die Wiedererhöhung des Grundbetrags auf 480 RM jährlich. Die Angestelltenversicherung müsse sich damit als soziale Rentenanstalt auch organisch weiterentwickeln und der Zeit anpassen. Die von dem Überwachungsbeamten gleich berechneten zusätzlichen 55 Mio. RM pro Jahr, die dafür nötig seien, dürften für die RfA kein Problem sein, für die in der Mehrzahl bedürftigen Volksgenossen unter den Empfängern jedoch ein wertvoller Zuschuss zum Lebensunterhalt. Zum verbreiteten Unmut hatte unter anderen auch beigetragen, dass eine Reihe vom Regime großzügig erlassener Hilfsleistungen wie etwa die Gewährung von Umstellungsbeihilfen und Familienunterhalt auf die gezahlten Renten der Reichsversicherung angerechnet wurden, wie die Betroffenen bald bemerkten. ${ }^{37}$

Vor diesem Hintergrund waren im RAM die Bemühungen zum Entwurf eines Gesetzes intensiviert worden, das endlich die Beseitigung der Rentenkürzungen vom Juni 1932 beinhaltete. Angesichts der andauernden großen Missstimmung unter den Rentnern und Versicherten könne die Aufhebung der Kürzungen auf die Dauer nicht mehr umgangen werden und die „augenblicklichen besonderen Verhältnisse lassen den jetzigen Zeitpunkt für die Beseitigung des früheren Unrechts als besonders geeignet erscheinen“. ${ }^{38}$ Der Entwurf sah eine Rücknahme der Kürzungen vor, d.h. der monatliche Grundbetrag in der Angestelltenversicherung bei den laufenden Renten sollte um sieben RM im Monat steigen, bei den neu festzustellenden Renten sich der Grundbetrag sofort auf 444 RM im Jahr erhöhen. Die Witwen- und Hinterbliebenenrenten sollten um fünf RM im Monat, die der Waisen um vier RM erhöht werden. Daneben sah der Gesetzentwurf nun auch im Reich die Einführung einer Krankenversicherung der Rentner vor. Für die Kosten der Rentenerhöhung wurden in der Invalidenversicherung rund 320 Mio. RM veranschlagt, in der Angestelltenversicherung dagegen nur 45 Mio. RM. Dazu kamen insgesamt rund 160 Mio. RM für die Rentnerkrankenversicherung, wobei allerdings den Löwenanteil der Mehrkosten nicht die Versicherungsträger, sondern das Reich durch Zuschüsse tragen sollte. ${ }^{39}$

Ursprünglich war das Inkrafttreten des Gesetzes zum 1. April 1941 vorgesehen; es sollte jedoch bis Juli dauern, bis das „Gesetz über die Verbesserung der Leistungen in der Rentenversicherung“ erlassen wurde, knapp ein Jahr später im Juni 1942 schon gefolgt von einem zweiten Leistungsverbesserungsgesetz. Grund für die Verzögerung

36 Bericht vom 14.2.1941, in: RfA-Archiv Fach 108, Nr. 4.

37 Vgl. dazu die entsprechende Abteilungsverfügung vom 25.6.1941, in: RfA-Archiv Nr. 26.

38 So die nicht mit veröffentlichte neunseitige Begründung des Gesetzes. Vgl. den Entwurf vom Februar 1941, in: RfA-Archiv Fach 111, Nr. 10. Vgl. auch Schlegel-Voß, S. 86.

39 Vgl. Gesetzesbegründung, S. 7 und auch Schlegel-Voß, S. 87. 
war offenbar hinter den Kulissen ein politisches Gerangel zwischen RAM und DAF, deren Sozialamt und Gaustellen nicht zu Unrecht kritisiert hatten, dass die Rentenerhöhungen eher halbherzig ausfielen und etwa die Kürzungen durch das Sanierungsgesetz weiter erhalten blieben..$^{40}$ Unter dem Strich blieb eine Rentenerhöhung in der Angestelltenversicherung um etwas über 20 Prozent; gleichzeitig erfolgte aber auch eine Beitragserhöhung um eine RM im Monat als Anteil für die Krankenversicherung. Das Gesetz räumte nun auch mit fast allen Fallstricken des Anwartschaftsrechts auf, die, wie Präsident Möbius vom Reichsverband Deutscher Rentenversicherungsträger eingestand, ,auch von Eingeweihten nur schwer zu entwirren sind“. Ihnen sei es in erster Linie zuzuschreiben, dass der Blick auf die großen Leistungen der Rentenversicherung so häufig getrübt worden sei. ${ }^{41}$ In das Gesetz war auch ein Großteil der von der RfA und dem Reichsverband Deutscher Rentenversicherungsträger gesammelten und immer wieder vorgebrachten Verbesserungsvorschläge eingeflossen. Bedeutende Änderungen ergaben sich auch im Bereich der Gesundheitsfürsorge. Obwohl nach wie vor keine gesetzliche Regelleistung, sondern eine Leistungsgewährung der RfA auf Kann-Basis, erfolgte durch das Gesetz nun stillschweigend eine Erweiterung der Heilverfahrensmöglichkeiten. Neben Maßnahmen gegen drohende Berufsunfähigkeit konnten nun auch Erholungskuren zum Erhalt der Arbeitseinsatzfähigkeit bzw. wegen der Anstrengungen der Kriegsarbeit gewährt werden.

Das erste Leistungsverbesserungsgesetz vom 24. Juli 1941 reihte sich, was den Charakter als lückenhaftes Rahmengesetz anging, in die Tradition der hastig zusammengeschriebenen Vorgängergesetze ein. Es umfasste gerade einmal sieben Paragraphen, ließ für die Durchführungsarbeit viele Fragen offen und ungeklärt und verwies die Versicherungsträger wieder einmal auf später noch $\mathrm{zu}$ erlassende Durchführungsverordnungen. ${ }^{42}$ Bezeichnenderweise hatte es, noch ehe das Gesetz überhaupt erlassen worden war, am 15. Juli 1941 im RAM schon eine Besprechung mit den Versicherungsträgern über die Durchführung der Maßnahmen gegeben, bei der auch die RfA vertreten war. ${ }^{43}$ Am Gesetzestext selbst konnte dabei nichts mehr geändert werden, da das Gesetz bereits von der Reichsregierung und von Hitler gebil-

40 Vgl. ebd.

41 Vgl. Möbius’ Rückblick und Ausblick, in: Deutsche Rentenversicherung 14 (1942), Nr. 1, S. 1. Zu neu durch $\S 3$ des Gesetzes vom 24.7.1941 aufgeworfenen, ,dringend eine brauchbare Lösung erfordernde[n]“ Detailproblemen, die sich aus dem neuen, vereinfachten Anwartschaftsrecht ergaben, vgl. aber den Aufsatz von RfA-Regierungsrat von Altrock: „Nochmals: Das Problem der Altersgrenze in der Angestelltenversicherung“, in: Deutsche Rentenversicherung Nr. 10 (1941), S. 132-134.

42 Vgl. das Gesetz, in: Mitteilungen der RfA Nr. 9, 1941, S. 33, 34. Dazu gab es einige Abmilderungen im Bereich der Wanderversicherung. Vgl. dazu auch RAM-Ministerialrat Heller über „Das Gesetz über die Verbesserung der Leistungen in der Rentenversicherung“, in: Deutsche Rentenversicherung 13 (1941), S. $103-104$.

43 Vgl. dazu den detaillierten Vermerk Kochs vom 17.7.1941 über das Ergebnis der Besprechung, in: RfA-Archiv Nr. 30. 
ligt - lediglich noch nicht unterzeichnet - worden war. ${ }^{44}$ Demnach waren die Leistungsverbesserungen bereits wenige Tage nach dem Erlass zum 1. August 1941 auszubezahlen, was bei den laufenden Renten eine pauschale Anwendung der Zuschläge ohne jeweilige Neuberechnung der Renten bedeutete. Die damit verbundenen Unstimmigkeiten wurden in Kauf genommen. In einer Reihe von neugewährten und -berechneten Fällen, z. B. bei den Teilrenten, gelangten deshalb niedrigere Renten zur Auszahlung als bei den laufenden Renten. Zudem wurden aufgrund der rückwirkenden Erhöhung der Rente irrtümlich vom 1. Juni an auch eine RM für die Krankenversicherung einbehalten, obwohl diese erst mit dem 1. August 1941 in Kraft trat. Missverständnisse, Unmut und Verwirrung bei den betroffenen Versicherten waren damit vorprogrammiert.

Tatsächlich dauerte es nicht lange, bis bei der RfA aus den Kreisen der Versicherten wie der Unternehmen besorgte Anfragen und Beschwerden eintrafen. Die Angestellten-Pensionskasse des IG-Farben-Konzerns bat etwa unter Berufung auf eine (falsche) Information des Versicherungsamtes in Ludwigshafen um nähere Auskunft, inwiefern tatsächlich diejenigen Rentenbezieher, die lediglich Ruhegeld aus der Angestelltenversicherung ohne Steigerungssätze aus der Invalidenversicherung erhielten, den Zuschlag von monatlich sieben RM nicht bekommen würden. ${ }^{45}$ Für die Pensionskasse war das neue Gesetz insofern von Bedeutung, als man den damals von den Kürzungen Betroffenen einen Ausgleich aus der Kasse gewährt hatte, der nun wieder wegfallen konnte. Gleichzeitig machten wilde Gerüchte die Runde, dass die Leistungsverbesserungen nur in der Invalidenversicherung eintreten würden, während bei der Angestelltenversicherung die Härten der früheren Notverordnungen beibehalten worden seien. ${ }^{46}$ Irritierte Anfragen kamen auch aus Kreisen derjenigen Rentenempfänger, die bereits bei einer Privatkrankenversicherung versichert waren, wegen des Abzugs von einer RM im Monat für die Krankenversicherung, die zurückgefordert wurde. Die RfA antwortete darauf mit einem bald als Standardschreiben formulierten Hinweis, wonach die eine RM nicht von der Rentenerhöhung einbehalten werde, sondern vom Ruhegeld.

Sie ist auch nicht für die Krankenversicherung eines bestimmten Rentners, sondern für die Gesamtheit der Renten bestimmt. Wenn der Rentner die nach dem Gesetz zuständige Krankenkasse nicht in Anspruch nimmt, sondern eine Privatkrankenkasse, so ist das seine Sache. Die 1 RM wird auf jeden Fall eingehalten. Hierzu ist sein Einverständnis nicht erforderlich. ${ }^{47}$

44 Vgl. das Rundschreiben des Reichsverbands Deutscher Rentenversicherungsträger vom 16.7.1941, in: RfA-Archiv Nr. 132 a.

45 Vgl. das Schreiben der IG-Farben-Pensionskasse an die RfA vom 11.9.1941, in: RfA-Archiv Nr. 94 b. 46 Vgl. das Schreiben an die RfA vom 8.7.1941, in: RfA-Archiv Fach 111, Nr. 10.

47 Vgl. die Anfrage vom 6.10.1941 sowie das Antwortschreiben vom 11.10.1941, in: ebd. Hier auch ähnliche Schreiben, unter anderem der Betriebskrankenkasse Trier vom 3.9.1941. 
Die RfA war schon kurz nach Veröffentlichung des Gesetzes aus Kreisen der Versicherten darauf hingewiesen worden, dass sich aus den Bestimmungen für einen sehr großen Teil der Ruhegeldempfänger eine gewisse Härte ergeben werde, da diese dann faktisch zu einem Wechsel der Krankenkasse gezwungen würden. ${ }^{48}$ Und ein Großteil der Berufs- und Betriebskrankenkassen bot tatsächlich bedeutend bessere Leistungen als die Ortskrankenkassen, wie etwa ein Sterbegeld. Angesichts der vielen Zuschriften schrieb RfA-Direktor Koch denn auch umgehend einen entsprechenden Brief an das RAM, verbunden mit einer Reihe von Vorschlägen zur Ergänzung oder Änderung der entsprechenden Gesetzesbestimmungen, ohne jedoch auf Gehör zu stoßen. ${ }^{49}$ Als problematisch stellte sich etwa auch die Bestimmung heraus, dass die Krankenversicherung der Rentner erst mit der Zustellung des Rentenbescheids in Kraft trat. Die Folge war, dass es immer wieder zu Beschwerden von Rentenberechtigten kam, denen aufgrund der langen Dauer des Rentenfeststellungsverfahrens für die lange Zeit vom Rentenbeginn bis zur Erteilung des Rentenbescheids der Anspruch auf die Krankenversicherung entging. ${ }^{50}$

Es spricht vieles dafür, dass man sich im RAM über die vielfältigen Auswirkungen der Rentnerkrankenversicherung auf Leistung, Beitragserstattung, Befreiung von der Versicherungspflicht und Zusatzversicherung nicht viele Gedanken gemacht hatte, geschweige denn über den verwaltungstechnischen Aufwand für die Versicherungsträger. Das von der RfA hierzu entworfene Merkblatt, das sich an die Versicherten richtete und diesen bei entsprechenden Anfragen ausgehändigt wurde, war über drei Seiten lang. ${ }^{51}$ Und der Verwaltungsaufwand war enorm. Vor allem musste man sich bei der Durchführung mit den Ortskrankenkassen über Meldeverfahren, Zahlungsunterlagen, Auszahlungslisten und Adresskarten austauschen und abstimmen, und dies lief im Fall der RfA und dem Reichsverband der Ortskrankenkassen im Frühjahr 1942 nicht konfliktfrei ab, so dass das RAM schließlich vermittelnd eingreifen musste. ${ }^{52} \mathrm{Im}$ Übrigen waren vom RAM, wie sich allerdings erst später herausstellen sollte, mit 3,30 $\mathrm{RM}$ je Rentner viel zu hohe monatliche Ablieferungsbeiträge durch die Versicherungsträger für die Krankenversicherung festgelegt worden. Das hatten die RfA und auch der Reichsverband Deutscher Rentenversicherungsträger schon frühzeitig moniert und auf tatsächlich erforderliche Beiträge in Höhe von 2,74 RM im Monat ver-

48 Schreiben an die RfA vom 3.8.1941, in: RfA-Archiv Nr. 30a.

49 Vgl. Schreiben Kochs vom 9.8.1941, in: ebd.

$50 \mathrm{Vgl}$. Schreiben der RfA an den Reichsverband der Ortskrankenkassen vom 23.6.1943, in: RfA-Archiv Nr. 30 c. Keine Lösung war, wie von den Betroffenen gefordert wurde, jedem Antragsteller sofort nach Eingang des Antrags eine Bescheinigung bzgl. der Krankenversicherung zuzusenden, da, wie die RfA argumentierte, viele Anträge nicht zur Bewilligung führten.

51 Vgl. das Merkblatt vom 1.8.1941 sowie dazu auch das Schreiben der RfA an den Reichsverband der Ortskrankenkassen vom 17.5.1944, in: RfA-Archiv Nr. 30.

52 Vgl. dazu das Schreiben der RfA an das RAM vom 9.2.1942 und ein zwölfseitiges Beschwerdeschreiben des Reichsverbandes an das RAM vom 13.3.1942, in: RfA-Archiv Nr. 30 b. 
wiesen - was das Statistische Reichsamt in seinen Berechnungen 1944 dann auch bestätigen sollte..$^{53}$

Erhebliche Ernüchterung erlebten auch viele Wanderversicherte beim Blick auf ihre Rentenauszahlungen. Denn in den Genuss der zumindest teilweisen Rücknahme der Kürzungen bei den Steigerungsbeträgen aus der Invalidenversicherung von 144 RM auf 72 RM im Jahr kamen nur die nach dem 27. Juli neu festgesetzten Renten, während bei den laufenden Renten die Kürzungen voll bestehen blieben. Auf diese Ungerechtigkeit hingewiesen, antwortete die RfA mit dem lapidaren Hinweis, dass der Gesetzgeber auch diese Frage durchaus geprüft habe, von einer Verbesserung der laufenden Renten jedoch abgesehen habe. „Von einer Ausdehnung [der Erhöhung] auf die bereits laufenden Renten ist uns nichts bekannt. Es ist daher zwecklos, in diesen Fällen einen entsprechenden Antrag zu stellen. “54 Bereits im September 1941 berichtete Grießmeyer dem RVA wie dem RAM von einer Reihe nicht beabsichtigter Auswirkungen des Gesetzes, darunter etwa Fälle, „in denen dem Berechtigten die Rentenerhöhung geschmälert werden kann, unter Umständen sogar seine wirtschaftliche Lage schlechter wird, als sie vor der Erhöhung war“. ${ }^{55}$ Eine ganze Reihe von Rentnern war durch die Erhöhung in die nächsthöhere Steuerstufe gerutscht, wodurch der Zugewinn von der fällig werdenden höheren Einkommenssteuer zum Teil mehr als aufgezehrt wurde.

Die RAM-Beamten waren zudem auch erst durch die Rentenexperten der RfA darauf hingewiesen worden, dass die Bestimmungen von $\S 3$ des Gesetzes faktisch bedeuteten, dass auch alle Anwartschaften jener Versicherten erhalten blieben, die bei Wiedereintritt in eine Beschäftigung über 60 Jahre alt waren und damit angestelltenversicherungspflichtig wurden, auch wenn sie bisher nur einen geringen Beitrag gezahlt hatten und sich jahrelang nicht mehr um den Erhalt ihrer Anwartschaft gekümmert hatten. Unter den gleichen Voraussetzungen verloren zudem die bei Eintritt über 50 Jahre alten Versicherten ihre Befreiungsmöglichkeiten von der AV, ohne aber aufgrund ihres Alters jemals Aussicht zu haben, die Wartezeiten noch erfüllen zu können. ${ }^{56}$ Gegenüber diesbezüglichen Milderungsvorschlägen der RfA stellte man sich im RAM jedoch taub, eine weitergehende Auslegung des $\S 3$ halte man ,keinesfalls für erwünscht und auch nicht begründbar“. ${ }^{57}$ Dagegen wurde im RAM durchaus erwogen, die Anwartschaftsbestimmungen weiter zu mildern oder ganz zu beseitigen:

53 Vgl. Schreiben des Reichsverbandes Deutscher Rentenversicherungsträger an das RAM vom 12.12. 1944, in: ebd.

54 Vgl. Antwortschreiben vom 24.9.1941 auf einen Beschwerdebrief eines Versicherten vom 8.8.1941 hin sowie auch das RfA-Schreiben vom 26.8.1942, in: RfA-Archiv Fach 111, Nr. 10. Siehe auch den entsprechenden Hinweis auf das Gesetz vom 24.7.1941 im internen Jahresbericht der Leistungsabteilung für 1941, S. 3, in: RfA-Archiv Nr. 79.

55 Schreiben vom 13.9.1941, in: BArch R 89/3171.

56 Vgl. dazu auch den entsprechenden Hinweis im Rundschreiben Nr. 69 an die Überwachungsbeamten vom 6.10.1941, in: RfA-Archiv, ohne Signatur.

57 Vermerk vom 23.3.1942, in: BArch R 89/3171. 


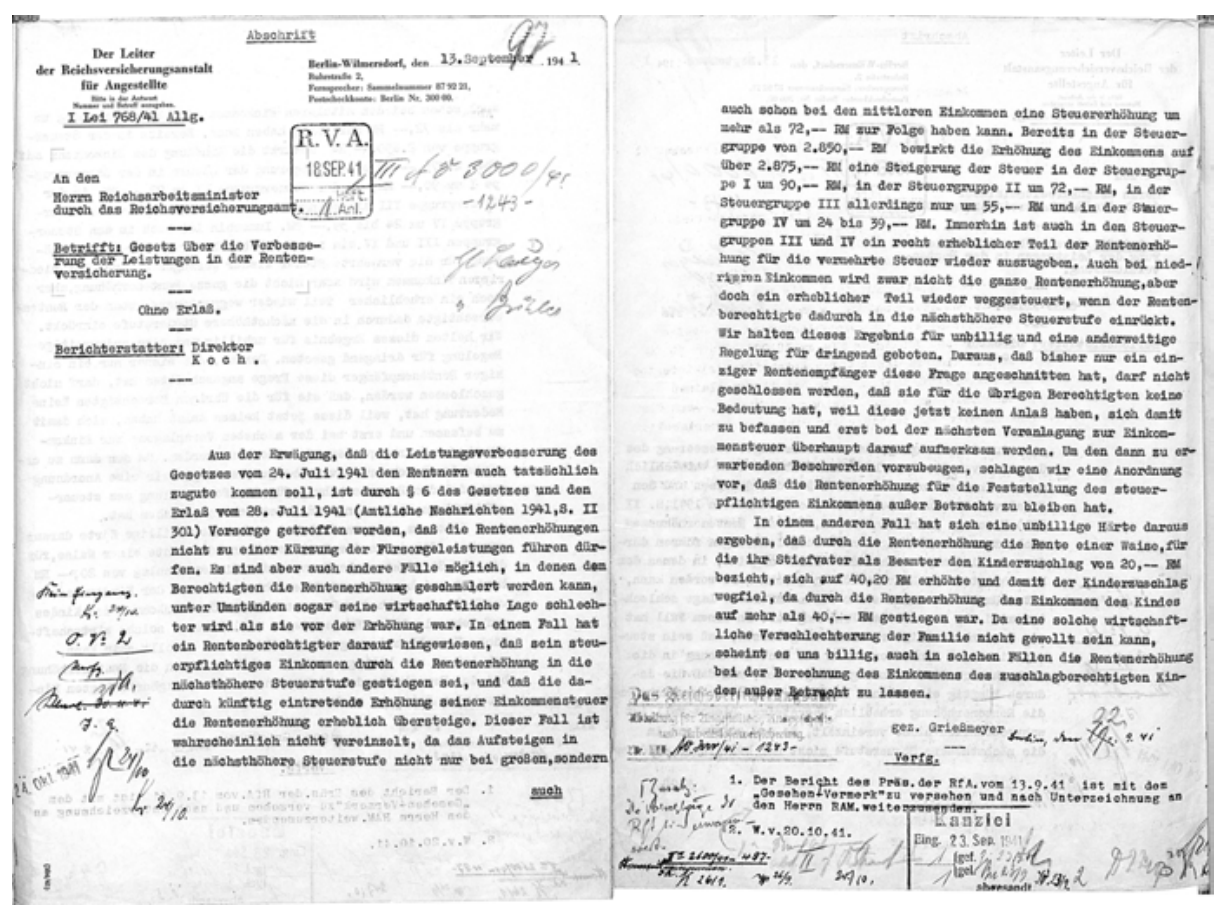

Abb. 29: Schreiben Grießmeyers an das RAM vom 13. September 1941 über die ungeplanten Auswirkungen des Leistungsverbesserungsgesetzes

Es ist jedoch bisher nicht gelungen, eine Form zu finden, die allen berechtigten Wünschen gerecht wird, zugleich aber verhindert, dass aus längst verfallenen Anwartschaften noch Rentenansprüche von solchen Personen geltend gemacht werden können, die einer Rente nicht bedürfen. ${ }^{58}$

Anfang August 1941 war es vermutlich auf Initiative der RfA im RVA zu einer erneuten Besprechung über die Durchführung des Leistungsverbesserungsgesetzes gekommen, wobei „unsere anliegenden Vorschläge für eine Durchführungsverordnung grundsätzlich gebilligt wurden“, wie RfA-Direktor Koch in einem Vermerk notierte. ${ }^{59} \mathrm{Im}$ Oktober wurde durch einen Erlass des RAM endlich auch die offene Frage der Gewährung von Steigerungsbeträgen geklärt. Demnach wurden für die Zeiten der Kriegsteilnahme Steigerungsbeträge nach der Klasse gewährt, zu der der letzte Betrag vor Einberufung zur Wehrmacht entrichtet worden war. Auf Antrag des Berechtigten konnte aber auch der Durchschnitt der letzten drei Monate zugrunde gelegt werden eine Bestimmung, die den mit der Feststellung der Steigerungsbeträge befassten Dienststellenleiter in der RfA wegen der Kompliziertheit und des bürokratischen

58 Ebd.

59 Vgl.Vermerk vom 11.8.1941 in: RfA-Archiv Nr. 67 sowie auch die Niederschrift über die Besprechung am 7.8.1941, in: BArch R 89/3171. 
Aufwands nachgerade zur Verzweiflung bringen sollte ${ }^{60}$ Bis 31 . Mai 1943 sollten im Bereich der RfA insgesamt bereits knapp 71.000 Renten mit zusätzlichen, vom Reich getragenen Ausgaben von 1,292 Mio. RM unter diese Regelung fallen, wobei kriegsbedingt der Löwenanteil (62.000 Renten) auf Witwen- und Waisen entfiel und nur 8185 Ruhegeldempfänger selbst noch in den Genuss der Zulage kommen konnten. ${ }^{61}$ Wenn man den Durchschnitt zugrunde legt, dann machte die Erhöhung durch die kriegsbedingten Steigerungsbeträge gerade einmal eine RM im Monat aus. Die pauschale Erhöhung um eine feste Summe der kriegsbezogenen Steigerungsbeträge, wie es im Übrigen von den RfA-Beamten vorgeschlagen worden war, hätte weit weniger Verwaltungsaufwand erfordert und wäre genauso effektiv gewesen. Auch wenn es sich bei all dem um eine für die Betroffenen materiell eher unbedeutende Maßnahme handelte, der zu diesem Zeitpunkt weit eher symbolpolitische Bedeutung zukam, so erscheint sie unter verwaltungsorganisatorischer Perspektive doch nachgerade exemplarisch und symptomatisch. Denn die RfA hatte, ohne sich beim RVA abzusichern, eine eigene Auslegung und daraus abgeleitete Ausübung im Verwaltungswege entwickelt. Es ging um die schwierige Frage der Berechnung des Steigerungsbetrages, wenn die Einziehung zum Militär im Laufe eines Beitragsmonats stattfand, ein Problem, das auch alle anderen Versicherungsträger umtrieb. ${ }^{62}$ Auch auf das Risiko, dass die Rechtsprechung mit der Verwaltungspraxis und Auslegung der RfA nicht konform gehen könnte, war man aus nachvollziehbaren Gründen dazu übergegangen, den Einberufungsmonat als Ersatzzeit zu streichen und stattdessen den vorhergehenden ganzen Monat für die Berechnung zugrunde zu legen. Von Seiten des RVA folgte dann aber prompt eine Ermahnung, dass dies von der Wortfassung des Gesetzes nicht gedeckt sei. Die RfA wurde aufgefordert, ihre Auslegung und Auffassung schriftlich in einem Bericht niederzulegen. ${ }^{63}$

Während man in der Ruhrstraße noch mit der Umsetzung des ersten Leistungsverbesserungsgesetzes befasst war, trat am 19. Juni 1942 - für die meisten Beteiligten in der Rentenverwaltung durchaus überraschend - ein „Zweites Gesetz über die Verbesserung der Leistungen in der Rentenversicherung“ in Kraft. ${ }^{64}$ Ursprünglich waren damit vom RAM offenbar angesichts der gestiegenen Lebenshaltungskosten weitere Rentenerhöhungen in durchaus nennenswertem Umfang vorgesehen gewesen, denn die unter anderem bei der RfA nach wie vor eingehenden Rufe und Forderungen nach

60 Vgl. die Verordnung vom 8.10.1941, in: RfA-Archiv Nr. 67 sowie die darauf basierende Abteilungsverfügung vom 29.10.1941 zur Durchführung der Verordnung, ergänzt durch eine weitere Abteilungsverfügung vom 25.11.1941 und der sich darauf beziehenden internen Vermerk an den Unterabteilungsleiter der Abt. I Leistung vom 13.1.1942, in: ebd. Später sollten weitere Ergänzungen und Änderungen hinzukommen, so am 17.6.1942 und zuletzt sogar noch am 23.1.1945.

61 Vgl. Vermerk vom 7.6.1943 mit der Meldung der Zahlen an das RVA, in: RfA-Archiv Nr. 67.

62 Vgl. dazu etwa den Aktenvermerk über eine Besprechung mit der Reichsknappschaft im RVA vom 12.12.1941, in: BArch R 89/3170.

63 Vgl. ebd.

64 Vgl. den Beitrag von Präsident Fix, LVA Westfalen, über „Das Zweite Gesetz über die Verbesserung der Leistungen in der Rentenversicherung“, in: Deutsche Rentenversicherung 14 (1942), Nr. 8, S. 75 - 80. 
einer Erhöhung der Renten waren nach dem ersten Leistungsverbesserungsgesetz keineswegs verstummt. ${ }^{65}$ Doch nach massiven Widerständen in Parteistellen und beim Reichsfinanzministerium verzichtete das RAM auf eine Erhöhung der Renten und legte stattdessen einen Gesetzentwurf vor, der sich vor allem auf den Abbau struktureller Mängel insbesondere in der Invalidenversicherung der Arbeiter beschränkte. ${ }^{66}$ Mehr denn je waren die Arbeiten an dem Gesetz unter massivem, vom Regime ausgeübten Zeitdruck und unter ständigen Interventionen aus der Parteikanzlei Hitlers erfolgt. ${ }^{67}$ Auch von einer angemessenen Beratung und der Gelegenheit zu eventuellen Änderungsvorschlägen durch die Versicherungsträger konnte diesmal keine Rede sein. In weiten Teilen der Versicherungsträger, auch und gerade bei der RfA, traf das Gesetz daher von Anfang an auf wenig Zustimmung. ${ }^{68}$ Das Gesetz brachte für die Mehrzahl der laufenden Renten denn auch keine echten Verbesserungen, außer eine Erhöhung des Kinderzuschusses. Das Gesetz war aber insofern von Bedeutung, als es Verbesserungen der Witwenrenten durch die Berücksichtigung von Kindererziehung und „Kindergebären“ mit sich brachte und vor allem auch eine Witwenrente für geschiedene Ehefrauen vorsah. Der Kreis der HinterbliebenenrentenBerechtigten wurde mithin ausgeweitet und eine neue Rentenart eingeführt, die allerdings nur eine Kann-Leistung war. Und es gab, zumindest aus Sicht der Rentenexperten in der RfA noch eine weitere Bedeutung des Gesetzes, denn es waren zum einen weitergehende Rechtsnivellierungen zur Invalidenversicherung erfolgt und man war einer Vereinheitlichung des Leistungsrechts in beiden Versicherungszweigen ein gutes Stück nähergekommen. Zum anderen aber galt nun, dass der Versicherte, der durch einen Arbeitsunfall invalide oder berufsunfähig wurde oder starb, auch ohne Erfüllung der Wartezeit die Rente erhielt. Auch die Regelleistung der Beitragserstattung im Heiratsfall verlangte als Voraussetzung nun nicht mehr die Erfüllung der Wartezeit und der Anwartschaft. ${ }^{69}$ Mit anderen Worten: Mit diesen Änderungen beim Anwartschaftsrecht und der Wartezeit waren zwei bislang gültige fundamentale Grundsätze des Versicherungsprinzips der Angestelltenversicherung aufgegeben worden.

65 Vgl. dazu den Entwurf vom 2.4.1942, in: BArch R 89/3171 und dazu auch Schlegel-Voß, S. 94 f. Exemplarisch für die Haltung bei den Rentnern das Schreiben vom 14.8.1942, in: RfA-Archiv Nr. 95 a. 66 Vgl. ebd.

67 Das Gesetz sollte „wegen seiner politischen Bedeutung“ ursprünglich schon anlässlich des Geburtstags des „Führers“ im April 1942 verabschiedet werden. Vgl. dazu das von Reichsarbeitsminister Seldte persönlich unterzeichnete Rundschreiben vom 13.4.1942, in: RfA-Archiv Nr. 31.

68 Vgl. dazu die durchaus kritischen Bemerkungen im Beitrag von LVA-Präsident Fix, die RfA-Direktor Koch mit dicken Anstreichungen und zustimmenden Randbemerkungen versah. Vgl. RfA-Archiv Nr. 31. Auch von Seiten des RVA war schon zum ersten Gesetzesentwurf vom April 1942 ungewöhnlich deutliche Kritik geäußert worden. Vgl. Schreiben des RVA an das RAM vom 14.4.1942, in: BArch R 89/ 3171.

69 Vgl. dazu den Jahresrückblick 1942 von Reichsverbandspräsident Möbius in: Deutsche Rentenversicherung Nr. 1 (1943), S. 2. 
Die beiden Leistungsverbesserungsgesetze waren keine zukunftsweisenden, gar innovativen und auf eine moderne Sozialversicherungsgesetzgebung verweisenden Maßnahmen, sondern längst fällige und aus der Defensive des Gesetzgebers RAM wie des NS-Regimes entstandene Maßnahmen. Auch damals deutete in der RfA niemand die Gesetze auch nur ansatzweise anders. Es ging weniger um Mobilisierung von Loyalität als um die bloße, gleichwohl vom NS-Regime symbolpolitisch groß aufgeladene Rücknahme eines alten Unrechts aus der Weimarer Republik, verbunden mit der Vermeidung weiterer Enttäuschungen und weiter abbröckelnder Zustimmung zum NS-Regime. Wenn es tatsächlich je Pläne im RAM gegeben hatte, mit sukzessiven Erhöhungen der Renten wieder an das Rentenniveau der späten 20er Jahre anzuknüpfen, dann waren sie spätestens jetzt, nicht zuletzt auch unter den Bedingungen des Krieges, endgültig gescheitert.

\subsection{Rentenversicherungsverwaltung im Schatten der Sozialversicherungspropaganda der DAF}

Die Gesetzgebung des RAM vollzog sich inzwischen zunehmend vor dem Hintergrund intensivierter eigener sozial- und rentenpolitischer Aktivitäten der DAF. Mitte Februar 1940 hatte Hitler DAF-Führer Robert Ley den Auftrag zur Schaffung von Grundlagen und Vorbedingungen für ein umfassendes und großzügiges Altersversorgungswerk des Deutschen Volkes gegeben. ${ }^{70}$ Daraufhin erschienen im Laufe des Oktober und November in verschiedenen Fachzeitschriften eine Reihe von Aufsätzen, in denen erste Grundgedanken des neuen nationalsozialistischen Rentensystems veröffentlicht wurden. Beginnend mit einem Aufsatz Leys im DAF-Organ Der Angriff am 1. Oktober 1940 wurde mit großer propagandistischer Begleitmusik „ein gesicherter Lebensabend für ein ganzes Volk“ versprochen, ohne Unterscheidung nach „Rang und Stand“ “. ${ }^{71}$ Soweit es die ebenso blumigen wie vagen Darlegungen zuließen, waren zumindest einige Grundgedanken erkennbar, die den bisherigen Prinzipien des Alterssicherungssystems in Vielem zuwiderliefen: Aufhebung der Unterscheidung von Invaliden- und Angestelltenversicherung, staatliche Zuweisung von Versorgungsleistungen - finanziert mit Steuermitteln - anstelle des bisherigen Versicherungs- und Beitragsprinzips und damit Abkoppelung der Rentenhöhe von der Beitragsleistung, ein Junktim zwischen Versorgungsanspruch und Arbeitspflicht sowie Abgehen vom geltenden Anwartschaftsdeckungs-, wie auch vom Kapitaldeckungsverfahren zugunsten eines Umlageverfahrens. ${ }^{72}$ Es sollte, wie auch der Präsident der LVA Hamburg, Gottlieb Storck, in der Zeitschrift Soziale Praxis unter dem Titel „Versorgung und

70 Zur Vorgeschichte der DAF-Pläne, vgl. Schlegel-Voß, S. $83 \mathrm{ff}$.

71 Vgl. Gesicherter Lebensabend für ein ganzes Volk, in: Monatshefte für NS-Sozialpolitik 7 (1940), Heft 19/20, S. 217-219 sowie auch schon der Bericht im Völkischen Beobachter vom 18.9.1940, „Deutscher Sozialstaat gegen plutokratisches Almosensystem“, als Kopie in: RfA-Archiv Fach 119, Nr. 2. 72 Vgl. dazu im Einzelnen auch Schlegel-Voß, S. $158 \mathrm{ff}$. 
Versicherung (Prinzip und Praxis)“ schrieb, nicht lediglich eine Reform verbesserungsfähiger Teile der jetzigen Sozialversicherung erfolgen, sondern eine „umwälzende Neuordnung “. ${ }^{73}$ Storck hatte sich schon im November 1940 in derselben Zeitschrift in einem damals noch anonym erschienenen Aufsatz unter dem Titel „Versicherung oder Versorgung“ für das Versorgungsprinzip und damit für die nationalsozialistischen Prinzipien in der Sozialpolitik stark gemacht. ${ }^{74}$

Ob in den Plänen des Versorgungswerks tatsächlich „moderne“ Grundgedanken wie der einer umlagefinanzierten dynamischen Rente enthalten waren, sei dahingestellt. ${ }^{75}$ Zum damaligen Zeitpunkt waren es mit Schlagworten nationalsozialistischer Ideologie durchsetzte Ankündigungen und sozialpolitische Propaganda. Dies änderte sich grundsätzlich auch nicht. Die Folgen dieser und ähnlicher Veröffentlichungen in der Tagespresse unter den Versicherten wie Rentnern waren aber gewaltig und die Reaktionen in einer Art und Weise, wie sie von den verantwortlichen DAF-Funktionären vermutlich weder beabsichtigt noch vorhergesehen waren. Bei der RfA wie auch bei den anderen Rentenversicherungsträgern setzte eine Flut von Briefen zutiefst verunsicherter Beitragszahler ein. Vor allem bei den freiwillig Versicherten, weiter Versicherten und höher Versicherten stellte sich nun die Frage, ob es überhaupt noch einen Sinn habe, Beiträge zu entrichten, wenn demnächst die bisherigen Leistungen der Versicherungsbehörden durch die Leistungen der DAF-Altersversorgung abgelöst würden. ${ }^{76}$ Auch von den Überwachungsbeamten kamen regelrechte Alarmmeldungen über die Stimmungslage bei den Versicherten, die sich vielfach auch mit Vorwürfen gegen die RfA mischten. Die langjährigen Bemühungen der RfA, als Repräsentant des bestehenden Altersversorgungssystems nach der angeschlagenen Reputation im Zuge der Rentenkürzungen in den Notverordnungsjahren bei Versicherten wie Rentnern wieder Vertrauen und Ansehen zu gewinnen, schienen auf einen Schlag zunichtegemacht. Von den Überwachungsbeamten wurde etwa zunehmend die Beobachtung gemacht, dass auch die Betriebsführer mit der Entrichtung von Pflichtbeiträgen zur Rentenversicherung laxer umgingen und die Säumnisse damit entschuldigten, dass demnächst das gesamte Beitragssystem doch beseitigt werde. ${ }^{77}$

Bemerkenswerterweise reihte sich RfA-Präsident Grießmeyer zunächst in diejenigen ein, die öffentliche Lobreden auf das „Altersversorgungswerk“ der DAF hielten. Bereits im Juni 1940 veröffentlichte er in der italienischen Fachzeitschrift Le Assicurazioni Sociali auf Deutsch einen Beitrag unter dem Titel „Die Altersversorgung des Deutschen Volkes“, in dem er die wichtigsten Prämissen und die Einbettung in die

73 Vgl. den Aufsatz in: Soziale Praxis 50 (1941), S. 817-824.

74 Vgl. Versicherung oder Versorgung, in: Soziale Praxis 49 (1940), S. 673-680. Vgl. dazu auch Storcks Brief „an den lieben Parteigenossen Schmitt“, den Vizepräsidenten des RVA vom 22.5.1941, in dem er auf dessen Publikationen Bezug nimmt, in: BArch R 89/2639.

75 Zur Diskussion und Bewertung des Ley-Plans in der (älteren) Forschung, vgl. Schlegel-Voß, S. 173. 76 Vgl. dazu die zahlreichen Briefe und Zuschriften in: RfA-Archiv Fach 119, Nr. 2.

77 Vgl. dazu auch das Schreiben des Reichsverbands Deutscher Versicherungsträger an Ministerialdirektor Pohl vom Arbeitswissenschaftlichen Institut der DAF vom 30.10.1940, in: RfA-Archiv Nr. 204. 
nationalsozialistische Volksgemeinschafts-Ideologie ausbreitete. ${ }^{78}$ Aber, wie so viele andere Sozialversicherungs- und Rentenfachleute, versuchte sich auch Grießmeyer an der Exegese der spärlichen verfügbaren Informationen über das Versorgungswerk. Aus den bisherigen verschiedenen Veröffentlichungen dazu träten, so schrieb er, die leitenden Grundgedanken bereits ziemlich deutlich in Erscheinung „und gewähren einen ausreichenden Blick auf das Gesamtbild dessen, was von Dr. Ley geplant ist““ ${ }^{79}$ Der Beitrag macht deutlich, dass auch Grießmeyer als RfA-Präsident faktisch nichts über die Details des geplanten Versorgungswerks der DAF wusste und auch nicht in etwaige Beratungen eingebunden war. Nach außen hin konnte der Aufsatz durchaus als vorauseilende Ergebenheitsadresse an die DAF aus Sorge um den Fortbestand der RfA verstanden werden; er ließ aber offen, was Grießmeyer wirklich von den LeyPlänen hielt. Und bei genauerem Hinsehen werden - anders als in den Beiträgen der LVA-Präsidenten - durchaus grundsätzliche Bedenken sichtbar. Da war von „Unzulänglichkeiten und Mängeln“ die Rede; es wurde auf die „offen zu Tage tretende scharfe gegensätzliche Einstellung zu dem bisherigen Versicherungsgedanken“ und auf die wichtige ungeklärte Frage hingewiesen, inwieweit und in welcher Weise die bisher geleisteten Versichertenbeiträge im Rahmen des künftigen Altersversorgungsystems „Berücksichtigung und Abgeltung erfahren werden“. ${ }^{80}$ Auch mit dem Hinweis darauf, dass die organisatorische Seite des kommenden Sozialwerks ungeklärt sei bzw. dass „noch nicht erkennbar geworden [sei]“, in welcher behördlichen Form das Reich die damit verbundenen Aufgaben lösen wolle, deckte Grießmeyer die verwaltungspraktischen Defizite des Konzepts auf. Und nicht zuletzt las sich für die mit den verwaltungsmäßigen Details der Rentenfinanzierung vertrauten Experten der Hinweis Grießmeyers, dass sich die künftige Versorgung auf dem Ethos der Volksgemeinschaft gründe und künftig auch keine Ansammlung von Rücklagen zur Deckung der erworbenen Anwartschaften mehr notwendig sei, durchaus als kritischer Hinweis auf die ideologische Utopie, weit entfernt von einer praktischen Umsetzung. ${ }^{81}$

Tatsächlich hatte die RfA intern schon damit begonnen, die voraussichtlichen Kosten und Finanzierungsgrundlagen des Altersversorgungswerks zu berechnen und genauer unter die Lupe zu nehmen. Im August 1940 wurde in einem internen Vermerk der durchaus ironisch zu verstehende Wunsch nach konstruktiven Einzelheiten geäußert, „um deren Eignung zum Anschluss an das bisher segensreich Bestehende zu prüfen“, damit auch die RfA als Betreuerin bedeutender sozialer Anwartschaften und einer bereits sehr großen Zahl an Ruhegeldern „den Anschluss ihrer bisher schon

78 Vgl. Albert Grießmeyer, Die Altersversorgung des Deutschen Volkes, in: Le Assicurazioni Soziali 16 (1940), S. 621-625.

79 Ebd., S. 621.

80 Ebd., S. 625.

81 „Die Steuerkraft des Volkes wird als nie versiegende Quelle zur Finanzierung auch der steigenden Versorgungslasten angesehen.“ Vgl. ebd., S. 623. 
segensreichen Tätigkeit zur Mitarbeit an dem kommenden Werk nicht versäumt“ ${ }^{82}$ Der Verfasser zerpflückte dabei ebenso nüchtern wie kompetent die bisher bekannten Planungen und macht dabei aus versicherungsrechtlicher Perspektive auf die dahinterstehenden grundsätzlichen Denkfehler aufmerksam, durch die bei genauerem Hinsehen die erworbenen und bestehenden Rechte der Versicherten nachgerade mit den Füßen getreten würden. Zur Wahrung der Belange der Versicherten der Angestelltenversicherung müsse die RfA daher zumindest auf entsprechende Ergänzungen der Bestimmungen des Altersversorgungswerks bestehen. In einem weiteren Vermerk nahm sich derselbe RfA-Beamte schließlich auch die Finanzierungsfrage des Altersversorgungswerks vor. Ausgehend von 2,5 Mio. deutschen Männern und drei Mio. deutschen Frauen jeweils über 65 Jahren ergaben sich gemäß den Ankündigungen der DAF zu den geplanten Versorgungsleistungen in Höhe von zehn Prozent des gesamten Volkseinkommens jährliche Ausgaben von 9,5 Mrd. RM. Im Verlauf der kommenden 30 Jahre, so rechnete der Beamte vor, würden jedoch aufgrund der demographischen Entwicklung aus den insgesamt 5,5 Mio. Rentnern 10,061 Mio. Rentner werden und damit die kalkulierten Versorgungsausgaben auf ca. 16,5 Mrd. RM klettern, d. h. alle vier Jahre um eine Mrd. RM. „Wird“, so heißt es abschließend dazu in dem Vermerk, „sich das Einkommen des Deutschen Volkes stetig in je 4 Jahren um 10 Mrd. RM erhöhen?" 83 Vermutlich kannte Grießmeyer diese Vermerke, denn sie wurden direkt RfADirektor Granzow vorgelegt, der der höchstrangige Rentenexperte der Behörde in Grundsatzangelegenheiten war und dessen Ausarbeitungen, Anschreiben und Vorlagen an RVA oder RAM Grießmeyer nur noch unterzeichnete.

Auf den RfA-Beiratssitzungen jedenfalls gab Grießmeyer eine relativ ungeschminkte Sicht der Ley-Pläne zu erkennen, die nicht ideologisch, sondern von der Perspektive der Behörde, ihrer Interessen, aber auch Verantwortung geprägt war. Sie zeigte vor allem, dass nicht nur die Versicherten, sondern auch sämtliche Führungskräfte und leitenden Beamten der Versicherungsträger hinsichtlich der Einzelheiten und dem jeweiligen Entwicklungsstand der gesetzgeberischen Pläne nicht nur weitestgehend, sondern praktisch völlig im Dunkeln tappten. Trotz beharrlicher Nachfragen kam vom RAM auch keinerlei Aufklärung. Anfang April 1940 war aus dem Beirat in Richtung des anwesenden RAM-Vertreters, Ministerialrat Dr. Engel, der Wunsch vorgebracht worden, etwas über die Altersversorgungspläne Leys zu erfahren, was von diesem jedoch mit Hinweis auf die noch laufenden Arbeiten und darauf, „dass es das Bestreben aller Beteiligten sei, eine möglichst günstige Versorgung der schaffenden Deutschen zu erhalten“, abgebügelt wurde. ${ }^{84}$ Auf der nächsten Sitzung des Beirats im Dezember 1940 ging dann Grießmeyer von sich aus ausführlich auf das geplante Altersversorgungswerk ein, wobei er suggerierte, dass es sich dabei bereits

82 Vermerk vom 19.8.1940 zur Altersversorgung des Deutschen Volkes (unter Bezug auf die Veröffentlichungen vom 25.4.1940 und vom 9.7.1940) durch ORR Schenkendorff, in: RfA-Archiv Handakte Granzow, ohne Signatur.

83 Vermerk vom 20.1.1941 „Zur Frage der Altersversorgung“, in: ebd.

84 Vgl. Niederschrift der elften Beiratssitzung vom 8.4.1940, S. 16, in: BArch R 89/3470. 
um einen „in seinen Grundzügen vom Führer gebilligten“ Entwurf handelte, dessen praktische Durchführbarkeit nach siegreichem Kriegsausgang, an dessen unmittelbar bevorstehendes Ende zu diesem Zeitpunkt fast alle glaubten, ,als gesichert angesehen wird“. ${ }^{85}$ Tatsächlich war in der Presse kurz zuvor groß von der Vollendung der Planungen und der Fertigstellung des neuen Altersversorgungskonzepts die Rede gewesen. Gegenüber dem Beirat pries Grießmeyer einerseits die Bedeutung dieser Altersversorgung, gleichzeitig jedoch sehe er, so äußerte er gegenüber dem Beirat, mit größtem Interesse den näheren (und bisher fehlenden) Darlegungen entgegen, „die die für die praktische Durchführung sehr wichtige Frage, nämlich die finanzielle, zu behandeln und lösen haben werden“. ${ }^{86}$ So wenig sich der RfA-Präsident offenbar um die organisatorische Zukunft seiner Behörde Gedanken machte - vermutlich würde ein neuer behördlicher Apparat entstehen, in dem die bisherigen Organe irgendwie aufgehen würden -, so große Probleme und Schwierigkeiten sah Grießmeyer jedoch, „wenn man über das Grundsätzliche hinaus in die Einzelheiten der künftigen materiellen Regelung hineinsteigt““ ${ }^{87}$ Die weiteren Äußerungen Grießmeyers auf der Beiratssitzung seien im Folgenden ausführlicher wiedergegeben:

Allein die Frage: Was geschieht mit den Anwartschaften, die die bisher in der Invaliden- und Angestelltenversicherung versicherten Volksgenossen durch ihre Beiträge sich erworben haben? Wie steht es mit den Anwartschaften aus der freiwilligen Versicherung, aus der Höherversicherung, aus der freiwilligen Fortsetzung einer Pflichtversicherung? Soll derjenige, der statt in der Sozialversicherung seinen Lebensabend bei der Privatversicherung gesichert hat, keine Anrechnung der späteren dortigen Rente erleiden, wohl aber der Sozialversicherte? Mit anderen Worten: Soll der wirtschaftlich Schwache sein Geld umsonst aufgewendet haben, der Begüterte aber nicht? Soll der Handwerker, der aus Gemeinschaftsgefühl zu unserer Versicherung kam, eine Anrechnung erleiden, der andere Handwerker aber nicht, der den Weg des Individualisten ging? Nur ein paar Fragen, aber Fragen von größter sozialer und politischer Bedeutung für die betroffenen Volksgenossen! Über die beabsichtigte Lösung allein dieser einen von vielen Detailfragen ist noch nichts bekannt geworden; so weit sind die Beratungen wohl noch nicht vorgedrungen. Uns jedenfalls haben diese Fragen in den letzten Monaten reichlich viel besorgte Anfragen aus den Kreisen unserer Versicherten ins Haus gebracht, die Aufklärung wünschen, die keine Neigung mehr zeigten, Pflichtbeiträge zu zahlen, die unter Umständen nutzlos gezahlt werden, weil man in Bälde ja alles umsonst bekomme. Wir sind nicht in der Lage, auf solche Fragen Antwort zu geben; wir sind bisher nicht eingeweiht worden in die Verhandlungen, die Herr Dr. Ley mit dem Herrn Reichsarbeitsminister führt; wir mussten uns darauf beschränken, all diese Fragen dem Herrn Reichsarbeitsminister zuzuleiten mit der Bitte, uns eine Antwort an die Hand zu geben, die die starke Beunruhigung zu bannen vermag. Bisher haben wir noch nichts gehört und ich kann deshalb auch den Mitgliedern des Beirats nichts zu diesen Dingen sagen [...]. Gleichwohl hielt ich es für meine Pflicht, den Herren das mitzuteilen, was ich weiß und was uns bedrückt, und ich möchte an Herrn Ministerialrat Heller die Bitte richten, im Reichsarbeitsministerium Fürsprecher unserer Sorgen und der Sorgen unserer Versicherten zu sein. ${ }^{88}$

85 Niederschrift der zwölften Beiratssitzung vom 2.12.1940, S. 3, in: ebd.

86 Ebd.

87 Ebd., S. 4.

88 Ebd., S. 5. 
Diese offene und unverblümte Kritik am geplanten Versorgungswerk war, zumal quasi halböffentlich vorgebracht, bislang noch nirgendwo geäußert worden. Im Beirat regte sich jedoch weder Zuspruch noch Widerspruch zu Grießmeyers Ausführungen, und auch der RAM-Vertreter blieb stumm.

Tatsächlich war der RfA-Präsident mit den unmittelbaren Folgen der Ankündigungen zum Altersversorgungswerk konfrontiert und beschäftigt. Bereits am 17. Oktober und abermals kurz darauf hatte sich Grießmeyer, wie er gegenüber dem Beirat andeutete, in dringenden Schreiben an das RVA bzw. RAM gewandt, um auf die massiven Probleme und Reaktionen aus dem Kreis der RfA-Versicherten aufmerksam zu machen. Neben den Fragen um die Anrechnung der bezahlten Beiträge machten etwa auch Gerüchte über die Höhe der künftig garantierten Mindestrente (etwa 81 RM im Monat) die Runde. ${ }^{89}$ Grießmeyer bat denn auch beim RAM um die Absegnung eines inzwischen von der RfA aus der Not der Anfragenflut heraus bei gleichzeitiger Unwissenheit über die DAF-Pläne entworfenen Standardschreibens. Darin verwies man auf die „streng vertraulichen“ Arbeiten am Altersversorgungswerk und wies offen auf die Nichtbeteiligung der RfA und den fehlenden Kenntnisstand der Behörde hin. Entscheidungen zu drängenden Fragen stünden noch aus und könnten zur Zeit noch nicht beantwortet werden.

Sollte Ihnen diese Auskunft nicht genügen, müssen wir es Ihnen überlassen, sich an das Arbeitswissenschaftliche Institut der Deutschen Arbeitsfront zu wenden. Die Frage, ob Sie unter den obwaltenden Umständen Ihre Versicherung in der Angestelltenversicherung freiwillig fortsetzen oder die Fortsetzung bis zum Erlass des Gesetzes über die Altersversorgung des Deutschen Volkes aufschieben, müssen wir Ihrer Entschließung überlassen. ${ }^{90}$

Der vom RAM genehmigte RfA-Bescheid an die besorgten Versicherten wich dann allerdings von diesem Text ab, gab aber quasi fast eine Garantie für die erworbenen Rechte und geleisteten Beitragszahlungen.

Auch in der Folgezeit schickte die RfA regelmäßig dutzende Anfragen, die nun nicht mehr nur aus den Kreisen der Versicherten stammten, sondern auch von Unternehmen, Wirtschaftsverbänden und kommunalen Versicherungsämtern, an das RAM weiter. ${ }^{91}$ Die vielen Fragen zum Altersversorgungswerk würden in der Öffentlichkeit weiter ständig erörtert, so monierte etwa auch das RVA gegenüber dem RAM, eine baldige Klarstellung erscheine deshalb dringend erwünscht. ${ }^{92}$ Doch dies, wie auch die Scheiben der RfA, blieben ohne unmittelbare Resonanz. Für erhebliche Unruhe hatte darüber hinaus vor allem auch eine Passage in dem erwähnten anonymen Aufsatz über „Versicherung oder Versorgung“ in der Sozialen Praxis vom

89 Vgl. etwa die entsprechende Anfrage eines ehemaligen Vertrauensmanns (,als solcher werde ich immer noch ab und zu über diese Sachen gefragt“) Ende April 1940, in: RfA-Archiv Fach 119, Nr. 2. 90 Vgl. den Entwurf und daraus entwickelten Vordruck, in: RfA-Archiv Fach 91, Nr. 6.

91 Vgl. dazu eine Liste der jeweils dem RAM beigefügten Anschreiben und Briefe, in: RfA-Archiv Fach 119, Nr. 2. Zuletzt ging noch im Januar 1941 ein entsprechender Bericht an das RAM.

92 Schreiben des RVA an das RAM vom 27.1.1941, in: BArch R 89/3173. 


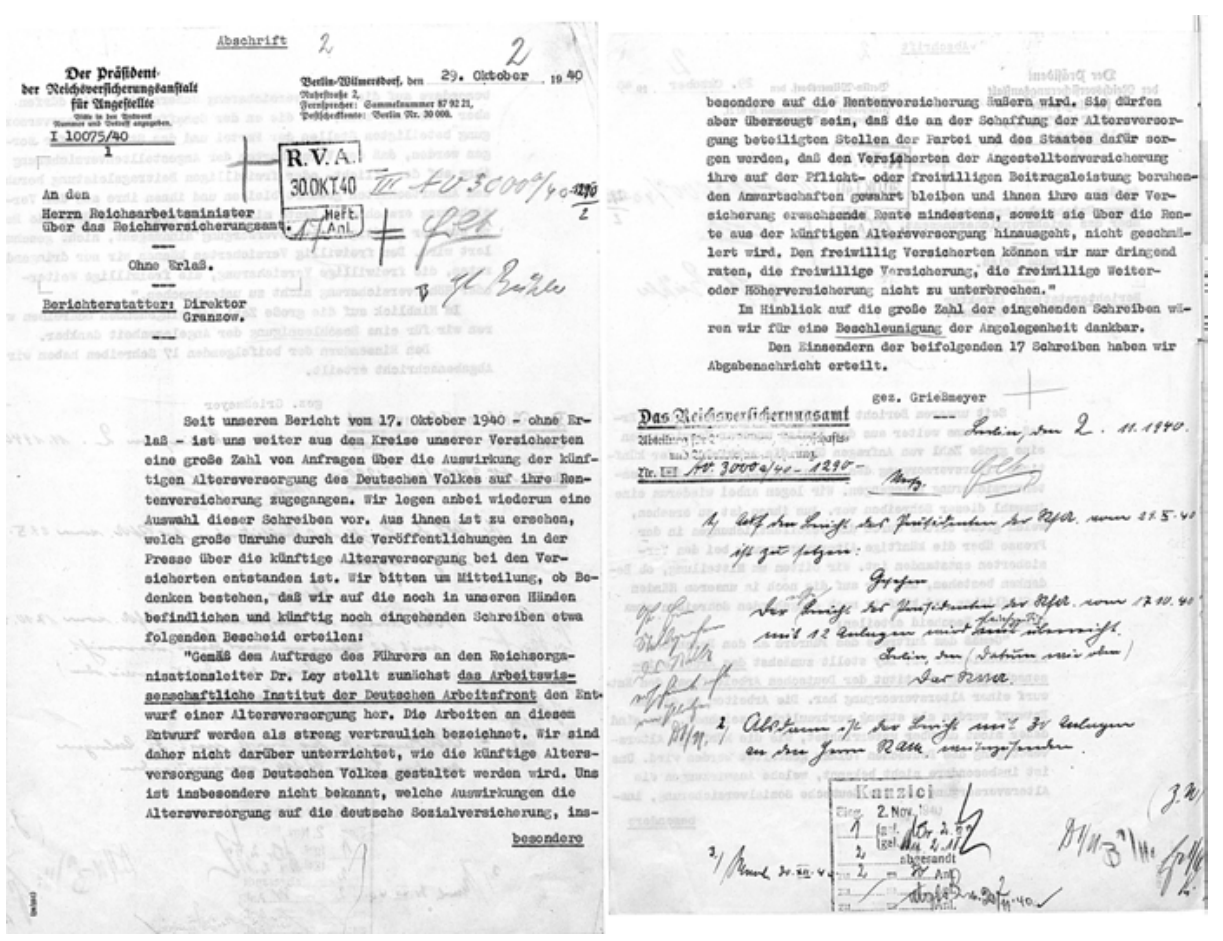

Abb. 30: Schreiben Grießmeyers an das RAM vom 29. Oktober 1940 zum geplanten Altersversorgungswerk der DAF

November 1940 gesorgt. ${ }^{93}$ Darin hatte es geheißen, dass die höchstmögliche Rente in der Angestelltenversicherung $125 \mathrm{RM}$ im Monat betrage und damit in keinem Verhältnis zur bisherigen Lebenshaltung stehe. Der Satz war von einer Reihe von Tageszeitungen aufgegriffen worden und stellte eine von der RfA empfundene öffentliche Diskreditierung dar. Man sah sich in der Ruhrstraße daher zu einer ebenfalls öffentlichen Richtigstellung der faktisch falschen Darstellung gezwungen. Ein Versicherter, so hieß es in einer von Grießmeyer am 5. Dezember 1940 unterzeichneten Verlautbarung, für den seit Bestehen der RfA bis jetzt stets Beiträge in der jeweils höchsten Pflichtbeitragsklasse entrichtet worden waren, habe gegenwärtig im Versicherungsfall einen Anspruch auf 134,10 RM im Monat, ein in der höchsten Beitragsklasse freiwillig Versicherter sogar auf 195,80 RM, wozu in beiden Fällen noch für jeden weiteren Beitrag entsprechende Steigerungsbeträge kämen. ${ }^{94}$ Die Fehlinformation in dem Aufsatz, von der Presse zum Teil noch erheblich später ungeachtet der

93 Vgl. Versicherung oder Versorgung, in: Soziale Praxis 49 (1940), S. 673-680.

94 Vgl. den Bescheid bzw. die Verlautbarung, auch veröffentlicht in Mitteilungen der RfA Dezember 1940, S. 3. Gleichlautend auch das Antwortschreiben auf die entsprechenden besorgten Anfragen von Versicherten, in: RfA-Archiv Fach 1, Nr. 1. 
Richtigstellung durch die RfA aufgegriffen, entwickelte geradezu eine Eigendynamik und sorgte noch im Februar 1941 in zahlreichen Betrieben für erhebliches „Aufsehen und Befremden“ unter den älteren Gefolgschaftsmitgliedern, wie ein Betriebsobmann schrieb. ${ }^{95}$

Auch der Reichsverband der Rentenversicherungsträger blieb im Ungewissen. Man versorgte zwar regelmäßig seine Verbandsmitglieder mit den scheinbar neuesten Fachartikeln und Zeitschriftenaufsätzen zum Altersversorgungswerk, aber an echte Informationen aus der DAF oder aus dem RAM kam trotz aller Bemühungen und der weit größeren ideologischen Nähe zum Regime, verglichen mit Grießmeyer, auch Präsident Möbius nicht. ${ }^{96}$ Ende Juli 1940 hatte zwar auf der Tagesordnung des Ständigen Ausschusses, dessen stellvertretender Leiter ja Grießmeyer inzwischen war, ein Vortrag von Möbius über das Altersversorgungswerk gestanden, aber mehr als eine Wiedergabe der schon in der Presse allenthalben veröffentlichten kryptischen Äußerungen und Formulierungen und die angebliche Zusage des RAM, „dass er sofort eingeschaltet werde, sobald die Erörterungen sich $\mathrm{zu}$ einer diskussionsfähigen Grundlage verdichtet hätten“, war vom Reichsverbandspräsidenten nicht zu hören. ${ }^{97}$ Es entspannte sich dennoch eine ausführliche Diskussion über etliche der für alle Anwesenden sich aus dem Versorgungswerk ergebenden brennendsten Fragen, auf die aber niemand Antworten geben konnte. Letztlich wussten alle Anwesenden Experten nichts und so manchem Sozialversicherungsfachmann mag inzwischen der Verdacht aufgekommen sein, dass hinter der Geheimnistuerei gar kein in Sozialversicherungsrecht gegossenes Konzept eines neuen Alterssicherungssystems steckte, sondern nicht viel mehr als die bekannten ideologischen Schlagworte. Dennoch prägte die Ley'sche Altersversorgungswerk-Propaganda weiter die öffentliche Debatte. Und nach wie vor wusste niemand in den Amtsstuben und Dienststellen der Versicherungsträger genauer Bescheid. Nach wie vor sammelte man in der RfA ebenso akribisch wie beharrlich alle nur erdenklichen Informationen und Veröffentlichungen zum Altersversorgungswerk und legte dafür sogar einen eigenen Ordner an. ${ }^{98}$ Darin findet sich neben dutzenden, aus rentenversicherungsrechtlicher Sicht inhaltslosen

95 Das Schreiben vom 8.2.1941, in: RfA-Archiv Fach 119, Nr. 2.

96 Vgl. etwa das Schreiben an die Verbandsmitglieder vom 27.5.1940 sowie vom 23.7.1940, in: RfAArchiv Fach 119, Nr. 2. Geradezu symptomatisch für die Situation ist etwa ebenfalls das darin befindliche Rundschreiben von Möbius an alle Leiter der Landesversicherungsanstalten vom 25.5.1940. „Wie ich gehört habe“, so heißt es darin, „ist der Leiter einer Landesversicherungsanstalt durch den zuständigen Gauleiter zum Vertrauensmann für Sozialversicherung ernannt worden. In dieser Eigenschaft hat er an den Besprechungen mit der Gauwaltung der DAF wegen Vorbereitung der Altersversorgung des Deutschen Volkes teilzunehmen. Ein solcher Einsatz der Anstaltsleiter würde für den Reichsverband von ungeheurer Wichtigkeit sein, und es muss das Bestreben eines jeden Verbandsmitgliedes sein, sich in dieser Art einschalten zu lassen.“ Vermutlich wusste Möbius gar nicht, wer dieser Vertrauensmann war und wollte es mit dem Rundschreiben evtl. herausfinden.

97 Vgl. Niederschrift über die Sitzung des Ständigen Ausschusses des Reichsverbands Deutscher Rentenversicherungsträger vom 26.7.1940, in: ebd.

98 Vgl. RfA-Archiv Fach 119, Nr. 2. 
Presseartikeln auch eine von der DAF verbreitete Broschüre. In ihr war eine Rede abgedruckt, die Ley im Frühjahr 1941 vor den Gauobleuten und Gauwirtschaftsberatern der NSDAP über „Das größte Sozialistische Aufbauwerk des Deutschen Volkes“ gehalten hatte. Darin war auf den wenigen Zeilen, die sich explizit auf das Altersversorgungswerk bezogen, unter anderem von einer Versorgungsobergrenze die Rede, die mit 400 RM im Monat angesetzt wurde, die Untergrenze dagegen mit 80 RM Monats- bzw. Renteneinkommen. Es gelte, so heißt es darin weiter, das Prinzip „Arbeit geht vor Rente“, d. h. es würden keine Rentengesetze mehr geschaffen und auch keine Rente gezahlt, sondern ein Ausgleich, den der Betroffene durch den Verlust seiner Arbeitskraft haben würde; alles war mithin eine Frage des Arbeitseinsatzes „und deshalb muss auch die Verwaltung im Arbeitsamt sein““.99 Das waren neue, höchst verunsichernde Äußerungen - für die Versicherten ebenso wie für die Verwaltungsbeamten bei den Versicherungsträgern und sie trugen kaum zur Beruhigung der öffentlichen Stimmung bei. Mehr denn je trafen in der Ruhrstraße Briefe von Versicherten ein, die, irritiert durch zahlreiche weitere Pressemeldungen, Aufklärung von der RfA verlangten.

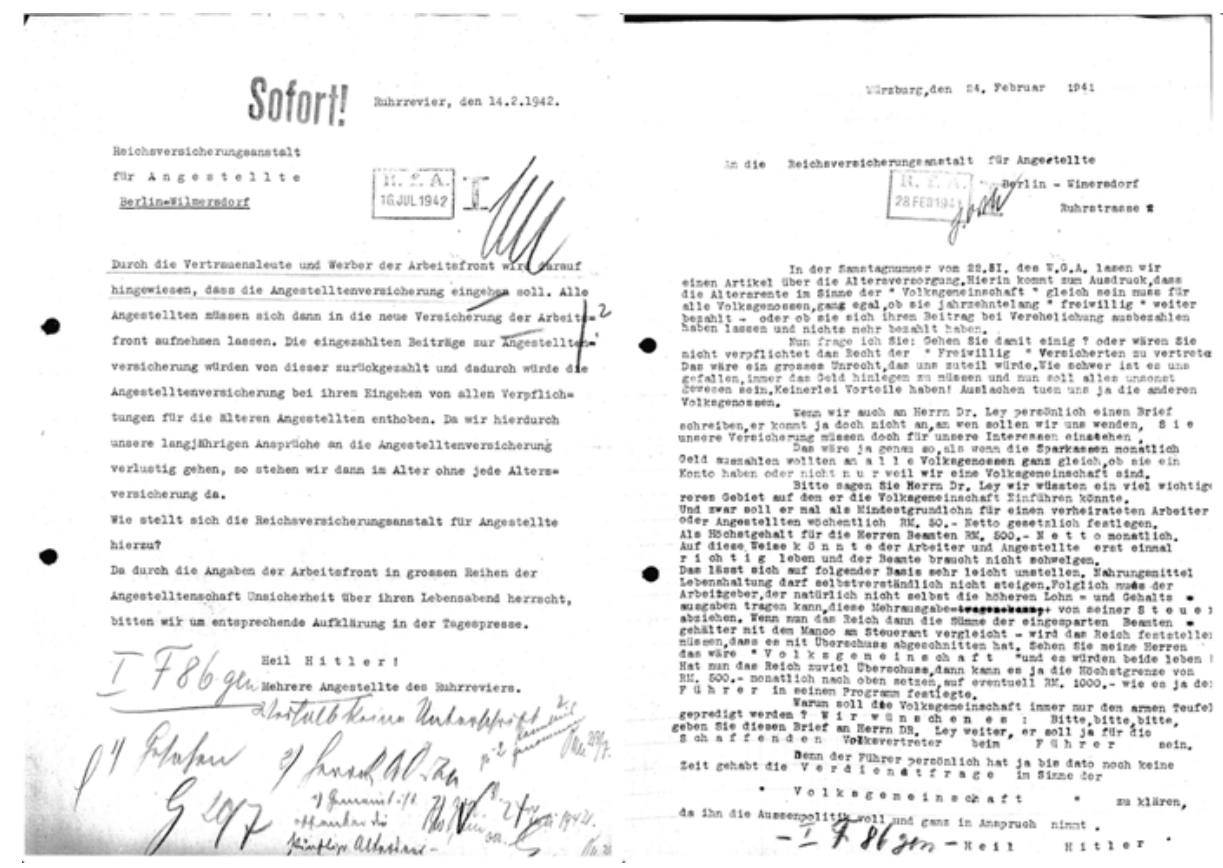

Abb. 31: Briefe verunsicherter Beitragszahler an die RfA bezüglich des geplanten Altersversorgungswerks der DAF

99 Vgl. S. 6 der Broschüre, in: ebd. 
Das ganze Thema der Altersversorgung hatte längst auch insofern eine aus Sicht des Regimes höchst unerwünschte Eigendynamik entwickelt, als nicht nur immer neue Presseveröffentlichungen mit falschen und verkürzten, durch Spekulationen und Gerüchte angereicherten Informationen erschienen, sondern die politischen Funktionäre der DAF auf dutzenden Veranstaltungen vor Ort und anlässlich von Betriebsappellen in den Unternehmen ihre jeweils eigene Darstellung der künftigen Verheißungen des Altersversorgungswerks gaben, ohne sich um die versicherungsrechtlichen Details zu kümmern oder diese auch überhaupt zu kennen. Nach einem dieser Betriebsappelle bei dem Kölner Elektroindustrieunternehmen Felten \& Guilleaume, bei dem der DAF-Redner kurzerhand versprochen hatte, „dass die Altersversorgung von Herrn Dr. Ley darin bestehen würde, dass zu den Renten aus allgemeinen Steuermitteln Zuschläge gezahlt werden würden, die nach der Einkommenshöhe gestaffelt wären“, blieben, wie der besorgte Vorstandsvorsitzende direkt an Grießmeyer berichtete, hunderte verunsicherte und ratlose Angestellte zurück. ${ }^{100}$ Und Grießmeyers Antwort war bezeichnend: „Die Ausführungen des politischen Leiters [...] waren für mich ebenso neu wie interessant; ob sie zutreffen, vermag ich aber nicht zu beurteilen."101 Auch über ihre Überwachungsbeamten bekam die RfA-Leitung weiterhin ein ziemlich ungeschminktes Bild der anhaltenden Sorgen und Ängste unter den Angestellten und Handwerkern (siehe Abb. 32). ${ }^{102}$

Zum wiederholten Male bat Grießmeyer daher das RAM geradezu händeringend darum, auf die anhaltende Flut von Briefen zu reagieren. „Es liegt im dringenden Interesse der Versicherten und auch der Rentenversicherung, auf die Anfragen baldigst eine klare Antwort zu geben“, schrieb er im Februar 1941 an das RAM. ${ }^{103}$ Mit allgemeinen Redewendungen wie „über das neue Gesetz ist nichts bekannt“ und anderen nichtssagenden Auskünften, so heißt es gleichsam ergänzend dazu in einem Schreiben des Versicherungsamtes Königsberg von Ende März, sei den Volksgenossen nicht gedient und sie machten zudem einen schlechten Eindruck. ${ }^{104}$ Auch von Wehrmachtsangehörigen bekam die RfA nun vermehrt per Feldpost besorgte Anfragen. „Die umlaufenden Ansichten und Gerüchte sind nicht gerade dazu angetan, beruhigend zu wirken“, schrieb etwa im Mai 1941 ein Oberleutnant und Kompaniechef an die RfA. Es sei an der Zeit, dass die RfA dazu endlich klar Stellung beziehe.

Besonders alle im Feld stehenden Versicherten, die schon den Weltkrieg mitmachten und seit Ende August 39 [...] ihrem Beruf erneut entzogen sind, machen sich ihre eigenen Gedanken, wenn sie hören, dass angeblich der höchste maximale Versicherungsbetrag bei ca. 70 RM im Monat als Maximum ab dem 65. Lebensjahr liegen würde, ganz gleich ohne Rücksicht darauf, was bis jetzt an Beiträgen entrichtet wurde. ${ }^{105}$

100 Vgl. dazu das Schreiben vom 6.8.1941, in: ebd.

101 Schreiben Grießmeyers vom 9.8.1941, in: ebd.

102 Vgl. dazu die zahlreichen Berichte in: ebd.

103 Schreiben der RfA an das RAM vom 24. 2.1941, in: RfA-Archiv Fach 119, Nr. 2.

104 Schreiben an die RfA vom 21.3.1941, in: ebd.

105 Das Schreiben vom 1.5.1941, in: ebd. 


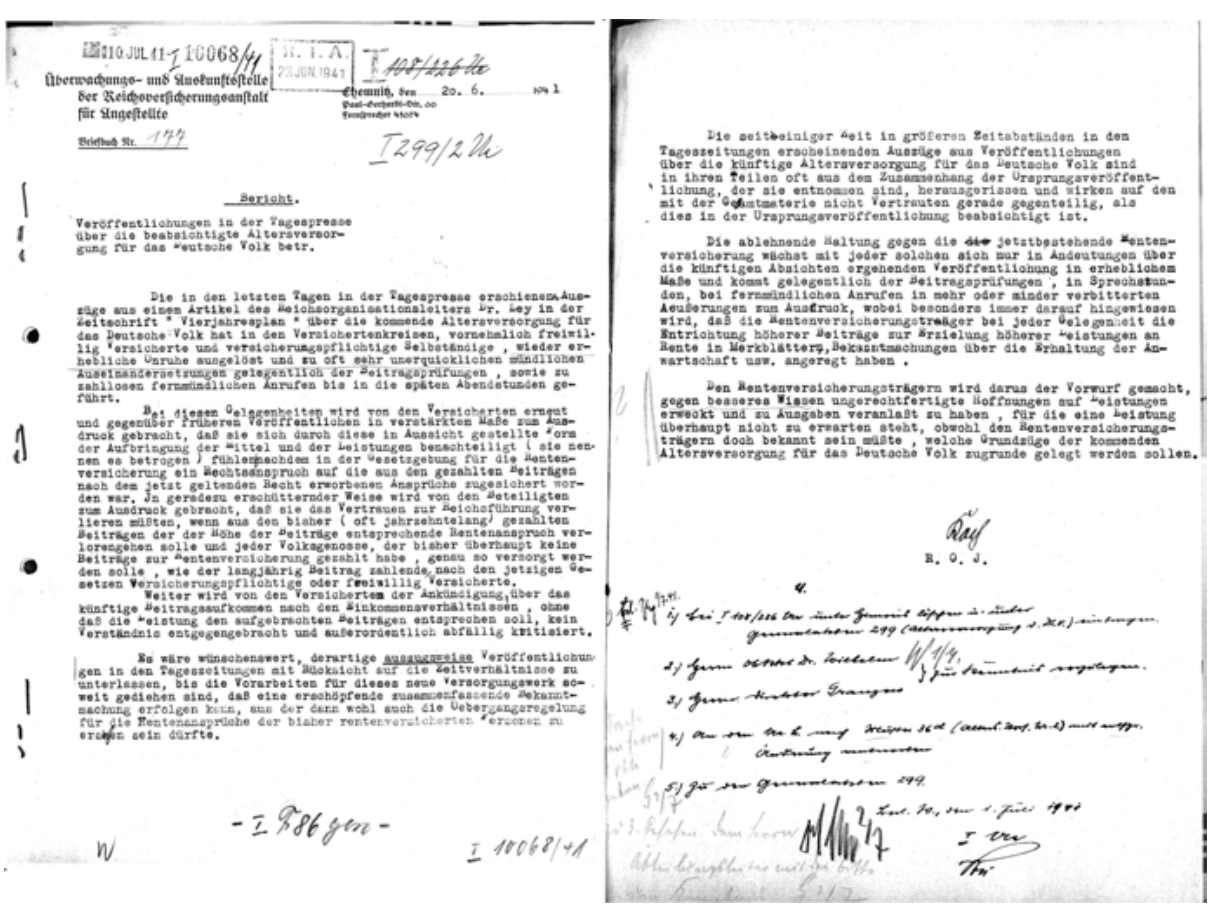

Abb. 32: Bericht der Überwachungsstelle Chemnitz vom 20. Juni 1941 zu den Auswirkungen der Presseveröffentlichungen zum Altersversorgungswerk

Doch das Problem des Umgangs mit den tausenden freiwillig Versicherten im künftigen Altersversorgungswerk blieb weiter ungeklärt. Einzig neu war, dass die RfA inzwischen, vermutlich auf Geheiß des RAM, ihre Antwortschreiben um einen Satz ergänzte: „Sicher ist aber, dass die Leistungen der Altersversorgung höher sein werden als die der Reichsversicherung. " ${ }^{106}$ Dass das kaum zur Beruhigung beitragen, sondern eher noch neue Fragen aufwerfen würde, war vermutlich auch den RfA-Beamten bewusst. Die große Rechtsunsicherheit, die die ebenso vollmundigen wie nichtssagenden Ankündigungen des Altersversorgungswerks der DAF in die Kreise der Versicherten und damit in die gesamte Gesellschaft hineingetragen hatten, war geradezu mit den Händen zu greifen. Anstatt den großspurigen Versprechungen des NS-Regimes über eines mindestens gesicherten und auskömmlichen Lebensabend zu glauben, sahen viele Versicherte, vor allem jene freiwillig Versicherten, die in Kürze einen Antrag auf Ruhegeldgewährung stellen wollten, ihre wohlerworbenen Altersruhegelder in akuter Gefahr. Mit der praktizierten Geheimhaltungspolitik, der Gleichgültigkeit und Ignoranz gegenüber den Sorgen der Versicherten wie auch der Versicherungsträger machte sich das RAM hier zu einem Komplizen der Ley'schen Propaganda.

106 So das Antwortschreiben vom 14.5.1941 an den Kompaniechef, in: ebd. 
Spätestens 1942 hatte jedoch der dunkle Schatten von Leys großem Plan eines „Altersversorgungswerk“ der DAF, der von manchem RfA-Beamten wohl auch für die Existenz der eigene Behörde als Damoklesschwert empfunden wurde, seinen Schrecken verloren. Je länger der Krieg dauerte, desto unwahrscheinlicher war es, dass die DAF-Pläne in welcher Form auch immer Wirklichkeit werden würden. Auch wenn im Oktober 1942 das Arbeitswissenschaftliche Institut der DAF RAM-Staatssekretär Krohn offenbar einen ausgearbeiteten Gesetzentwurf für das Versorgungswerk vorgelegt hatte, ${ }^{107}$ so war zumindest allen Experten in den Behörden doch klar, dass das Regime es sich weder verwaltungstechnisch noch loyalitätspolitisch leisten konnte, während der Dauer des Krieges umstürzende Maßnahmen in der Rentenversicherung vorzunehmen, während die große sozialpolitische Revolution des NS-Regimes auf die Zeit nach dem Krieg vertagt worden war. Vermutlich nur Ley selbst glaubte noch an die baldige Realisierung des Altersversorgungswerks. ${ }^{108}$ Unter den Versicherten jedoch bestand vielfach die Unsicherheit weiter. Noch im Februar 1944 berichtete ein Betrieb über die höchst unterschiedlichen Reaktionen unter den beschäftigten Angestellten auf die „Reformpläne“ der DAF.

Der eine hält es für undenkbar, dass bisher erworbene Rechtsansprüche mit einem Federstrich beseitigt werden könnten [...]. Er klebt daher seine Beiträge unverändert jeden Monat weiter. Der andere ist zweifelhaft und klebt deshalb nur noch jeden zweiten Monat, um die 66 Marken zu haben, die er zur Aufrechterhaltung der Anwartschaft braucht. Der dritte wieder sagt sich, dass er diese Marken gegebenenfalls bis ein Jahr nach Kriegsende ja immer noch nachkleben kann und hat die freiwillige Zahlung ganz eingestellt, um abzuwarten, wie die Entscheidung fallen wird. ${ }^{109}$

Unter vielen Versicherten hatte sich zu diesem Zeitpunkt ungeachtet der inzwischen erfolgten Rentenerhöhung aber auch eine Desillusionierung breitgemacht. „Die meisten Arbeitnehmer“, so heißt es in einem an Grießmeyer persönlich gerichteten Schreiben vom August 1943, „schauen einem grauen armseligen Alter entgegen, auch die geplante Altersversorgung des Deutschen Volkes wird da Entscheidendes nicht ändern können, denn wie sollen die zu einer wirklichen Besserung notwendigen Riesensummen aufgebracht werden?"110 Die große und sich letztlich über Jahre hinziehende Verunsicherung in der Altersversorgung hatte dem Ruf der RfA und ihrer gerade auch in der täglichen Verwaltungsarbeit mühsam erworbenen Vertrauensbasis durchaus geschadet. Aber auch der DAF kosteten die ständigen Diskussionen über das Altersversorgungswerk bei den Versicherten erhebliche Reputation. Die Rechtsbera-

107 Vgl. dazu Schlegel-Voß, S. $158 \mathrm{f}$.

108 Vgl. dazu den Vermerk des Reichsfinanzministeriums über die Besprechung vom 19.10.1942, bei der sich Ley entschieden gegen jede weitere Rentenerhöhungspläne des RAM wandte, da mit diesen nur beabsichtigt werde, sein Altersversorgungswerk zu sabotieren. Er stehe auf dem Standpunkt, dass man in der Rentenfrage während des Krieges entweder gar nichts tun dürfe oder seine Altersversorgung in Kraft setzen müsse. Vgl. BArch R 2/18562.

109 Schreiben an die RfA vom 14.2.1944, in: RfA-Archiv Fach 119, Nr. 2.

110 Schreiben vom 10. 8.1943, in: RfA-Archiv Fach 14, Nr. 2. 
tungsstellen der Arbeitsfront konnten den Ratsuchenden ebenso wenig Auskunft geben wie die RfA. Zudem schien die DAF ihrer Aufgabe als als Beratungs- und Informationsinstanz sowie der Interessenvertretung in Streitfällen mit dem Versicherungsträger zunehmend weniger Aufmerksamkeit zu schenken, was auch an den zunehmenden Einberufungen der DAF-Rechtsberater zur Wehrmacht lag. In der Ruhrstraße häuften sich jedenfalls die Meldungen und Beschwerden über verwaiste oder gar verwahrloste Rechtsberatungsstellen. Der Ortsbürgermeister von Genthin berichtete im November 1940 an die RfA, dass nach der Einberufung des dortigen Rechtsberaters die örtliche Arbeitsfront die Entgegennahme von Rentenanträgen überhaupt ablehne. ${ }^{111}$ Auch aus anderen Orten kamen solche und ähnliche Meldungen, die DAF in Pirna etwa lehnte die weitere Entgegennahme von Anträgen mit der Bemerkung ab, dass sie nicht zuständig sei und man dies bisher nur aus Kulanz getan habe. Der zuständige Überwachungs- und Revisionsbeamte der RfA hielt dies aufgrund der damals 1934 mit der RfA getroffenen Vereinbarungen für nicht zulässig, was man auch in der Ruhrstraße so sah; und daher richtete man eine entsprechende Beschwerde an die zuständige Gaurechtsberatungsstelle in Dresden. ${ }^{112}$ Die Beratungslücke füllten mancherorts inzwischen zum Teil dubiose Rentenversicherungs- und Steuerberater, die sich, auf eigene Rechnung und ohne von der RfA als vertretungsberechtigt anerkannt zu sein, in das durch den Krieg massiv ausweitende „Versicherungsgeschäft“ mit Witwen- und Hinterbliebenenrenten drängten. Der Kreis der vertretungsberechtigten Personen in Rentenversicherungsangelegenheiten war jedoch gesetzlich genau geregelt und ermächtigte den Versicherungsträger nur dann zur Zulassung anderer Personen, wenn eine Partei nicht ordnungsgemäß vertreten war und wenn dazu aber ein dringendes Bedürfnis bestand. Das galt in erster Linie für die Vertretung von Juden. ${ }^{113}$ Ansonsten gab es jedoch keine Ausnahmen. Viele DAFRechtberatungsstellen arbeiteten zwar weiter, hatten aber ihre Öffnungszeiten zum Teil radikal auf wenige Stunden an nur noch einem Tag der Woche reduziert. Das betraf die Versicherten insofern, als sich damit erhebliche zeitliche Verzögerungen bei der Abgabe ihrer Leistungsanträge ergeben konnten, die im ungünstigsten Fall den Ausfall von zwei Monatsrenten nach sich ziehen konnten. ${ }^{114}$

Es gibt eine Reihe von Indizien dafür, dass die vor dem Krieg weitgehend reibungslose Zusammenarbeit zwischen DAF-Rechtsberatungsstellen und RfA auch aus politischen Gründen schwieriger geworden war. Zum einen betrieb die DAF nun vehement eine Anerkennung als Dienststelle mit Behördencharakter, womit die Versicherungsträger dann auf entsprechende „Rechtshilfeersuchen“ ihr gegenüber auskunftspflichtig werden würden und das gesetzliche Schweigeverbot nach §§ 141 und

111 Schreiben vom 15.11.1940, in: RfA-Archiv Nr. 93b.

112 Vgl. den Schriftwechsel des Oberbürgermeisters von Pirna mit der RfA vom September/Oktober 1944, in: RfA-Archiv Nr. 87.

113 Vgl. dazu den Vermerk vom 30.3.1944 im Zusammenhang mit der Auseinandersetzung der RfA mit einem dieser Steuerberater, die auf eigene Initiative agierten, in: RfA-Archiv Fach 19, Nr. 2.

114 Vgl. dazu eine entsprechende Beschwerde vom 15.4.1944 an die Auskunftsstelle der RfA, in: ebd. 
142 der Reichsversicherungsordnung praktisch ausgehebelt würde. ${ }^{115}$ Als das RAM daraufhin im März 1940 dazu eine Meinungsäußerung von den verschiedenen Versicherungsträgern einholte, zeigten sich deutliche Unterschiede in den Positionen. Während von Seiten der Reichsknappschaft eine regelrechte Ergebenheitsadresse gegenüber der DAF geliefert wurde, fiel die Stellungnahme der RfA deutlich distanziert aus. ${ }^{116}$ Die Annahme, dass der NSDAP und damit auch der DAF ein unbeschränktes Recht auf Rechtshilfe zustehe, „trifft nicht zu“, so hieß es da.

Soweit es sich um Leistungen handelt, besteht kein Bedürfnis, der DAF das Recht auf Rechtshilfe einzuräumen [...]. Schon jetzt werden der DAF in weitem Umfang Auskünfte erteilt. Ein Bedürfnis nach weitergehender Rechtshilfe in Leistungsverfahren an die DAF ist nicht anzuerkennen. Es erscheint daher bedenklich, auf die Wünsche der DAF einzugehen. ${ }^{117}$

Andere Indizien für politische Gründe des getrübten Verhältnisses zwischen DAF und RfA betreffen versicherungsrechtliche Streitfälle. Auch wenn die Zahl der gerichtlich ausgetragenen Konflikte um RfA-Bescheide im Krieg abnahm, so scheint es doch vermehrt zu Differenzen mit dem Versicherungsträger gekommen zu sein, weil die DAF aus ideologischen Gründen und mit Berufung auf das nationalsozialistische Rechtsempfinden entsprechende Verfahren anstrengte. Mitte Dezember 1942 fragte etwa die Büroleitung der Leistungsabteilung in den ihr unterstehenden Dienststellen an, ob und wieviele Fälle bekannt seien, in denen die Rechtsberatungsstellen Hamburg und Köln Vertretungen von Rentenbewerbern übernommen hatten, obwohl deren Rentenansprüche nach den vorliegenden ärztlichen Gutachten oder nach den Beitragsentrichtungen ausgeschlossen waren. ${ }^{118}$ Das zeitweise durchaus eingespielte Zusammenwirken von DAF-Rechtsberatungsstellen und RfA erodierte im Gefolge wachsender Ideologisierung, propagandistischer Aufladung der Altersversorgungsfrage und unter den Belastungen des Krieges.

\subsection{Die anhaltenden Probleme mit der Durchführung des Handwerkerversorgungsgesetzes oder: Beitragsüberwachung und Leistungsbescheide im Zeichen nationalsozialistischer Rechtsanwendung}

Die Bedeutung der DAF-Rechtberatungsstellen hatte auch deshalb abgenommen, da die Zahl der Streitfälle und Revisionsverfahren im Krieg tatsächlich zurückgegangen

115 Vgl. Schreiben des RAM an die Versicherungsträger vom 19.3.1940, in: ebd.

116 Vgl. das Schreiben der Reichsknappschaft vom 10.5.1941 und die Stellungnahme der RfA vom 30.5.1941, in: RfA-Archiv Fach 116, Nr. 9.

117 Ebd. Vgl. auch das Schreiben der RfA an das Amt für Rechtsberatungsstellen der DAF vom 24.4. 1940, in: RfA-Archiv Nr. 86.

118 Schreiben vom 14.12.1942, in: RfA-Archiv Nr. 55. 
war. 1939 waren noch 3518 Einsprüche von Versicherten gegen Bescheide der RfA erhoben worden, von denen 395 erfolgreich waren, nur 352 gelangten in das Revisionsverfahren. 1943 gab es nur noch 2496 Fälle, in denen Berufung eingelegt wurde, nur 280 von ihnen, d.h. 11,2 Prozent hatten Erfolg, das bedeutete einen Rückgang der sozialgerichtlichen Streitfälle in der Angestelltenversicherung um fast 30 Prozent. ${ }^{119}$ Mit ein Grund dafür war neben kriegsbedingten Entwicklungen auch eine als Verfahrensvereinfachung deklarierte Restriktion, durch die die Möglichkeit der Anrufung der Versicherungsämter und vor allem auch des Reichsversicherungsamtes stark beschränkt worden war. ${ }^{120}$ Im Prinzip hielt das RAM jedoch an der Sozialversicherungsgerichtsbarkeit und dem Prinzip des Widerspruchsrechts gegenüber den Bescheiden der Versicherungsträger fest. Im Juli 1942 ermahnte man den Regierungspräsidenten in Trier, der zugleich Vorsitzender des dortigen Oberversicherungsamtes war, dass die Rechtsprechung in der Sozialversicherung keinesfalls hinter anderen wichtigen Aufgaben zurücktreten dürfe. „Vielmehr müssen gerade in Kriegszeiten die Belange der Bevölkerung bei der Verfolgung ihrer Rechte aus der Sozialversicherung unbedingt gewahrt bleiben. " ${ }^{2121}$ Von einer drastischen Verkürzung der Rechtsmittel, von der gelegentlich in der späteren Forschung die Rede war, kann zumindest in der Angestelltenversicherung keine Rede sein. ${ }^{122}$ An den Motiven der Widersprüche gegen die RfA-Bescheide hatte sich insgesamt anteilsmäßig nichts geändert: Nach wie vor richtete sich der Großteil gegen die Ablehnung des Ruhegehaltsanspruchs wegen noch nicht bestehender Berufsunfähigkeit; danach folgten die Widersprüche gegen die Entziehung des Ruhegeldes nach Wiedereintritt der Berufsfähigkeit. ${ }^{123}$ Weitere Berufungsgründe waren die in den Augen der Betroffenen zu geringen, sprich falsch berechneten Ruhegeld- oder Hinterbliebenenrenten oder aber Streitigkeiten um den Zeitpunkt des Rentenbeginns. ${ }^{124}$ Häufiger Konfliktpunkt war dann aber auch die Kürzung des Steigerungsbetrags der Invalidenversicherung beim Zusammentreffen mit Ansprüchen aus der Angestelltenversicherung. Diese Kürzun-

119 Zu den Zahlenangaben vgl. RfA-Geschäftsbericht für 1939, S. 40f., in: BArch R 89/3470 sowie Material zum Jahresbericht der Leistungsabteilung 1943, in: RfA-Archiv Nr. 80. Über die Höhe der Erfolgsquote bei den Einsprüchen gibt es unterschiedliche Angaben. Bis 1943 weisen die Zahlen auf eine Quote von kanpp über zehn Prozent hin, eine spätere, 1944 vorgenommene Stichprobe aus 700 Berufungsfällen ergab dagegen eine Quote von ca. 25 Prozent ganz oder teilweise erfolgreicher Berufungen. Vgl. dazu ORR Restle, Aus welchen Gründen werden in der Rentenversicherung Rechtsmittel eingelegt? Eine kritische Betrachtung von Berufungsfällen, in: Deutsche Sozialversicherung Dezember 1944, Heft 2, S. 9-12.

120 So auch der Hinweis Grießmeyers auf der zehnten Beiratssitzung vom 11.12.1939, S. 2, in: BArch R $89 / 3470$.

121 Schreiben des RAM an das OVA Trier vom 29.7.1942, in: BArch R 89/10141.

122 So pauschal und ohne weiteren Hinweis Christmann/Schönholz, Die Errichtung des Reichsversicherungsamtes, S. 40, in: Entwicklung des Sozialrechts: Aufgaben der Rechtsprechung, Köln 1984. 123 Vgl. Material zum Jahresbericht der Leistungsabteilung 1943, in: RfA-Archiv Nr. 80 sowie dort auch eine handschriftliche Auswertung der Berufungsgründe für das Jahr 1939.

124 Exemplarisch dazu das Berufungsschreiben an das Oberversicherungsamt Berlin vom 24.1.1940, in: RfA-Archiv Fach 112, Nr. 5. 
gen würden als unberechtigt empfunden, so notierte dazu der zuständige RfA-Beamte in einem strittigen Fall Ende Juli 1940,

weil die Versicherten nicht verstehen, dass nach versicherungsmathematischen Grundsätzen neben der Leistung der AV nicht auch die volle Leistung der IV gezahlt werden kann und weil sie glauben, durch ihre Beitragsleistung zu beiden Versicherungen auch den Anspruch auf die vollen Leistungen aus beiden Versicherungen erworben zu haben. Den Beschwerden der Versicherten kann eine gewisse Berechtigung nicht abgesprochen werden. ${ }^{125}$

Die Berufungsfälle und die Art der Streitpunkte unterschieden sich dabei, bedingt durch die unterschiedliche Gesetzeslage, in der AV erheblich von denen der Invalidenversicherung, wo die Klagen um Anerkennung der Invalidität deutlich dominierten. In der Angestelltenversicherung gab es zudem auch nach dem Tod des Versicherten keinen Streit um die Invaliditätsfrage der Witwe, während in der IV in diesem Punkt die Zahl der Berufungen relativ hoch war. ${ }^{126}$

Diese Zahlen berücksichtigten noch nicht die Beitragsstreitverfahren. Das Recht der Rentenversicherung kannte neben dem Spruchverfahren für die Verfolgung von Leistungsansprüchen auch das Beschlussverfahren über Beitragsstreitigkeiten - zwei voneinander scharf getrennte Verfahrensarten. ${ }^{127}$ Und hier, bei der Eintreibung von Beitragsrückständen, erwiesen sich die Überwachungsbeamten nach wie vor als hartnäckig und unnachgiebig, ungeachtet dessen, dass es sich bei den säumigen Zahlern oft um hohe Parteistellen handelte; davon zeugt etwa die dicke ArbeitgeberAkte zur NSDAP-Gauleitung Berlin. ${ }^{128}$ Die Auseinandersetzungen mit der Behörde hatten schon Ende Juli 1939 begonnen, nachdem sich die Gauleitung geweigert hatte, für etwa 60 ihrer zu militärischen Übungen eingezogenen Gefolgschaftsmitglieder für die Übungszeiten die vollen AV-Beiträge nachzuentrichten. Die RfA schaltete schließlich den Reichsschatzmeister der NSDAP in München ein, um an ihr Geld zu kommen, und leitete ein offizielles Streitverfahren ein. Es ging nicht nur um die Klärung einer prinzipiellen Frage, sondern auch um 1146 RM. Erst im April 1941 wurde der Konflikt nach Überweisung des Betrags durch die Berliner Gauleitung beigelegt. Für einigen Wirbel sorgte später auch ein Streitverfahren um die Berechtigung zur Selbstversicherung, sprich die Nachentrichtung von freiwilligen Beiträgen, die laut Gesetz nur bis vom vollendeten 40. Lebensjahr zulässig war. ${ }^{129}$ In diesem Fall hatte die RfA gegen einen Bescheid des Oberversicherungsamtes Stuttgart geklagt, der dann durch Beschluss des Revisionssenats des RVA Ende September 1942 zugunsten der RfA entschieden wurde. Zur selben Zeit deckte ein Berliner Überwachungsbeamter

125 Schreiben zum Fall eines Ruhegeldbescheids an das RVA vom 30.7.1940, in: RfA-Archiv Nr. 25. 126 Vgl. Restle, Rechtsmittel, S. 9.

127 Vgl. dazu RfA-Regierungsrat A. von Altrock, Das Beitragsstreitverfahren der Rentenversicherung, in: Deutsche Rentenversicherung (1944), Nr. 1/3, S. 5-7.

128 Vgl. RfA-Archiv Fach 22, Nr. 1.

129 Vgl. den Fall, beginnend mit einem Schreiben der RfA an das OVA Stuttgart vom 2.6.1942, in: BArch R 89/22706. 
auch beim „Amt für Sippenforschung der NSDAP“, einer untergeordneten Dienststelle des Reichssippenamts, erhebliche Unregelmäßigkeiten auf. Bei den 23 dort Beschäftigen bestanden deutliche Beitragsrückstände, aber der dortige Büroleiter versuchte den RfA-Überwachungsbeamten immer wieder abzuwimmeln. „Da es meines Erachtens beim Amt für Sippenforschung nicht einwandfrei zuzugehen scheint“, so notierte der ebenso hartnäckige wie unerschrockene Beamte, „halte ich es für dringend nötig, dem Schatzamt der NSDAP durch Übersendung meines Berichts Kenntnis zu geben“ was dann tatsächlich auch geschah. ${ }^{130}$

$\mathrm{Zu}$ welchen Absurditäten der bürokratische Rigorismus der RfA-Beamten bei der Geltendmachung von Nachzahlungsansprüchen führen konnte, zeigte sich im März 1942. Anfang dieses Monats hatte die noch bestehende, aber längst unter Oberhoheit des Reichssicherheitshauptamtes stehende Reichsvereinigung der Juden in Deutschland ein Schreiben aus der Ruhrstraße erhalten, in dem für die Jüdischen Kultusvereinigungen die Nachentrichtung von AV-Beiträgen für die damals dort tätigen Gemeindebeamten gefordert wurde, und zwar rückwirkend für die Zeit vom 1. Januar 1913 bis zum 31. März 1938. Hintergrund war der Verlust des Status einer Körperschaft des öffentlichen Rechts der Kulturgemeinden zu diesem Zeitpunkt und die damit ausgelöste Nachversicherungspflicht, die sich auf die gewaltige Summe von 185.000 RM allein bei der jüdischen Kultusvereinigung zu Berlin summierte. Die RfA erhielt daraufhin umgehend Post aus dem Reichssicherheitshauptamt, und in dem Schreiben wies der sichtlich konsternierte RSHA-Beamte sämtliche Ansprüche, unter anderem mit dem zynischen, jedoch kaum von der Hand zu weisenden Argument zurück, dass den hohen Nachzahlungsansprüchen keinerlei entsprechende Leistungen der RfA gegenüberstünden, da ein erheblicher Teil der jüdischen Arbeitnehmer inzwischen ausgewandert oder deportiert worden war und damit so oder so keine Rentenverpflichtung der RfA mehr bestand. Abschließend heißt es in dem Schreiben:

Falls es nach den gesetzlichen Bestimmungen nicht möglich sein sollte, auf die Geltendmachung der Forderung schon jetzt endgültig zu verzichten, bitte ich, die Angelegenheit weiterhin dilatorisch zu behandeln, da sie sich durch längeren Zeitablauf nach Endlösung der Judenfrage von selbst erledigen wird. ${ }^{131}$

Die Praxis vieler Versicherter, die sich von der RfA unrechtmäßig behandelt fühlten, zur Beschleunigung des Widerspruchverfahrens und vor allem auch zur Erlangung des Rechts, an oberste Parteiführer und insbesondere die Kanzlei des Führers zu schreiben, blieb dabei auch im Krieg erhalten. Im Januar 1940 beschwerte sich etwa

130 Bericht des Überwachungsbeamten vom 11.11.1942, in: RfA-Archiv Fach 15, Nr. 4.

131 Schreiben des RSHA an die RfA vom 10.3.1942, S. 3, das sich nicht in den Arbeitgeberakten des RfA-Archivs fand, sondern als eine Zufallsüberlieferung in der privaten Sammlung eines Direktors der LVA Westfalen überdauerte. Das Dokument wurde abgedruckt in: Marc von Miquel (Hrsg.), Sozialversicherung in Diktatur und Demokratie - Lernen und Forschen, Münster 2008, S. 74-76. Für den Hinweis auf das Dokument danke ich Mark von Miquel. 
ein Werftbürogehilfe aus Norden (Ostfriesland) bei Hitler, dass ihm seitens der RfA die Aufnahme in die Angestelltenversicherung verweigert worden war. ${ }^{132}$ Aus versicherungsrechtlicher Sicht war der Fall unstreitig, da der Angestellte bereits über 60 Jahre alt war, kriegsbedingt jedoch wieder eine Beschäftigung aufgenommen hatte. Schon im Juli bzw. Dezember 1939 war die Beschwerde daher vor dem Oberversicherungsamt und dann auch vor dem Berufungssenat des RVA zurückgewiesen worden, aber der Betroffene versuchte nun (letztlich vergeblich) auf direktem Weg noch einmal eine Änderung des Urteils zu erreichen, und dabei argumentierte er nun mit nationalsozialistischen Kategorien. Die Beweisführung der Ablehnung „ist für mich ein neuer Beweis des unzulänglichen moralischen Bewusstseins [der RfA] einem Volksgenossen gegenüber, der alle Voraussetzungen für ein Entgegenkommen geschaffen hat“, so heißt es in einem Schreiben an das RVA von Ende Juni $1940 .{ }^{133}$ Nur wenig später hätte sich der Betroffene zur Untermauerung seiner Forderung auf ein Rundschreiben des Reichsversicherungsamtes berufen können, in dem auf fast drei Seiten unter dem Titel „Soziale Rechtsanwendung“ die Versicherungsträger „auf das Erfordernis einer sozialen und volksnahen Rechtsanwendung“ hingewiesen wurden. ${ }^{134}$ Es sei nicht nur selbstverständliche Pflicht, die betreuten Volksgenossen rechtzeitig und gemeinverständlich aufzuklären und zu beraten, sondern auch ihre Anträge und Beschwerden wohlwollend $\mathrm{zu}$ prüfen und offenbare Härten und Unbilligkeiten soweit irgend möglich zu vermeiden. Dieses Streben habe zwar seine Grenze in den bestehenden Gesetzen, indessen sei inzwischen vielfach die Entscheidung in das pflichtmäßige Ermessen der Versicherungsträger gestellt ,und ihnen damit die Möglichkeit gegeben, sie in wahrhaft nationalsozialistischem Geiste zu treffen“. ${ }^{135}$

Das Rundschreiben hatte aus der Sicht eines RfA-Beamten eine verheerende Wirkung, denn es war in der Presse veröffentlicht worden, so dass sich nun jeder Versicherte, der sich von seinem Versicherungsträger unrechtmäßig behandelt fühlte, darauf berufen konnte. Dennoch machte Grießmeyer in einer Präsidialverfügung diese neuen Grundsätze auch für die Verwaltungspraxis der RfA verpflichtend. „In jedem Falle, in dem ein Anspruch aus formellen Gründen abgelehnt werden soll, ist sorgfältig zu prüfen, ob nicht nach den Grundsätzen des Rundschreibens dem Antrag stattzugeben ist“, hieß es darin. ${ }^{136}$ Entsprechende Fälle seien dem Unterabteilungsleiter zur Entscheidung vorzulegen. Wollte dieser dennoch den Anspruch ablehnen, so musste die Entscheidung des Abteilungsleiters eingeholt werden. Das brachte die mit der Entscheidung betrauten RfA-Beamten in eine gewisse Zwickmühle. Allerdings fühlte man sich zuerst und vor allem dem bestehenden Recht verpflichtet, das prin-

132 Der Fall mit Schreiben vom 24.1.1940 und der dazugehörende weitere Schriftwechsel in: BArch R $89 / 22705$.

133 Vgl. das Schreiben vom 30.6.1940, in: ebd.

134 Das Rundschreiben vom 20.7.1941, in: RfA-Archiv Nr. 26.

135 Ebd.

136 Verfügung vom 12.8.1941, in: ebd. 
zipiell ausschloss, Leistungen über den gesetzlichen Rahmen hinaus zu gewähren. ${ }^{137}$ Ende Mai 1942 erließ Grießmeyer auf Anordnung des RVA aber eine erneute Präsidialverfügung, in der er eine großzügige Auslegung der Gesetze zugunsten der Ansprüche der Versicherten „nach allgemeinem Volksempfinden und nationalsozialistischen Grundsätzen“ forderte. ${ }^{138}$ Damit wurde der Druck auf die Verwaltungsarbeit weiter erhöht und die Politisierung bzw. Ideologisierung verstärkt.

Vor allem eine Reihe von Parteistellen nahmen die RVA-Verlautbarung zur „sozialen Rechtsanwendung“ umgehend zum Anlass, gleichsam die Probe aufs Exempel zu machen. Mitte Dezember 1941 schrieb etwa der Organisationsleiter der Berliner NSDAP-Gauleitung direkt an Grießmeyer und bat um die Auszahlung der geleisteten Versicherungsbeiträge einer infolge eines Fliegerangriffs getöteten Versicherten an die Eltern. Der entsprechende Antrag des Vaters war von der RfA mit Verweis auf die Gesetzeslage abgelehnt worden. Nun forderte die Gauleitung entgegen der buchstabenmäßigen Auslegung der Paragraphen eine großzügigere Behandlung, „die ja auch vom Führer ausdrücklich gewünscht wird“. ${ }^{139}$ Die Voraussetzung für eine anteilige Beitragsrückerstattung, so antwortete die RfA knapp, seien nicht erfüllt, da die Angehörigen zur Zeit ihres Todes in häuslicher Gemeinschaft mit der ... Versicherten gelebt hätten. Dies sei im Übrigen „auch keine bloße Formvorschrift, über die in besonderen Fällen hinweggesehen werden könnte, sondern eine materielle Gesetzesvorschrift, die vom Versicherungsträger unter allen Umständen zu berücksichtigen ist". ${ }^{140}$

Während es in diesem Fall immerhin noch um den Ausgleich einer sozialen Härte ging, markiert ein weiterer Fall den Versuch einer skrupellosen, allein parteiideologisch begründeten Privilegierung. Die RfA, so heißt es in einem Schreiben der NSDAPKreisleitung im hessischen St. Goarshausen von Mitte August 1942, solle doch solle doch grundsätzlich den Ehrenzeichenträgern der NSDAP nicht nur die Renten auszahlen, sondern eine zusätzliche monetäre Leistung gewähren. ${ }^{141}$ Das Begehren wurde von der RfA aus grundsätzlichen Erwägungen jedoch abgelehnt. Mit den neuen Entscheidungsgrundsätzen war aber auch die Ursache für neue Ungerechtigkeiten geschaffen, stellte doch etwa die Annahme verspäteter Anträge oder anderweitige Kulanz bei der Berechnung der Rente eine kaum zu rechtfertigende Begünstigung säumiger Versicherter gegenüber den pflichtbewussten Versicherten dar. ${ }^{142}$ Im Juni 1943 beschwerte sich denn auch das Oberversicherungsamt Breslau bei Grießmeyer über die unterschiedliche Behandlung von zwei Ruhegeldanträgen und bat, in seiner

137 So auch das Argument in einem Schreiben vom 15.11.1941 an das OVA Karlsruhe zu einem Berufungsfall, in: RfA-Archiv Nr. 26.

138 Die Präsidialverfügung vom 29.5.1942, in: RfA-Archiv Fach 1, Nr. 3.

139 Schreiben vom 18.12.1941, in: RfA-Archiv Nr. 26.

140 Schreiben der RfA an die Gauleitung vom 3.1.1942, in: ebd.

141 Schreiben vom 12.8.1942, in: RfA-Archiv Nr. 205 b.

142 So der Vermerk eines RfA-Beamten vom 14.11.1941 zur Vorlage einer Antragsentscheidung an den zuständigen Unterabteilungsleiter bzw. Referenten, in: ebd. 
Der Präsident

chsvergicherungsanstalt Berlin-Wilmersdorf, den 29. Mai 1942.
fur Angestellte

$\frac{\text { Präs. Abt. } 2000 / 7.5 \text {. }}{1}$

Pr a s 1 d a 1 ver 1 g u $\mathrm{g}$.

Sozlale Reohtsfindung.

Im Nacheang zu meiner Verfligung vom 12. August 1941 - Prïs. Abt. 2000/12.8, - gebe ich nachstehend ein weiteres Rundschreiben des Reichsversicherungsamts vom 7. Mai 1942 - I $1603 / 42$ - 379 uber die Soziale Rechtsfindung bekannt, mit dem Ersuchen, hisernach zu verfahren:

"Das Relchsversicherungsamt hat Anlaß, auf die Beachtung seines Rundschreibens vom 30. Jul1 1941 betr. Soziale Rechtsanwondung (AN. 1941 S. II 311) hinztrieisen und bemerkt dazu noch folgendes:

Be1 der Bearbeltung von Anträgen haben lediglich finanziello Bedenken unbedingt zurilckzutreten. In erster Iinie ist zu prifen, ob dem Anspre des Versicherten nach dem allgemeinen Volksempfinden und nationalsozialistischen Grundsătzen im Rahmen der geltenden Gesetzesvorschriften stattgegeben werden kann. Die Versicherten sollen ebenso wie die unmittelbaren Gefolgschaftsmitglieder der Versicherungsträger das sichere Gefihl haben, in guter, wahrhaft nationalsozialistischer Obhut zu stehon. Es geht nicht an, daß mit formalen juristischen Grinden eine Ablehnung dort erfolgt, wo das Gesetz bel verstindnisvollex Priterung und Auslegung ebenso eine dem Versicherten glinstige Iösung zulaßt. Denn allein diese Auslegung entspricht der Grundeinstellung der nationalsozialistischen Gesetzgebung und dem gesunden Rechtsempfinden. Nur so wird die Rechtsfindung im Sinhe des Fuhrers volksnah und wahrhaft sozial sein und sich daduroh die allgemoino Achtung erringen."

Zu vervielfaltigen und in je einem Abdruck vorzulegen:

mir,

meinem Stelivertreter,

den Unterabteilungsleitern,

den Referenten,

dem Burodirektor und dem Hauptkassendirektor,

den Burovorstehern und den Reeierungsamtmännern, den Dienststellenleitern,

sämtlichon Expedienten und Zuarbeltern,

den tberwachungsbeamten durch die Dst, I/15.

Z. d. A.

gez. G $\mathrm{r} 1$ e $\mathrm{m}$ e $\mathrm{y}$ e $\mathrm{r}$

Abb. 33: Präsidialverfügung Grießmeyers zur „Soziale[n] Rechtsfindung“ vom 29. Mai 1942

Behörde „auf eine gleichmäßige Behandlung der Leistungsanträge hinzuwirken“. ${ }^{143}$ Ermessensspielräume der RfA-Beamten in der Leistungsabteilung, insbesondere wenn es um die Würdigung der je spezifischen einzelfallbedingten Konstellationen ging, hatte es mithin schon immer gegeben. Sie waren nun aber um eine nationalsozialistisch-ideologische Dimension erweitert worden.

143 Das Schreiben vom 24.6.1943 sowie das Antwortschreiben der RfA vom 5.7.1943, in: RfA-Archiv Nr. 206. 


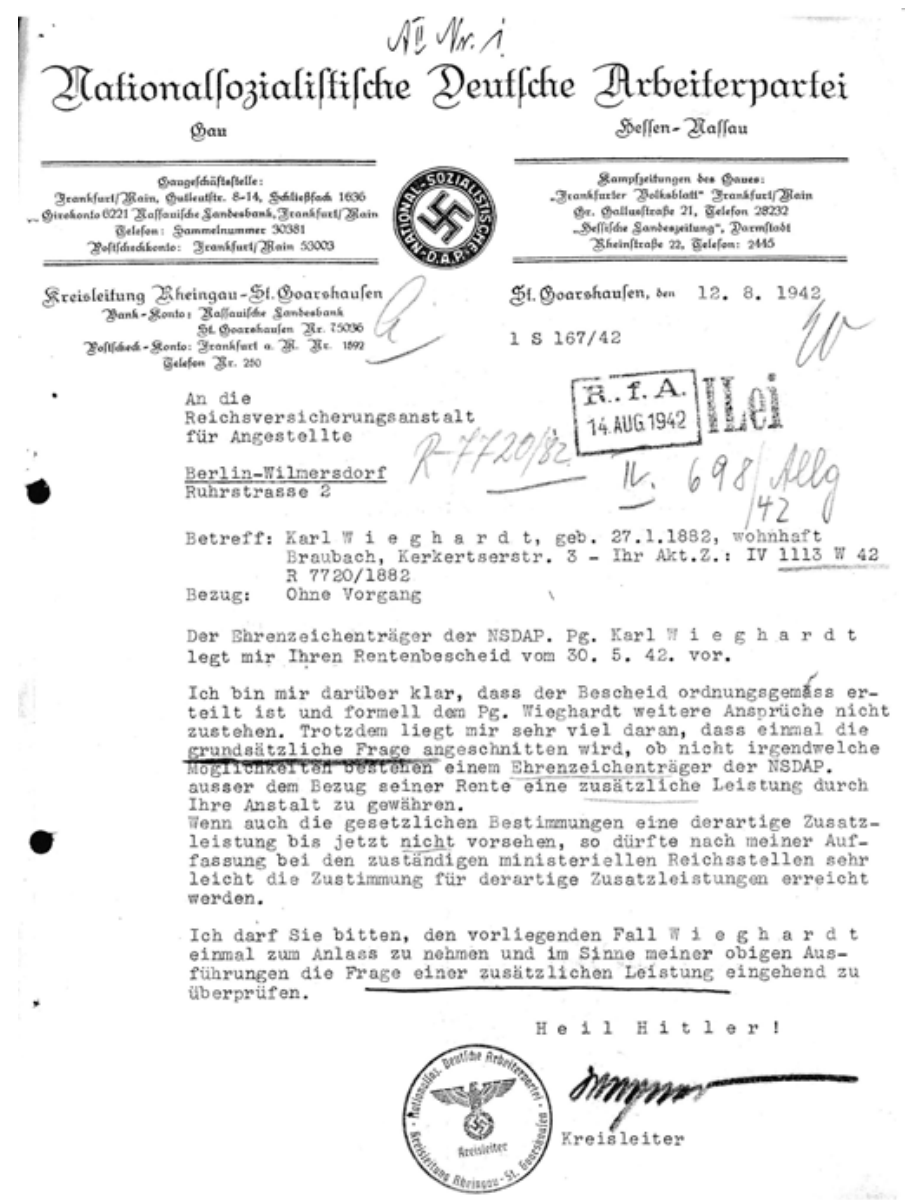

Abb. 34: Schreiben der Kreisleitung Rheingau an die RfA vom 12 . August 1942

Letztendlich traten aber Aspekte einer nationalsozialistisch gefärbten Rechtsanwendung gegenüber den Schwierigkeiten infolge des zunehmenden Bombenkriegs in den Hintergrund. Bei einem Luftangriff auf Hannover waren etwa im Oktober 1943 die Diensträume des Oberversicherungsamtes vollständig zerstört worden und damit auch sämtliche Aktenvorgänge in Berufungs-, Beschwerde- und Beschlusssachen verloren gegangen. Oft ließen sich die Unterlagen mit Hilfe der Akten in den Registraturen und Archiven der RfA wieder rekonstruieren, doch die entsprechenden Hiobsbotschaften auch von anderen Versicherungsämtern trafen in der Ruhrstraße schneller ein, als von dort Ersatz kommen konnte. Schließlich wurde der Aktenaustausch und die Versendung von Versicherungskarten bei Spruchverfahren auf das 
notwendige Maß reduziert. ${ }^{144}$ Im September 1944 sollte dann das Verfahren zur Prüfung der Berufsunfähigkeit dahingehend beschleunigt und vereinfacht werden, dass größere Kulanz gegenüber den Versicherten möglich wäre. Wie sich diese ganze Entwicklung zu diesem Zeitpunkt aus Sicht eines RfA-Beamten darstellte, lässt ein Aufsatz in der Deutschen Rentenversicherung erahnen.

\begin{abstract}
„Allein das formale Recht verwirklicht das materielle Recht. Das Gebiet der Rentenversicherung ist im Zuge der letzten Entwicklung so schwierig und unübersehbar geworden, wie kaum ein anderes. Selbst nebensächliche Fragen beanspruchen oft eine dem Laien unverständliche Fülle von Scharfsinn. Die einzelnen Behörden vermochten dem nur dadurch zu begegnen, dass sie sich im Rahmen ihrer jeweiligen Zuständigkeit scharf spezialisierten. Die Beschlussbehörden übersehen nicht mehr vollständig das Recht der Leistungsvoraussetzungen. Die Spruchgerichte beherrschen ihrerseits das Beitragsrecht nur noch insoweit, als es im Feststellungsverfahren üblicherweise zu berücksichtigen ist. Mit dem Schlachtruf: „Nur ein Verfahren, nicht mehrere!“ ist daher heute kaum etwas zu gewinnen. Solange das materielle Recht seinen heutigen Charakter beibehält, soll man auch den Rechtsweg so lassen, wie er bisher war, und wie es sich nach den Bedürfnissen der Praxis herausgebildet hat. Abweichungen haben keine Arbeits- und Zeitersparnis, dafür aber viel Verwirrung ergeben. ${ }^{145}$
\end{abstract}

Offizielle Streitverfahren, Berufungen und Revisionen blieben mithin an der Tagesordnung. Die verschiedenen Instanzen der Sozialgerichtsbarkeit funktionierten auch noch in den letzten Kriegswochen $1945 .{ }^{146}$

Es gab eine weitere Folgewirkung der DAF-Pläne für ein Altersversorgungswerk, die ebenfalls weder intendiert noch erwünscht war. Es ging um die weitere Anwendung der zu diesem Zeitpunkt (1940/41) noch mitten in der Umsetzung stehenden Altersversorgung der Handwerker. Die verschiedenen Zeitungsartikel, so äußerte Grießmeyer auf der 13. Beiratssitzung im April 1941, „haben die gewiss nicht beabsichtigte Nebenwirkung gehabt, dass [...] besonders bei den Handwerkern das soziale Pflichtgefühl nicht gerade gestärkt wurde, es entstand die Auffassung: Wozu noch Beiträge bezahlen, wenn man über kurz die Versorgung auch ohne sie erhält! “147 Im Bericht eines Überwachungsbeamten vom Oktober 1940 hatte es gleichsam ergänzend dazu geheißen: „Diejenigen Handwerker, die pflichtig sind, haben zu 99 Prozent noch nicht angefangen. Es ist ein Elend."148 Die Durchführung des Handwerkerversorgungsgesetzes geriet in eine Krise. Die Probleme betrafen auch die privaten Versicherungsunternehmen, denn aufgrund der Einberufungen konnten viele Handwerker nun nicht mehr ihre laufenden (und oft sehr hohen) Lebensversicherungsprämien

144 Vgl. dazu die diversen Meldungen der betroffenen Versicherungsämter vom Oktober 1943 und das Rundschreiben der RfA an die Oberversicherungsämter vom Oktober 1944, in: RfA-Archiv Nr. 104.

145 von Altrock, Beitragsstreitverfahren, S. 6.

146 Vgl. dazu einige Fallbeispiele in: BArch R 89/23091.

147 Niederschrift der 13. Beiratssitzung vom 21.4.1941, S. 3, in: BArch R 89/3470.

148 Schreiben des Kölner Überwachungsbeamten an die RfA vom 18.10.1940, in: RfA-Archiv Fach 119, Nr. 2. 
bezahlen und mussten um Stundung nachsuchen. ${ }^{149}$ Damit geriet zwar nicht die Voraussetzung für die Versicherungsbefreiung bei der RfA ins Wanken, da während des Wehrmachteinsatzes die Beitragspflicht des selbständigen Handwerkers zur Angestelltenversicherung ruhte und damit der Bestand der Lebensversicherung für die Angestelltenversicherung zunächst keine Rolle spielte; an der Pflicht der Betroffenen zur Aufrechterhaltung des Versicherungsschutzes durch Beitragszahlungen entsprechend der vorgeschriebenen Höhe der Versicherungssumme in der Lebensversicherung änderte das jedoch nichts. Im Versicherungsfall wäre der Handwerker im Falle von Beitragsrückständen nur im Todesfall voll versichert gewesen, während im Erlebensfall erst nach Wiederaufnahme der normalen Prämienzahlungen und der Nachzahlung der zu wenig entrichteten Prämien zuzüglich etwaiger Zinsen die ursprünglich vereinbarte Versicherungssumme zur Auszahlung hätte kommen können. Infolge der Prämienstundungen änderte sich mithin sowohl die Art der Versicherung wie die Höhe der Mindestversicherungssumme, so dass die RfA in diesen Fällen eigentlich doch die Versicherungsbefreiung aufheben und die betroffenen Handwerker als angestelltenversicherungspflichtig ansehen musste. ${ }^{150}$

Nach wie vor gab es auch in vielen anderen Detailfragen Klärungsbedarf. Die Überwachungsbeamten beanstandeten etwa, dass in vielen Versicherungsscheinen Vermerke über die erforderliche Begünstigung der Ehefrau und der Kinder fehlten. ${ }^{151}$ Zudem ergaben sich einige kriegsbedingte Verwerfungen. Denn aufgrund der Notdienstverordnung waren eine ganze Reihe von Handwerkern gezwungen, ihren Betrieb aufzugeben und invalidenversicherungspflichtige Tätigkeiten aufnehmen. Sie wurden nun von den Landesversicherungsanstalten zur Beitragszahlung verpflichtet, was es den vormals selbständigen Handwerkern unmöglich machte, ihre kurz zuvor im Rahmen des Handwerkerversorgungsgesetzes abgeschlossenen Lebensversicherungen aufrechtzuerhalten. Diejenigen Handwerker dagegen, die kriegsbedingt von der Selbständigkeit in eine angestelltenversicherungspflichte Beschäftigung wechselten, blieben davon unberührt und weiterhin versicherungsbefreit. ${ }^{152}$ Mit der versicherungsrechtlich ungeklärten Stellung der sogenannten Meistersöhne kam auch eine eklatante Gesetzeslücke zu Tage. Ende März 1940 hatte deshalb auch das Amt für Rechtsberatung der DAF eine Neuregelung des Handwerkerversorgungsgesetzes gefordert. ${ }^{153}$ Nach wie vor bestand auch Uneinigkeit zwischen dem Reichsstand des

149 Vgl. dazu etwa das Schreiben der Volksfürsorge Lebensversicherungs AG an die RfA vom 3.1.1940 und das Antwortschreiben der RfA vom 29.1.1940, in: RfA-Archiv Fach 82, Nr. 1.

150 Vgl. dazu auch das Schreiben des Reichsstands des Deutschen Handwerks an das RAM vom 13.9. 1939, in: RfA-Archiv Fach 82, Nr. 2.

151 Vgl. dazu das umfangreiche Schreiben der Fachgruppe Lebensversicherung an die RfA vom 5.1. 1940, in: RfA-Archiv Fach 87, Nr. 3.

152 Vgl. dazu den Beschwerdebrief der Volksfürsorge Lebensversicherungs AG an das RVA vom 26.2. 1940, in: BArch R 89/3199.

153 Vgl. dazu das Schreiben der DAF vom 29.3.1940 sowie das Antwortschreiben der RfA vom 18.4. 1940, dazu auch ein an Grießmeyer geschicktes, von der Akademie für Deutsches Recht erstelltes Gutachten über die Sozialversicherung der Meistersöhne vom 10.6.1940, in: RfA-Archiv Fach 110, Nr. 13. 
Deutschen Handwerks und der RfA über die Folgen von Fehlentscheidungen seitens der Kreishandwerkerschaften, denen die ausschließliche Zuständigkeit über die Anträge der Handwerker auf Befreiung von der halben Beitragsleistung (die sogenannte Halbversicherung) oblag. Die RfA vertrat den Standpunkt, dass die jeweiligen Handwerker die vollen Konsequenzen zu tragen hatten, wenn nach ausgesprochener Befreiung sich doch herausstellte, dass die materiellen Voraussetzungen in Wirklichkeit nicht gegeben waren. Dagegen plädierte der Reichsstand für erheblich mehr Kulanz und beschwerte sich beim RAM über die harte Haltung der RfA. ${ }^{154}$ Geharnischte Kritik brachte der Reichsstand jedoch auch direkt gegenüber dem RAM als Gesetzgeber vor.

Dass viele Handwerker auch ein Jahr nach dem Inkrafttreten des Gesetzes die zentralen Bestimmungen noch immer nicht begriffen hätten, lag nach Meinung des Reichsverbands auch an den komplizierten Bestimmungen dieses Gesetzes und seiner Ausführungsbestimmungen, die sich nicht auf einfache Grundlinien beschränkten, „sondern auch jede einzelne Frage zu reglementieren sucht“. ${ }^{155}$ Die in den Durchführungsverordnungen enthaltenen Bestimmungen über die Ordnungsmäßigkeit der abgeschlossenen Lebensversicherungsverträge ,führte in vielen Fällen [dazu], dass Handwerker trotz ihrer abgeschlossenen Lebensversicherungsverträge angestelltenversicherungspflichtig sind, ohne dass sie es wissen“. ${ }^{156}$ Auch eine am 20. Dezember 1940 erlassene dritte Durchführungsverordnung zum Handwerkerversorgungsgesetz änderte daran nichts. Gleichzeitig aber war man in vielen Kreishandwerkerschaften völlig ratlos, wie man gegenüber jenen Handwerkern vorgehen sollte, deren Lebensversicherungsverträge nach wie vor nicht in Ordnung und auf die Bestimmungen des Altersversorgungsgesetzes umgestellt worden waren oder die sich mit Hinweis auf ein angeblich zu geringes Einkommen überhaupt kategorisch weigerten, der Altersversicherung beizutreten. Erstere waren, da inzwischen die Übergangsfristen abgelaufen waren, voll versicherungspflichtig in der Angestelltenversicherung, und bei Letzeren stellte sich die Frage, ob und wie man ihren Eintritt in die Versicherung erzwingen konnte. ${ }^{157}$

Auch von den Überwachungsbeamten kamen regelmäßig Hiobsbotschaften über die desolate Entwicklung der Beitragsentrichtung der Handwerker und die zahllosen Probleme bei deren Überwachung und Überprüfung. So heißt es denn auch im Rundschreiben der RfA an ihre kontrollierenden Außendienstmitarbeiter von Mitte März 1940:

Nach den Berichten der Überwachungsbeamten stößt die Prüfung der Versicherungsverhältnisse der Handwerker in ihren Betrieben und Wohnungen auf erhebliche Schwierigkeiten, die viel Zeitverlust zur Folge haben und bei der großen Zahl der Handwerker das gesamte Prüfungsge-

154 Vgl. Schreiben des Reichsstands des Deutschen Handwerks an das RAM vom 4.4.1940, in: RfAArchiv Fach 87, Nr. 3.

155 Schreiben des Reichsstands an den Reichsarbeitsminister vom 8.10.1940, in: BArch R 89/3200. 156 Ebd.

157 Vgl. Schreiben der Kreishandwerkerschaft Sonthofen vom 29.2.1940, in: RfA-Archiv Fach 85, Nr. 1. 
schäft stark beeinträchtigen. Ein wesentliches Hindernis bildet die abwartende, ja oft ablehnende Haltung der meisten Handwerker, die sich zum Teil aus den Kriegsverhältnissen, in der Hauptsache aber aus ihrer ungenügenden oder falschen Unterrichtung erklärt. Es muss deshalb zunächst noch durch verstärkte Aufklärungsarbeit das Verständnis für ihre Altersversorgung geweckt und vertieft werden. ${ }^{158}$

Ende Oktober 1939 hatte man seitens der RfA noch gehofft, dass mit zunehmender Aufklärung durch den Reichsstand des Deutschen Handwerks die Überwachungsbeamten mit dem Handwerkerversorgungsgesetz nicht allzu sehr belastet würden und die Handwerkerüberprüfungen gleichsam nebenher im Zuge der laufendenden Beitragsüberprüfungen bei den Arbeitgebern erfolgen könnten. Doch die öffentliche Propaganda und Diskussion über das Ley’sche Versorgungswerk hatte alle Aufklärungsbemühungen zur Makulatur werden lassen und die RfA zu einer erheblichen Intensivierung der Bemühungen zur Umsetzung des Handwerkerversorgungsgesetzes gezwungen. Innerhalb kurzer Zeit war infolgedessen fast der gesamte Beitragsprüfungsapparat der RfA mit den entsprechenden Prüfmaßnahmen lahmgelegt. Zwar setzte man seitens der RfA zunächst nicht auf eine strenge Durchführung der Gesetzesmaßnahme, sondern zeigte notgedrungen eine abwartende Haltung. Von Sanktionsmöglichkeiten sahen die Überwachungsbeamten daher ab und verlegten sich auf die Vorladung eines säumigen Handwerkers in die Sprechstunde sowie die Meldung an die Kreishandwerkerschaft.

Doch durch die weiterhin unbefriedigende Entwicklung und die anhaltenden Krisenberichte der Überwachungsbeamten sah sich Grießmeyer im März 1941 zum Handeln gezwungen. In einem gegenüber RVA und RAM erstatteten Bericht über den Stand der Versicherungspflichtprüfungen und Beitragsentrichtungen der Handwerker rekapitulierte er noch einmal ausführlich die bisherigen Bemühungen seitens der Behörde, die angesichts der desolaten Entwicklung im Oktober 1940 dazu übergegangen war, systematisch im ganzen Reichsgebiet anstelle der aufwändigen und wenig erfolgreichen Einzelprüfungen nun Sammelprüfungen der Handwerker durchzuführen. ${ }^{159}$ Auch das war bei 130 Überwachungsbeamten gegenüber 1,4 Mio. Handwerkern eine Sisyphusarbeit. Viele Handwerker konnten aufgrund ihres Wehrmachteinsatzes nicht erfasst werden, zudem behinderte die mangelnde Mithilfe der Kreishandwerkerschaften wegen des kriegsbedingten Personalmangels erheblich die Prüftätigkeit. Dazu kam, dass viele Angestellte den Überwachungsbeamten gegenüber die vorgeschriebene Einsicht in den Einkommenssteuerbescheid zur Berechnung des AV-Beitrags verweigerten. Die Überwachungsbeamten mussten sich dann erst mühsam die nötigen Angaben bei den Finanzämtern beschaffen, stießen dort aber immer wieder auch auf Ablehnung der erwünschten Amtshilfe. Es scheint, dass es offenbar in einigen Behörden kein großes Interesse daran gab, dass die RfA ihre gesetzlich vorgeschriebenen Aufgaben bei der Umsetzung des Handwerkerversorgungsgesetzes

158 Rundschreiben Nr. 49 vom 12.3.1940, in: RfA-Archiv ohne Signatur, Ordner Rundschreiben. 159 Vgl. Schreiben Grießmeyers vom 10.3.1941, in: BArch R 89/3171. 
tatsächlich effektiv erfüllen konnte. ${ }^{160}$ Unter diesen Umständen hatten die Überwachungsbeamten im ersten Vierteljahr der Sammelprüfungen, d.h. zwischen Oktober und Dezember 1940, die Versicherungsverhältnisse von gerade einmal 5,7 Prozent der Handwerker abschließend prüfen können. Angesichts dessen war mit einem Abschluss sämtlicher Handwerkerprüfungen frühestens in zwei Jahren, d.h. im März 1943 zu rechnen. Da zudem, wie Grießmeyer durch einen Anruf aus dem RAM erfahren hatte, die von der RfA erbetene und für die Überwachung nötige Strafbefugnis gegen säumige Handwerker aus politischen Gründen nicht erteilt wurde, war eine weitere Prüftätigkeit eigentlich unmöglich und auch sinnlos. Er bat daher darum, von der Prüfung der Handwerker bis auf weiteres absehen zu dürfen. ${ }^{161}$

Grießmeyer musste drei Monate warten, bis er eine Antwort erhielt. In einem Erlass bestimmte das RAM am 11. Juni 1941, dass man mit dem RVA einer Meinung sei, „dass die Überwachung der Handwerker in dem Maße fortgeführt werden muss, wie dies bei den jetzigen Personalschwierigkeiten möglich ist, ohne dass hierbei die Überwachung der übrigen Versicherten vernachlässigt wird“. ${ }^{162}$ Gleichzeitig wurde die RfA aber dazu verpflichtet zu berücksichtigen, dass durch die Kriegsverhältnisse die geschäftliche Lage vieler Handwerker erschwert war. „Bei der Einziehung von Rückständen wird mit der durch die Zeitumstände gebotenen Zurückhaltung vorzugehen sein. Das Recht zur Verhängung von Strafen kann der RfA nicht eingeräumt werden. " ${ }^{163}$ Frustrierender für die Motivation der Überwachungsbeamten hätte dieser Erlass nicht ausfallen können, zumal man inzwischen tatsächlich in hunderten von Fällen säumiger Beitragszahlungen dazu übergegangen war, entsprechend der gesetzlichen Vorschriften Beitragsnachzahlungen einzufordern. Diese Rückstände summierten sich aufgrund der bis 1. Januar 1939 zurückreichenden Zahlungsverpflichtung auf jeweils dreistellige Summen und sorgten unter den betroffenen Handwerkern daher für erheblichen Unmut. ${ }^{164}$ Der RfA entgingen daher bei Verzicht der Beitreibung nicht unbedeutende Summen. Ob die Behörde tatsächlich in der

160 Vgl. dazu das Schreiben Grießmeyers an das RVA bzw. das RAM mit der Bitte um entsprechende Weisung durch das Reichsfinanzministerium vom 17.10.1941, in: BArch R 89/3200. Im November 1943, d.h. über zwei Jahre später, reagierte das Finanzministerium und erklärte sich mit den Auskünften der Finanzämter an die RfA einverstanden - allerdings unter der Voraussetzung, dass der betroffene Handwerker sein Einverständnis dazu erklärte, was völlig unrealistisch war. Vgl. dazu das Schreiben vom 18.11.1943, in: RfA-Archiv Fach 54, Nr. 3. Dieses Schreiben, so notierte dazu auch frustriert ein Überwachungsbeamter im Februar 1944, „stellt keineswegs ein Entgegenkommen zur Erfüllung der der RfA obliegenden Aufgaben dar. Im Gegenteil wird es m. E. der RfA, vor allem den Überwachungsbeamten, eher zum Nachteil gereichen.“ Bericht vom 11.2.1944, in: ebd.

161 Vgl. Schreiben Grießmeyers vom 10.3.1941, in: BArch R 89/3171.

162 Eine Abschrift des Erlasses in: RfA-Archiv Fach 85, Nr. 2.

163 Ebd.

164 Vgl. dazu das Schreiben der Kreishandwerkerschaft Saarbrücken an den Reichsstand des Deutschen Handwerks vom 6.5.1941, in: RfA-Archiv Fach 87, Nr. 3. Exemplarisch etwa der Fall eines Baumeisters, der im September 1941 gegen einen entsprechenden Nachentrichtungsbescheid der RfA (erfolglos) geklagt hatte, in: BArch R 89/3201. 
Folgezeit ihre Nachforderungspraxis lockerte, lässt sich nicht genau sagen. In den Akten finden sich zwar einige Fälle von Kulanz, in denen etwa die Beschwerde gegen den RfA-Bescheid von Handwerkerwitwen erhoben und direkt an die Kanzlei des Führers geschickt worden war. Die Behörde war zwar nicht bereit und rechtlich auch kaum in der Lage, auf die rückständigen Beiträge zu verzichten, aber man gestattete in diesen Fällen eine Stundung bis zum Kriegsende und dann eine Rückerstattung in monatlichen Teilzahlungen. ${ }^{165}$ Daneben aber finden sich nach wie vor Bescheide, in denen Handwerkern, die die Auskunft etwa hinsichtlich ihrer Lebensversicherungsverträge verweigerten, deutliche Fristen verbunden mit der Androhung eines Zwangsgeldes gesetzt wurden. „Wir sind befugt, Zwangsstrafen im Einzelbetrag bis zu 1000 RM so oft zu verfügen, bis Sie unsere Aufforderungen befolgt haben“, heißt es in den entsprechenden Bescheiden. ${ }^{166}$

Gezwungenermaßen setzte die RfA ihre Prüftätigkeit bei den Handwerkern fort, und sie blieb weiter aufwändig und wenig erfolgreich. Bis Ende März 1941 waren noch immer erst 175.138, also 12,46 Prozent aller Handwerker erfasst und überprüft worden, und nur rund 43 Prozent von ihnen gehörten zur Angestelltenversicherung als Volloder Halbversicherte. Diese frustrierende Entwicklung schilderte Grießmeyer denn auch ziemlich ungeschminkt Ende April 1941 gegenüber dem Beirat. Das Handwerkerversorgungsgesetz mit seinen nur zwölf Paragraphen „scheint kurz und einfach“, so der RfA-Präsident. „Leider hat sich die Durchführung des Gesetzes aber als recht schwierig und unerfreulich erwiesen. “167

\begin{abstract}
Seitdem das große Problem der allgemeinen Altersversorgung in der Presse erörtert wird, ist es begreiflicher Weise noch schwieriger geworden, die selbständigen Handwerksmeister von der Notwendigkeit einer Beitragsleistung und dem Beitritt zur Angestelltenversicherung zu überzeugen [...]. Wenn nicht die Erörterung über die allgemeine Altersversorgung Zweifel am Wert der gegenwärtigen Sozialversicherung geweckt hätte, so wäre wohl das Handwerkerversorgungsgesetz erheblich leichter durchführbar gewesen. ${ }^{168}$
\end{abstract}

All das führte $\mathrm{zu}$ einer sich in ihrer Auswirkung potenzierenden Mischung aus Unwissen und Unwillen bei den Handwerkern, so dass die Umsetzung des Versorgungsgesetzes auch drei Jahre nach seiner Einführung kaum vorangekommen war. ${ }^{169}$

165 Vgl. exemplarisch den Fall einer Witwe eines Müllers und deren Schreiben an die Führerkanzlei vom 20.3.1941, in: BArch R 89/3200.

166 Bescheid der RfA an einen Stuttgarter Handwerker vom 19.6.1941, in: RfA-Archiv Fach 87, Nr. 3. Exemplarisch auch der Bericht der Überwachungsstelle 64 in Kassel über die Prüfung der Lebensversicherungsverträge bei einem Drechslermeister vom 18.4.1942, in: ebd.

167 Niederschrift der 13. Beiratssitzung vom 21.4.1941, S. 8f., in: BArch R 89/3470.

168 Ebd.

169 Ein sehr großer Teil der Handwerker, so berichtete der Überwachungsbeamte über die Lage im hessischen Kreis Dieburg-Erbach, „hat die Bedeutung des Altersversorgungsgesetzes nicht erkannt oder will sie nicht erkennen und dadurch haben sie auch nach Ablauf von fast drei Jahren nach dem Inkrafttreten des Gesetzes immer noch keine Veranlassung gefunden, die durch das Gesetz auferlegte Verpflichtung zu erfüllen“. Der Bericht ohne Datum, in: RfA-Archiv Fach 85, Nr. 2. 
Es gab weitere Ungereimtheiten der Gesetzesanwendung, auf die das RVA und das RAM offenbar erst durch die RfA aufmerksam gemacht wurden. So erhielten diejenigen Handwerker, die bei der RfA versichert waren, wie jeder andere pflichtversicherte Angestellte auch die Kriegsdienstzeit rentensteigernd angerechnet. Dies galt nicht für die von der Versicherung befreiten Handwerker, denen auch die Möglichkeit der Nachentrichtung von freiwilligen Selbstversicherungsbeiträgen verwehrt war. Jeder Nichthandwerker konnte sich aber freiwillig und nachträglich selbst versichern. ${ }^{170}$ Für Verwirrung unter den Handwerkern sorgte auch, dass die Kreishandwerkerschaften zwar als Informations- und Auskunftsstellen agierten und auch das erwähnte Recht zur Bestätigung der Versicherungsfreiheit innehatten, jedoch nicht zur Entgegennahme der Rentenanträge selbst befugt waren bzw. diese erst dann wirksam wurden, wenn sie an die RfA weitergeleitet wurden und in der Ruhrstraße eintrafen. Die Durchführung der Handwerkerversorgung blieb auch deshalb weiter kompliziert, da es geplante wie ungeplante Interferenzen mit den anderen seit Kriegsausbruch erlassenen Rentenversicherungsgesetzen gab. Durch das Gesetz vom 15. Januar 1941 war den säumigen Handwerkern erneut die Möglichkeit eröffnet worden, ihre Lebensversicherungsverträge aus früherer Zeit an die neue Rechtslage anzupassen. Die neue Frist war allerdings mit 1. April 1941 ziemlich kurz, so dass nur wenige Handwerker die nötigen Anpassungen vornahmen, soweit sie überhaupt von der Möglichkeit erfahren hatten. ${ }^{171}$ Dazu kam, dass die durch den Krieg bedingte Wirtschaftslage bei den meisten Handwerkern zur Folge hatte, dass die Einkommen 1939 zunächst sprunghaft in die Höhe geschnellt, dann aber 1940 stark zurückgegangen waren. Daher bestand nun die Gefahr, dass viele Betroffene in absehbarer Zeit ihre hohen Prämien nicht mehr aufbringen konnten und dann die Lebensversicherungen verfielen. Viele Handwerker weigerten sich daher ungeachtet der gesetzlichen Bestimmungen, ihre Lebensversicherungen entsprechend anzupassen. ${ }^{172}$

Gravierende Folgen hatte dann auch das erste Leistungsverbesserungsgesetz vom 24. Juli 1941, denn durch die damit erfolgte Erhöhung des Grundbetrags um mehr als ein Fünftel wurde ebenfalls eine Nachbesserung der Lebensversicherungsverträge notwendig. Für tausende von Handwerkern, die anstelle einer Angestelltenversicherung einen Lebensversicherungsvertrag in der bisher verlangten Mindesthöhe von 5000 RM abgeschlossen hatten, wurden nun eigentlich Nachbesserungen und Nachzahlungen für ihre Vertragspolicen notwendig, da diese nun keinen gleichwertigen Ersatz zur Angestelltenversicherung mehr boten. Die RfA schlug daher im August 1941 den Erlass einer weiteren Durchführungsverordnung vor, durch die die Mindestversicherungshöhe für Lebensversicherungsverträge auf 6000 RM (bzw. auf 3000

170 Vgl. Bericht des RVA an das RAM vom 27.3.1941 auf der Basis eines Vermerks von RfA-Direktor Koch vom 10.3.1941, in: BArch R 89/3170 bzw. RfA-Archiv Fach 110, Nr. 7.

171 Vgl. auch den Bericht des Überwachungsbeamten aus Plauen vom 28.3.1941, in: RfA-Archiv Fach 85, Nr. 2.

172 Vgl. dazu den Bericht des Leipziger Überwachungsbeamten an den Referenten der Dienststelle I/ 12 vom 25.4.1941, in: RfA-Archiv Fach 87, Nr. 3. 
RM in der Halbversicherung) erhöht werden sollte. ${ }^{173}$ In dieser Frage gab es einen offenen Dissens mit dem RVA, denn dort verwies man nicht zu Unrecht auf die Tatsache, dass für die betroffenen Handwerker aufgrund des hohen Durchschnittsalters erhebliche Prämienmehraufwendungen erforderlich wären, so dass der einzelne Handwerker verhältnismäßig mehr für die Privatversicherung aufzuwenden hätte, als für die Versicherung bei der RfA notwendig sei. Selbst wenn dies nur für neu abzuschließende Handwerkerversicherungen galt, war mit erheblichem Unmut und Verärgerung unter den Handwerkern zu rechnen. Das RVA plädierte daher dafür, von einer Erhöhung abzusehen und die Frage bis nach Beendigung des Krieges zurückzustellen. ${ }^{174}$ Die gleichen Bedenken machte man auch gegenüber weiteren Vorschlägen der RfA geltend, die darauf hinausliefen, die Durchführung wesentlicher für die Handwerkerversicherung eigentümlicher Vorschriften für die Kriegsdauer außer Kraft zu setzen. Die RfA konnte sich daher mit ihren Änderungsvorschlägen nicht durchsetzen.

Probleme machte aber nicht nur die Beitragserhebung, sondern auch die Leistungserteilung bei den Handwerkern. Die vielen ungeklärten Probleme bei der Feststellung der Berufsunfähigkeit von Handwerkern füllten bei den RfA-Sachbearbeitern ganze Akten mit entsprechendem Schriftwechsel. Im Frühjahr 1941 etwa hatte man auffällige Beitragsnachzahlungen älterer Handwerker festgestellt, denen wenig später der Antrag auf Ruhegeld wegen Berufsunfähigkeit folgte, d.h. die Beitragsentrichtung erfolgte erst zu einem Zeitpunkt, in dem die Berufsunfähigkeit bereits bestand. In der Leistungsabteilung suchte man daher nach Wegen, diesen offensichtlichen Missbräuchen einen Riegel vorzuschieben, denn im Nachhinein war es praktisch unmöglich, den tatsächlichen Zeitpunkt des Eintritts der Berufsunfähigkeit zu bestimmen. Tatsächlich hatte der Gesetzgeber Tür und Tor für eine weitgehende Beitragsnachentrichtung geöffnet, was in der Handwerkerversicherung dazu geführt hatte, dass ein Rechtszustand geschaffen worden war, der mit dem Wesen einer Versicherung unvereinbar war. „In der privaten Versicherung ist es nicht möglich, ein brennendes Haus zu versichern. In der bestehenden Handwerkerversicherung ist es aber möglich, ein schon abgebranntes Haus zu versichern!“, hieß es in einem internen Vermerk vom Mai 1941. ${ }^{175}$ Es fehlte aus Sicht der RfA-Beamten an einer dringend benötigten Durchführungsvorschrift; welcher Weg dabei beschritten wurde, war aus Sicht der zuständigen Dienststellen gleichgültig, Hauptsache war, dass man erreichte, dass unzulässige Nachzahlungen rechtzeitig unmöglich gemacht werden konnten. Ergänzend heißt es in einem weiteren internen Vermerk:

Die Handwerkerversicherung stellt in ihrer vorliegenden Form ohnehin schon eine besondere Belastung der Angestelltenversicherung dar. Es ist den Handwerkern schon ohnehin besonders leicht gemacht, des Schutzes der Sozialversicherung teilhaftig zu werden. Die RfA sollte aber alles

173 Vgl. Schreiben der RfA an das RVA vom 12.8.1941, in: BArch R 89/3201.

174 Vgl. dazu die Niederschrift einer Besprechung vom 17.8.1941, S. 8f., in: BArch R 89/3171.

175 Vermerk vom 20.5.1941, in: RfA-Archiv Fach 110, Nr. 7. 
daran setzen, zu verhindern, dass diese Wege nicht nur vornehmlich von solchen Versicherten begangen werden, denen wegen bereits eingetretener Berufsunfähigkeit das Tor der Nachentrichtung verschlossen zu halten ist. Eine zu großzügige Annahme von Nachzahlungsbeiträgen, die sich bei den Handwerkern bald herumsprechen würde, könnte draußen den Eindruck erwecken, dass die RfA einen solchen Missbrauch der Versicherung nicht merke. Zu verhindern, dass ein solcher Eindruck aber überhaupt entsteht, sollte die RfA ihrem Ansehen, vor allem aber auch ihren anderen Versicherten schuldig sein. ${ }^{176}$

Das Problem der Berufsunfähigkeit von Handwerkern hatte man in der RfA schon im Frühjahr 1940 erkannt, aber man hielt aufgrund der zunächst noch kaum vorliegenden Fälle eine Festlegung von Richtlinien zur Beurteilung für noch verfrüht. Spätestens gegen Jahresende aber häuften sich die entsprechenden Anträge aus den Handwerkerkreisen und es zeichnete sich zudem ab, dass viele Handwerker im Fall ablehnender Bescheide durch die RfA bis in die Revision gehen würden. ${ }^{177}$ Anfang Mai 1941 war es deshalb auf Drängen der Reichsdienststelle der DAF, Gruppe Handwerk sowie der Reichsleitung der NSDAP zu einer Besprechung im RVA gekommen, bei der allerdings auf Seiten der RfA niemand eingeladen worden war. ${ }^{178}$ Hintergrund waren zahlreiche Beschwerden von Handwerkern bei der DAF oder der NSDAP darüber, dass ihnen von den Überwachungsbeamten der RfA das Kleben von Marken zur Angestelltenversicherung mit dem Hinweis darauf untersagt worden war, dass sie nicht berufsfähig im Sinne des Handwerkerversorgungsgesetzes seien. Als Beispiel wurde der Fall eines Frisörs im Rheinland aufgeführt, der, obwohl taubstumm, seit vielen Jahren sein Handwerk ohne jede Behinderung ausübe, vom Überwachungsbeamten der RfA aber für berufsunfähig erklärt worden war. Erhebliche Empörung gab es offenbar auch bei den in der Damenschneiderei und in Bekleidungsgroßfirmen beschäftigten Zwischenmeistern, weil ihnen nicht der hälftige Angestelltenversicherungsbeitrag durch die Unternehmer zustand, sondern sie als Handwerker voll versicherungspflichtig waren. ${ }^{179}$ Nach längerer Diskussion wurde zwischen RVA und DAF eine Übereinstimmung darüber erzielt, dass der Begriff der Berufsunfähigkeit des Handwerkers „entsprechend“ dem des AVG zu bilden sei. Man überließ es dem RVA, entsprechende Richtlinien zu entwerfen, die künftig für die RfA verpflichtend sein würden; allerdings schreckte man im RVA vor einer Grundsatzentscheidung mit entsprechender Durchführungsverordnung aufgrund der noch fehlenden nötigen Erfahrungen zurück. Gleichzeitig rangen aber auch RfA-intern die Leistungs- wie auch die Versicherungsabteilung um die Art und Weise der Kriterienbildung und -anwen-

176 Vermerk vom 16.7.1941, in: RfA-Archiv Fach 87, Nr. 3.

177 Vgl. dazu den Vermerk vom 30.11.1940, in: RfA-Archiv Nr. 28.

178 Vgl. Vermerk ohne Datum, als gesehen abgezeichnet u. a. von RfA-Direktor Koch am 2. 8.1941, in: ebd.

179 Vgl. das Schreiben eines Berliner Überwachungsbeamten vom 12.7.1941, in: RfA-Archiv Fach 87, Nr. 3. 
dung als möglichst objektiven Maßstab zur Beurteilung von Erwerbsfähigkeit bzw. Berufsunfähigkeit, um daraus eine handhabbare Verwaltungspraxis zu entwickeln. ${ }^{180}$

Die privaten Lebensversicherungsgesellschaften hatten inzwischen ungeachtet der weiteren Entwicklung ihre Werbetätigkeit und ihre Vertriebsaktivitäten keineswegs eingestellt, sondern nur die Taktik geändert. Da viele Männer im Krieg waren, konzentrierten sie ihre Bemühungen nun stark auf Frauen. Vor allem gelang es den Versicherungsvertretern auch infolge des Personalmangels bei den Kreishandwerkerschaften, bei deren Informationsbesuchen und Aufklärungsveranstaltungen mit auftreten zu können. „Ist es der Versicherungsanstalt bekannt“, so fragte ein verunsicherter Handwerker bei der RfA an, „dass mit den kontrollierenden Herrn auch Werber für Lebensversicherungen gehen?"181 Auf eine umgehende Beschwerde der RfA beim Reichsstand des Deutschen Handwerks versprach man Abhilfe und wies die Kreishandwerkerschaften ausdrücklich darauf hin, „dass Vertreter der Privatversicherung an der von der Kreishandwerkerschaft in ihrer Eigenschaft als Außenstelle der RfA durchzuführenden Prüfung nicht teilnehmen können“. ${ }^{182}$ Gegen eine Beratung hatte man allerdings nichts einzuwenden. Gleichzeitig war es aber auf Reichsebene zwischen dem Reichsstand des Deutschen Handwerks und der Reichsgruppe Versicherung zu einem heftigen Konflikt gekommen, in den die RfA allerdings mangels Zuständigkeit nicht involviert war. Es ging um die Altersversorgung derjenigen Handwerker, die bei Inkrafttreten des Gesetzes das 60. Lebensjahr bereits vollendet hatten. Während die jüngeren Handwerker per Gesetz der AV unterstellt wurden, fielen die älteren aus der Versicherungspflicht und besaßen auch keine Aussicht mehr auf den Erwerb irgendwelcher bzw. ausreichender Rentenansprüche. ${ }^{183}$ Die RfA schätze die Zahl der davon betroffenen Handwerker auf ca. 250.000; für sie waren Fürsorgeleistungen in Form der sogenannten Altershilfe vorgesehen, die allerdings erst im Juli 1940 eingeführt wurde. ${ }^{184}$ Über die Aufbringung der dafür notwendigen Mittel stritten sich schon seit März 1939 Handwerkerorganisation und Versicherungswirtschaft, die beide ursprünglich durchaus einen kleinen Anteil der Beitragseinnahmen zugesagt hatten. Erst im Juli 1942 sollte es nach langen und immer wieder stockenden Verhandlungen zu einer Einigung kommen. Die Lebensversicherer zahlten 1,5 Mio. RM sowie 0,3 Prozent der Versicherungssumme aller Neuabschlüssen der Handwerker. Dennoch blieb die Beteiligung an den Kosten der Altershilfe unter den Lebensversi-

180 Vgl. dazu unter anderem den Vermerk vom 30.6.1941, in: ebd. sowie „Zusammenstellung der bisherigen Verwaltungsübung der Leistungsabteilung der RfA in Handwerkersachen und Anregungen für die weitere Bearbeitung als abschließender Bericht des ORR Dr. Post über sein Sonderreferat für Handwerkersachen vom 3.4.1941 bis 11.3.1942“, in: RfA-Archiv Fach 110, Nr. 8. Dieses elfseitige Dokument ging im Juni 1942 auch an das RVA (BArch R 89/3201). Vgl. auch schon den Vermerk vom 12.11. 1941, in dem RfA-intern über die Einrichtung eines eigenen General-Referenten für Handwerkssachen nachgedacht wurde, in: RfA-Archiv Nr. 28.

181 Schreiben vom 11.3.1941, in: RfA-Archiv Fach 87, Nr. 3.

182 Schreiben an die RfA vom 7.5.1941, in: ebd.

183 Vgl. dazu Felix Schüler, Die Altershilfe des Handwerks, in: Soziale Praxis 49 (1940), S. 547-556. 184 Vgl. dazu Schlegel-Voß, S. $142 \mathrm{ff}$. 
cherungsgesellschaften auch weiter höchst umstritten. ${ }^{185}$ Gleichzeitig wurde auch die RfA zunehmend Gegenstand von Beschwerden aus der Versicherungswirtschaft, denn die Überwachungsbeamten prüften auch 1942 und 1943 zwar weniger systematisch, aber dennoch beharrlich die Rechtmäßigkeit der Lebensversicherungsverträge bei den Handwerkern und monierten unter Androhung von andernfalls fälligen Nachzahlungsforderungen die Anpassung der Verträge an die gesetzlichen Bestimmungen, was nicht nur für die RfA, sondern auch für die Versicherungsgesellschaften mit erheblichem bürokratischen Aufwand verbunden war. ${ }^{186}$ Die Behörde war durchaus für eine Vereinfachung des Verfahrens, aber einen entsprechenden Vorstoß hatte das RVA im August 1942 erneut abgelehnt. ${ }^{187}$

Mit Fortdauer des Krieges rückte das Problem der Beitragsüberwachung und die Frage der Angestelltenversicherungspflicht oder lebensversicherungsbedingten Befreiung der Handwerker zunehmend in den Hintergrund. Schwierigkeiten gab es zwar noch bei der Beantwortung der Frage, was mit jenen Handwerkern war, die im Zuge der sogenannten Auskämmaktionen zur Aufgabe ihrer Betriebe gezwungen und damit auch aus der Handwerksrolle gelöscht wurden. Als Lösung wurde ihnen - falls sie in keine invaliden- oder angestelltenversicherungspflichtige Tätigkeit in der Rüstungsindustrie überwechselten - das Recht eingeräumt, auf Antrag die Beiträge zurückerstattet zu erhalten, die sie aufgrund des Handwerkerversorgungsgesetzes geleistet hatten; oder sie konnten sich in der AV freiwillig weiterversichern. ${ }^{188}$ Das Kriterium der Eintragung in der Handwerksrolle als Voraussetzung der Gesetzesanwendung betraf auch jene selbständigen Handwerker, die nach Österreich, ins Sudetenland oder in die Ostgebiete verzogen oder dienstverpflichtet wurden. In all diesen Gebieten galt das Handwerkerversorgungsgesetz nicht, aber die Versicherung blieb für die Betroffenen dennoch im bisherigen Umfang bestehen. ${ }^{189}$ Zahlreiche Zweifelsfälle ergaben sich auch aus der Tatsache, dass viele Handwerksbetriebe durch den Kriegsdienst des Betriebsinhabers verwaist waren und von den Ehefrauen, die oft auch in der Handwerksrolle eingetragen waren, entweder weitergeführt oder zumindest formal aufrechterhalten wurden. Auch während des Ruhens des Betriebs und damit ausbleibendem Gewerbeeinkommen waren die Handwerkerehefrauen nun angestelltenversicherungspflichtig, was für er-

185 Vgl. ebd., S. 145.

186 Vgl. dazu exemplarisch das Beschwerdeschreiben eines Dachdeckermeisters an die RfA vom 9.3. 1943, in: BArch R 89/3201. Im Jahr 1942 prüften die Überwachungsbeamten die Versicherungsverhältnisse von 35.013 selbständigen Handwerkern im Altreich und in Danzig, 1943 waren es sogar 73.486. Hiervon waren 19.049 bzw. 1943 insgesamt 37.331 angestelltenversicherungspflichtig, 15.392 bzw. 35.096 waren aufgrund von Lebensversicherungen oder aus anderen Gründen versicherungsfrei. Vgl. die Angaben in dem Vermerk des Referenten für den Außendienst zum Geschäftsbericht für das Jahr 1943, in: RfA-Archiv Fach 56, Nr. 3.

187 Vgl. Schreiben des RVA an das RAM vom 27.8.1942, in: BArch R 89/3201.

188 Vgl. Rundschreiben Nr. 67 an die Überwachungsbeamten vom 2.7.1941, in: RfA-Archiv o. Sign. Ordner Rundschreiben.

189 Vgl. Abteilungsverfügung vom 6.6.1941 sowie Schreiben der RfA an die Kreishandwerkerschaft Zichenau/Südostpreußen vom 21.1.1943, in: RfA-Archiv Fach 34, Nr. 4. 
heblichen Unmut unter den Betroffenen sorgte. ${ }^{190}$ Gegenüber diesen Fällen rückten aber nun Leistungsgewährungen immer mehr in den Vordergrund, entweder für kriegsbeschädigte Handwerker oder aber für Handwerkerwitwen. Und dabei traten wiederum neue Unzulänglichkeiten, Unklarheiten und Lücken in der Handwerkerversorgung zu Tage. Empört berichtete etwa der Überwachungsbeamte aus Schwerin im August 1944 an die RfA:

Ein 40 Jahre alter Handwerker, vom Juli 1940 bis Dezember 1942 bei der Wehrmacht, hat bisher keine Beiträge zur Rentenversicherung entrichtet, wird im Juli 1944 berufsunfähig. Dieser Handwerker, der bisher nicht das geringste Interesse für seine Altersversorgung gezeigt hat, obwohl er wirtschaftlich in der Lage war, die gesetzlichen Beiträge zu entrichten, entdeckt jetzt, nachdem er arbeitsunfähig ist, dass nun ja die Rentenversicherung für ihn und seine Familie sorgen muss. Er zahlt also die Beiträge zur Angestelltenversicherung vom 1. Januar 1939 bis Juli 1944 in recht hohen Klassen nach, erhält das Ruhegeld unter Anrechnung der Kriegsdienstzeit und hat außerdem die Zinsen von den für 1939 bis 1944 nicht entrichteten Beiträgen. Nach den von mir gemachten Erfahrungen ist dies durchaus kein Einzelfall. ${ }^{191}$

Eine der Kernfragen war, was passierte, wenn ein Handwerker, der noch überhaupt keine oder nur unregelmäßige AV-Beiträge gezahlt hatte, im Krieg starb. Waren die bis zur Einberufung fälligen Beiträge nachzuentrichten und erhielt die Witwe Hinterbliebenenrente ${ }^{192}$ Dutzende Zuschriften erhielt die RfA nun aber auch von den Hinterbliebenen jener gefallenen Handwerker, die Lebensversicherungen bei den privaten Versicherungsunternehmen abgeschlossen hatten, jedoch zum Zeitpunkt des Vertragsabschlusses noch ledig gewesen waren und daher die Eltern im Todesfall als Begünstigte in den Verträgen standen. Inzwischen hatten aber viele geheiratet und zum Teil auch Kinder bekommen, so dass die Witwen und Waisen ohne jede Versorgung dastanden. Die RfA sollte nun, so das Verständnis der Betroffenen, hier einspringen. ${ }^{193}$ Auch in vielen anderen Fällen zeigte sich nach dem Tod von Handwerkern, dass die Lebensversicherungsverträge nicht den gesetzlichen Anforderungen entsprachen. Rein rechtlich waren damit die Voraussetzungen für die Befreiung von der Angestelltenversicherung nicht erfüllt. Auch die Möglichkeit zu Nachentrichtungen waren nicht mehr gegeben und damit bestand auch kein Anspruch auf Hinterbliebenenrente aus der Angestelltenversicherung. Auf entsprechende Bescheide der RfA und Beschwerden der betroffenen Handwerkerwitwen reagierte das RVA und stellte sich auf die Seite der Betroffenen und gegen die ihr unterstellte Behörde. Man entschied, dass die rückständigen Beiträge zur AV nachentrichtet werden könnten und die Hinterbliebenen damit leistungsberechtigt würden. Anstatt wie von der RfA

190 Vgl. dazu etwa den Bericht der Kasseler Überwachungsstelle vom 21.7.1942, in: RfA-Archiv Fach 86, Nr. 2.

191 Bericht vom 14.8.1944, in: RfA-Archiv Fach 86, Nr. 3.

192 Vgl. dazu unter anderem die Anfrage des Reichsstands des Deutschen Handwerks an die RfA vom 16.2.1942, in: RfA-Archiv Fach 86, Nr. 2.

193 Vgl. das Schreiben an die RfA vom 4.6.1943, in: ebd. 
gefordert die Gesetzeslücke zu schließen und den damit möglichen Missbrauch zu unterbinden, trug das RVA durch ihre angeordnete Verwaltungspraxis zur Durchlöcherung des Handwerkerversorgungsgesetzes bei. Man kann es auch so sehen, dass das RVA die RfA zu einem Abgehen von ihrer auf einer engen Gesetzesauslegung basierenden Verwaltungspraxis zwang, die letztlich aus einem Mangel des Handwerkerversorgungsgesetzes resultierte und nun wegen der Leistungsverpflichtung ohne ausreichende vorhergehende Beitragsdeckung sich zum Schaden des Versicherungsträgers auswirkte. ${ }^{194}$ Dahingestellt sei aber auch, ob die betroffenen Handwerkerwitwen trotz der großzügigen Nachentrichtungsregelung überhaupt zur rückwirkenden Zahlung der mehrere hundert RM ausmachenden Beiträge fähig waren. Und dann häuften sich auch die Fälle von gefallenen Handwerkern, bei denen erst nach deren Tod herauskam, dass sie weder in die Angestelltenversicherung gezahlt, noch eine private Lebensversicherung abgeschlossen hatten. ${ }^{195}$ Es häuften sich aber auch die Fälle von Fälschungen der Versicherungskarten. Um in den Genuss der Versorgungsleistung zu kommen, waren von vielen älteren Handwerkern die Einzahlungen der Beiträge vordatiert worden, obwohl sie die Nachzahlungen erst nach dem 60. Lebensjahr vorgenommen hatten - und es gab durchaus starke Indizien dafür, dass diese illegalen Praktiken auch mit Hilfe der örtlichen Kreishandwerkerschaften vorgenommen worden waren. ${ }^{196}$

Auch im Sommer 1944 kämpften RfA, RVA, die Kreishandwerkerschaften, die Lebensversicherungswirtschaft und der Reichsverband der Rentenversicherungsträger als Vertreter der Invalidenversicherungsträger noch immer mit der Umsetzung des Handwerkerversorgungsgesetzes und der Klärung sich daraus ergebender Zweifelsfragen. Den Tendenzen im RAM wie im RVA, neue Durchführungsverordnungen und ergänzende Regelungen zu erlassen, erteilte man in der RfA jedoch eine Absage. Gerade die Wahlmöglichkeit zwischen Lebensversicherung und Angestelltenversicherung habe so umfangreiche Durchführungsvorschriften nötig gemacht, „dass schon heute seine Anwendung wesentlich erschwert ist“, heißt es dazu in einem internen Vermerk vom Dezember 1943.

Es kann daher nur davon abgeraten werden, jeden Härtefall, der infolge dieses Wahlrechts auftreten kann, zum Anlass zu nehmen, eine weitere Sondervorschrift anzufügen. Umso mehr ist hiervon anzuraten, als auch damit nicht alle Härtefälle, die sich aus der Zulässigkeit einer Kapitalversicherung ergeben können, vermieden werden. Die größte Härte, die hierbei eintreten kann, dass nämlich das Kapital im Versicherungsfall nicht ausreicht oder unzweckmäßig oder unglücklich angewandt wird, bleibt immer möglich. Solange man nicht die Handwerker gleichmäßig der gesetzlichen Rentenversicherung unterstellt, sondern ihnen die Ausweichmöglichkeit

194 Vgl. dazu den Fall einer Handwerkerwitwe und der sich darüber ergebende Schriftwechsel zwischen RVA und RfA vom 16.9.1943 und vom 7.10.1943 sowie 15.11.1943, in: BArch R 89/3201.

195 Vgl. dazu Schreiben an die RfA vom 11.2.1944, in: ebd.

196 Vgl. Vermerk der Abt. I Leistung vom 4.11.1943, in: RfA-Archiv Fach 86, Nr. 3. Dort auch zu einem weiteren Fall der Bericht des Überwachungsbeamten in Plauen vom 20.11.1943. 
in die Lebensversicherung lässt, müssen dafür von ihnen auch die Härten, die sich aus diesem als Vorzug betrachteten Wahlrecht ergeben können, in Kauf genommen werden. ${ }^{197}$

Wenig später ordnete Grießmeyer dann an, dass aufgrund der Anpassung des Dienstes der Überwachungsbeamten an die Erfordernisse des totalen Krieges diese zum 1. Oktober 1944 die planmäßige Beitragsprüfung bei Handwerkern und sonstigen selbständigen sowie freiwilligen Versicherten einstellen sollten. ${ }^{198}$

Es gab schließlich noch einen weiteren indirekten Effekt der DAF-Versorgungswerk-Propaganda, dessen Kausalität nicht explizit nachweisbar ist, aber implizit vermutlich doch mit den sozialpolitischen Plänen des NS-Regimes zusammenhängt. Es geht um die sich weiter verstärkende Tendenz und den wachsenden politischen Druck zur Rechtsangleichung zwischen Invaliden- und Angestelltenversicherung. Der institutionelle Ort der entsprechenden Aktivitäten war der Reichsverband Deutscher Rentenversicherungsträger bzw. dessen Ständiger Ausschuss, in dem auch die RfA mit Grießmeyer als Vizepräsidenten vertreten war. Die Fäden zog dort aber Präsident Möbius, ein überzeugter NS-Anhänger und sozialpolitischer Hardliner ganz im Sinne des NS-Regimes. Möbius hatte im März 1940 die Initiative ergriffen, seitens des Reichsverbands im Einvernehmen mit dem Gaubeauftragten im Stabe von Reichsaußenminister Ribbentrop eine verbandseigene Auslandspropaganda für die im neutralen Ausland wohnenden Rentenempfänger aufzubauen, und empfahl den Verbandsmitgliedern, dies auch für ihre jeweiligen Rentenempfänger zu übernehmen. ${ }^{199}$ Gleichzeitig hatte Möbius angeregt, den Versicherungsträgern die Möglichkeit zur Gewährung von Spenden an die Hinterbliebenen gefallener Versicherter einzuräumen, ein Vorschlag, der bei der RfA auf entschiedene Bedenken stieß. Es sei nicht Aufgabe der Sozialversicherungsträger, über die ihnen nach dem Gesetz obliegenden Leistungen hinaus Schäden auszugleichen, die durch den Krieg entstehen. ${ }^{200}$ Auf den Sitzungen des Ständigen Ausschusses wurden zudem schon länger Angleichungen der Invaliden- und Angestelltenversicherung im Leistungsbereich diskutiert, allerdings ging es dabei zunächst nur um Maßnahmen der Heil- und Gesundheitsfürsorge. ${ }^{201}$ Die Aktivitäten mündeten schließlich in die Gründung eines großen Sozialerholungswerks der Rentenversicherungsträger, an das auch die RfA namhafte Beträge überwies. ${ }^{202}$

Im September 1941 wurde dann unter Leitung des Präsidenten der LVA Braunschweig eine Kommission zur Rechtsangleichung in der Rentenversicherung einge-

197 Vermerk vom 21.12.1943, in: RfA-Archiv Fach 110, Nr. 7.

198 Vgl. dazu Rundschreiben an die Überwachungsbeamten vom 21.9.1944 sowie auch das Rundschreiben vom 23.10.1944, in: RfA-Archiv Fach 87, Nr. 3.

199 Vgl. das vertrauliche Scheiben an die Verbandsmitglieder vom 11.3.1940, in. RfA-Archiv Nr. 68 b. 200 Vgl. Schreiben Möbius' an die Mitglieder des Ständigen Ausschusses vom 15.3.1940 sowie das Schreiben der RfA vom 21.3.1940, in: ebd.

201 Vgl. Niederschrift der Sitzung des Ständigen Ausschusses vom 25.7.1941, in: RfA-Archiv Nr. 69 a. 202 Vgl. dazu u. a. die Niederschrift der Sitzung des Ständigen Ausschusses vom 25.2.1942, in: ebd. 
richtet. An der ersten Sitzung nahm auch RfA-Direktor Koch teil. Selbstgestellte Aufgabe der Kommission war es, eine vollständige Angleichung in den beiden Versicherungen der Arbeiter bzw. der Angestellten zu erreichen, d.h. nicht nur die Angleichung der Leistungen, sondern auch der Voraussetzungen für Versicherungspflicht und Leistungen. ${ }^{203}$ Bereits im November erging die Einladung zur nächsten Kommissionssitzung, und diesmal sollte es bereits ganz konkret um die Beratung der Angleichung der Leistungen der Invalidenversicherung an die Leistungen der Angestelltenversicherung gehen. Doch diesmal erteilte Koch der Einladung eine deutliche Absage.

Ihre Einladung zu der geplanten Kommissionssitzung des Reichsverbandes habe ich Herrn Präsidenten Grießmeyer vorgelegt. Mit Rücksicht darauf, dass nach Ihrem Schreiben die Kommissionsberatung zum Gegenstand haben soll, die Leistungen der Angestelltenversicherung an die Invalidenversicherung anzugleichen, insbesondere hinsichtlich der Begriffe Berufsunfähigkeit und Invalidität sowie auch der Leistungen an die Witwen, hält er es nicht für zweckmäßig, dass ich an diesen Beratungen teilnehme. Da die Angleichung in der beabsichtigten Weise nur durch eine Verschlechterung der Leistungen der Angestelltenversicherung und ihrer wichtigsten Grundlagen erreicht werden könnte, scheint es ihm vom Standpunkt der Angestelltenversicherung nicht vertretbar zu sein, dass bei solchen Verhandlungen über die Minderung der Leistungen der Angestelltenversicherung ein Vertreter der Reichsversicherungsanstalt mitwirkt. ${ }^{204}$

Im Protokoll der zunächst verschobenen und erst am 5. Februar 1942 abgehaltenen Kommissionssitzung ist dann aber merkwürdiger Weise doch wieder Koch als Vertreter der RfA vermerkt; eventuell war man auf Geheiß des RVA bzw. RAM zur Teilnahme gezwungen worden. Es könnte jedoch auch gut sein, dass man in der RfALeitung sich doch noch für eine Präsenz entschieden hatte, um das Schlimmste für die Angestelltenversicherung zu verhindern. ${ }^{205}$ Koch jedenfalls wandte sich auf der Sitzung gleich zu Beginn grundsätzlich dagegen, dass die Angleichung zu einer Verschlechterung der Angestelltenversicherung führen würde, und er betonte nach der Debatte einer Reihe von Einzelpunkten auch am Ende noch einmal explizit, dass er für die RfA den Vorschlägen, insoweit sie für die Angestelltenversicherung eine Verschlechterung bedeuten würden, nicht zustimmen könne. ${ }^{206}$ Als der Kommissionsvorsitzende dann die entsprechenden Vorschläge auch im Ständigen Ausschuss präsentierte, die dort dann auch die Zustimmung erhielten, war es Grießmeyer, der die Bedenken und den Widerspruch der RfA deutlich formulierte und damit eine kontroverse Debatte auslöste. ${ }^{207}$ Doch letztendlich stand die RfA auf verlorenem Posten. Koch und Grießmeyer konnten sich dabei allerdings der Zustimmung ihrer Versi-

203 Vgl. das Protokoll der ersten Sitzung vom 24.9.1941, in: RfA-Archiv Nr. 205.

204 Vgl. das Einladungsschreiben an die RfA vom 26.11.1941 sowie das Antwortschreiben Kochs vom 28.11.1941, in: RfA-Archiv Nr. 26.

205 Vgl. Protokoll der Zweiten Sitzung der Kommission vom 5. 2.1942, in: RfA-Archiv Nr. 205.

206 Vgl. ebd., S. 3.

207 Vgl. Sitzungsniederschrift des Ständigen Ausschusses vom 25. 2.1942, S. 8, in: RfA-Archiv Nr. 69 a. 
cherten sicher sein. Viele bei der RfA Versicherte sahen die zum Teil auch in der Fachöffentlichkeit diskutierten Rechtsangleichungstendenzen keineswegs positiv. In einem Leserbrief an die Fachzeitschrift Deutsche Rentenversicherung vom Mai 1941 heißt es etwa:

Ich bin der Meinung, dass eine Angleichung nicht etwa gefunden werden muss, dass nun etwa Invaliden- und Angestelltenversicherung vereinigt werden und dann eine Altersversorgung eintritt, die für die Arbeiter besser, für den Angestellten aber schlechter ausfällt. Wo bleiben dann die vielen Gelder, die an Angestelltenversicherungsbeiträgen gezahlt worden sind und doch eigentlich nur den Angestellten und deren Hinterbliebenen zugute kommen müssten? ${ }^{208}$

Im August 1942 legte das RVA dann dem RAM eine 38-seitige Denkschrift zur Rechtsangleichung von IV und AV vor, die unter dem Etikett der kriegsbedingt notwendigen Verfahrensvereinfachungen umfangreiche Vorschläge zur Angleichung der Vorschriften für die einzelnen Versicherungszweige - über Versicherungspflicht und Versicherungsfreiheit - enthielt. ${ }^{209}$ All dies war offenbar Teil einer neuen, diesmal nicht mehr von der DAF, sondern vom RAM ausgehenden Initiative zur Neuordnung der Sozialversicherung. Im Oktober 1942 jedenfalls berichtete der Präsident der LVA Hamburg, Storck, an RVA-Vizepräsident Schmitt, dass alle Mitglieder in der vergangenen Sitzung des Ständigen Ausschusses gebeten worden seien, „unsere Gedanken über die Neuordnung der Sozialversicherung dem Präsidenten Grießmeyer zu übermitteln“. ${ }^{210}$ Die beigefügte neunseitige Ausarbeitung Storcks setzte sich dabei vor allem mit der Krankenversicherung auseinander. Die Rentenversicherung war insofern tangiert, als es offenbar einen Plan des Reichsverbands der Ortskrankenkassen gab, der radikal die Verbindung zwischen Krankenversicherung und Rentenversicherung beseitigen und dabei das Heilverfahren aus Letzterer herauslösen wollte - was Storck vehement ablehnte. ${ }^{211}$ Vor allem verband der LVA-Präsident seine Stellungnahme mit einer massiven Kritik am RAM und dessen sozialpolitischer Gesetzgebungsarbeit. Der Entwurf passe, so Storck, in die Arbeit des RAM der letzten Jahre:

\footnotetext{
Seit dem Aufbaugesetz, das wenigstens eine Richtung erkennen lässt, aber eine Halbheit geblieben ist, [gab es] nur Flickwerk ohne einheitliche Linie, ohne großen Zug. Man braucht ja nur die Leistungsverbesserungsgesetze für die Rentenversicherung anzusehen. Dieses Herumkurieren an einzelnen Bestimmungen, dieser Kleckerkram mit Regelungen, bei denen mit zwei Schritten vorwärts gleichzeitig eineinhalb Schritte rückwärtsgegangen wird. ${ }^{212}$
}

Diese Haltung war offenbar typisch für einen erheblichen Teil des stark nationalsozialistisch gesinnten Führungs- und Leitungspersonals unter den Versicherungsträ-

208 Schreiben vom 21.5.1941, in: RfA-Archiv Nr. 94 a.

209 Die Denkschrift vom 26.8.1942, in: BArch R 89/3172.

210 Schreiben Storcks an Schmitt vom 12.10.1942, in: BArch R 89/2638.

211 Vgl. Storcks „Gedanken über den Aufbau der Reichsversicherung“, in: ebd.

212 Schreiben Storcks an Schmitt vom 12.10.1942, in: BArch R 89/2638. Vgl. dazu auch einen Brief Storcks an RAM-Ministerialdirigent Zschimmer vom 14.11.1942, in: BArch R 89/2639. 
gern. Ob und welche Rolle hier Grießmeyer im weiteren Verlauf gespielt hat, ist unklar. Er gehörte aber zweifellos nicht zu dem Kreis um Storck, Möbius und RVA-Vizepräsident Schmitt. Im Übrigen gab es im weiteren Verlauf offenbar zunehmende Konflikte und Kompetenzstreitigkeiten zwischen dem Reichsverband Deutscher Rentenversicherungsträger und dem RVA, bei denen es im Lauf des Jahres 1943 auch um die Auflösung des Reichsverbands und die Übernahme der Aufgaben durch das RVA ging. ${ }^{213}$

Ein neues großes Rentengesetz kam durch das RAM letztendlich nicht zustande, aber die Maschinerie der Gesetzgebungsmaßnahmen, Verordnungen und Erlasse im Rentenversicherungsrecht stand dennoch auch 1943 und 1944 nicht still. Im Mittelpunkt der diversen Aktivitäten stand dabei der Ausbau der Gesundheitsfürsorge in der Rentenversicherung, unter anderem wurde ein Tuberkuloseversorgungswerk gegründet. $^{214}$ Im RAM liefen zur gleichen Zeit die Beratungen über den Entwurf einer zweiten Durchführungsverordnung zum zweiten Leistungsverbesserungsgesetz, das weitreichende Rechtsangleichungen zwischen IV und AV bei Versicherungspflicht, Beiträgen und Leistungen vorsah. Die Leistungsänderungen sollten allerdings nach den Vorstellungen des RAM nicht für die laufenden Renten gelten, da deren Umrechnung unmöglich erschien. ${ }^{215}$ Dagegen wurden von den an der Beratung beteiligten Vertretern der Versicherungsträger, darunter auch RfA-Direktor Koch, erhebliche Bedenken erhoben. Da die Altrentner auf eine Erhöhung ihrer Rente drängen würden, diese aber jetzt nicht durchführbar sei, wäre es besser, die Verordnung jetzt überhaupt nicht zu erlassen. Auch sonst brachte Koch deutlichen Widerspruch gegen die geplanten Regelungen zu Protokoll. ${ }^{216}$ Die Beratungen wurden fortgesetzt, währenddessen war im Oktober 1943 eine andere (zweite) Verordnung über Leistungsverbesserungen in den Alpen- und Donau-Reichsgauen, den eingegliederten tschechoslowakischen Gebieten sowie den eingegliederten Ostgebieten erlassen worden. Unter dem Gesichtspunkt der rentenversicherungsrechtlichen Gesetzgebung ist vorerst nur von Bedeutung, dass das Gesetz erst nach langem Anlauf und drei im Mai 1942 begonnenen Entwürfen schließlich erlassen wurde. ${ }^{217}$ Der Grund waren massive Interventionen durch die Partei-Kanzlei, die deutlich machen, wie stark die Gesetzgebung des RAM letztlich am Gängelband der NSDAP erfolgte. Denn die im zweiten Entwurf ursprünglich vorgesehenen Leistungsverbesserungen wurden in Bezug auf die Angestellten auf Parteiwunsch zurückgestellt, so dass die Verordnung zunächst nur Leistungsverbesserungen für Arbeiter enthielt. Erst mit Verzögerung wurden dann auch die Leistungsverbesserungen für Angestellte wieder aufgenom-

213 Vgl. dazu das Scheiben Möbius’ an Schmitt vom 18.3.1943, in: BArch R 89/2639.

214 Vgl. dazu der Jahresrückblick von Möbius, Der Ausbau der Deutschen Sozialversicherung im Jahre 1943, in: Deutsche Rentenversicherung (1944), Nr. 1/3, S. 2-3.

215 Vgl. Vermerk Kochs über die Besprechung im RAM vom 2.9.1943, in: RfA-Archiv Nr. 37.

216 Vgl. ebd.

217 Vgl. dazu RfA-Archiv Nr. 36. 
men. ${ }^{218}$ Seitens der RfA war der Entwurf im Juli 1943 regelrecht auseinandergenommen worden, vor allem auch im Hinblick auf die höchst komplizierte Berechnung der vorgesehenen Zusatzrenten, die für die Behörde einen ungeheuren zusätzlichen Verwaltungsaufwand bedeutete. ${ }^{219}$

218 Vgl. dazu das Schreiben des RAM vom 7.7.1943, in: RfA-Archiv Nr. 36, auch in: BArch R 89/3172. 219 Vgl. das Schreiben Grießmeyers an das RAM vom 20.7.1943, in: ebd. In RfA-Archiv Nr. 36 dazu auch der von Koch stammende Rohentwurf des Briefes. Noch im November 1943, einen Monat nach Erlass der Verordnung, fanden dazu zwischen RAM, RVA und RfA Gespräche im RAM zu Einzelheiten der Durchführung der Verordnung statt. Vgl. dazu die beiden Besprechungsvermerke der beteiligten RfA-Beamten in: RfA-Archiv Nr. 36. 